OECD Health Working Papers No. 69

\title{
Geographic Imbalances in Doctor Supply and Policy Responses
}

\section{Tomoko Ono,}

Michael Schoenstein,

James Buchan 


\section{Unclassified}

Organisation de Coopération et de Développement Économiques

Organisation for Economic Co-operation and Development

\section{DIRECTORATE FOR EMPLOYMENT, LABOUR AND SOCIAL AFFAIRS \\ HEALTH COMMITTEE}

English text only

\section{Health Working Papers}

OECD Health Working Paper No. 69

GEOGRAPHIC IMBALANCES IN DOCTOR SUPPLY AND POLICY RESPONSES

Tomoko Ono, Michael Schoenstein and James Buchan*

JEL Classification: I18

* James Buchan, Professor, Queen Margaret University Edinburgh, Specialist Advisor to Health Worforce Australia (HWA)

Authorised for publication by Stefano Scarpetta, Director, Directorate for Employment, Labour and Social Affairs

All Health Working Papers are now available through the OECD's Internet Website at http://www.oecd.org/health/workingpapers

Complete document available on OLIS in its original format

This document and any map included herein are without prejudice to the status of or sovereignty over any territory, to the delimitation of international frontiers and boundaries and to the name of any territory, city or area. 


\title{
DIRECTORATE FOR EMPLOYMENT, LABOUR AND SOCIAL AFFAIRS
}

\author{
www.oecd.org/els
}

\section{OECD HEALTH WORKING PAPERS}

\author{
http://www.oecd.org/health/workingpapers
}

OECD Working Papers should not be reported as representing the official views of the OECD or of its member countries. The opinions expressed and arguments employed are those of the author(s).

Working Papers describe preliminary results or research in progress by the author(s) and are published to stimulate discussion on a broad range of issues on which the OECD works. Comments on Working Papers are welcomed, and may be sent to the Directorate for Employment, Labour and Social Affairs OECD, 2 rue André-Pascal, 75775 Paris Cedex 16, France.

This series is designed to make available to a wider readership selected labour market, social policy and migration studies prepared for use within the OECD. Authorship is usually collective, but principal writers are named. The papers are generally available only in their original language - English or French with a summary in the other.

The statistical data for Israel are supplied by and under the responsibility of the relevant Israeli authorities. The use of such data by the OECD is without prejudice to the status of the Golan Heights, East Jerusalem and Israeli settlements in the West Bank under the terms of international law.

\section{Applications for permission to reproduce or translate all or part of this material should be made to:}

\author{
Head of Publications Service \\ OECD \\ 2, rue André-Pascal \\ 75775 Paris, CEDEX 16 \\ France
}

Copyright OECD 2014 


\section{ACKNOWLEDGEMENTS}

Five countries (Australia, Canada, France, Germany and Switzerland) asked the OECD Secretariat to review policies to foster a better geographic distribution of physicians. With France providing a voluntary contribution and Australia a secondment of Professor James Buchan, the project was started in midFebruary 2013. The participating countries also requested Denmark, Japan and Norway to be included in the review of polices.

The authors would like to thank the experts from the French Ministry of Social Affairs and Health and Health Workforce Australia involved with the project for their continued advice and comments on drafts of this paper. We also thank Marie-Camille Lenormand, formerly of the Ministry of Social Affairs and Health and now with CNAMTS, and Denis Maguain of the French Ministry of Social Affairs and Health for organising this collaboration.

Ricarda Milstein provided research assistance; Vicente Ruiz provided data on regional indicators.

As part of this project, the authors conducted several interviews with experts from member states of the OECD. Their time and support was essential in helping to understand different national policy frameworks and programs. We wish to thank in particular Gavin Brown and David Jones, from Health Canada; Irene Keinhorst from the German Federal Ministry of Health; Anders Astrup Haahr from the Danish Ministry of Health and Pernille Moll from the Center for Health policy, economy and social policy of the Danish Regions; Otto Christian Rø from the Norwegian Ministry of Health; Dunja Golanda from the Slovenian Ministry of Health; Tracey Conroy from the Irish Department of Health; Nadine Facchinetti from the Swiss Federal Agency of Health; Ewa Mariéthoz from the Swiss Conference of Cantonal Directors for Health; Yohei Ito from the Permanent Delegation of Japan to the OECD; Marilyn Barret, Annie Ingram, Ronald MacVicar, Gillian Needham, Pam Nicoll from NHS Scotland.

The authors wish to thank Mark Pearson, Valerie Paris, Divya Srivastava, and Yuki Murakami from the OECD for their comments. 


\section{EXECUTIVE SUMMARY}

Doctors are distributed unequally across different regions in virtually all OECD countries, and this causes concern about how to continue to ensure access to health services everywhere. In particular access to services in rural regions is the focus of attention of policymakers, although in some countries, poor urban and sub-urban regions pose a challenge as well. Despite numerous efforts this mal-distribution of physician supply persists. This working paper first examines the drivers of the location choice of physicians, and second, it examines policy responses in a number of OECD countries.

The choice of practice location is complex, but across the examined OECD countries, several key factors have emerged in studies of doctors and medical students in recent years. First, the relative unattractiveness as places to live and work is the root of an unequal distribution of physicians across regions and areas. Second, the mode of employment and payment for physicians set the frame for their options for location choices. Third, while incomes for general practitioners in rural regions are higher than those in urban regions in some counties, it may not be sufficient compensation as they work for longer hours and in generally more difficult working conditions. Furthermore, professional prestige plays a role as more prestigious specialties tends to be concentrated in urban areas and by default making rural practice less attractive. Finally rural origins and experience in rural settings are influential factors as doctors who are from rural regions are much more likely to go and practice in rural setting compared to those with an urban upbringing.

While a truly comprehensive regional development policy is helpful to tackle the maldistribution of physicians across regions, policymakers in the health sector have three broad strategies to respond to imbalances in physician distribution.

- The first strategy is to target future physicians to maximize the pool of physicians available for practice in relatively underserved regions. This means increasing the number of qualified physicians who are interested in practice in underserved regions, and/or the number of working hours they are willing to provide. The crucial focal point of action for this strategy is the selection and education of medical students.

- The second strategy is to target current physicians to maximise the share of physicians in the health system who practice in underserved regions. This requires a suitable incentive system, which may include both "carrots and sticks", i.e. not only financial incentives, but also suitable regulatory measures to influence physicians' location choices.

- The third strategy is to do with less, i.e. accept that staffing levels will be lower in some regions and focus on service re-design or configuration solutions. This can be done through expansion of involvement in health service delivery by non-physician providers. Service delivery innovations can also make a difference, by the use of technology (e.g. through better use of telemedicine), better management of human resources and their workload, or a combination thereof.

Policymakers in most countries will have to blend a range of elements of these three strategies, and review this mix over time. The best mix of such strategies will depend on various factors: patient needs, demography of the population and the physician workforce, health system characteristics, the budgetary situation, and the overall health reform context. While broad characteristics of interventions can be identified, more robust evaluations are required to improve the evidence basis for these policies and strategies in order to support policymakers to make better informed choices. 


\section{RÉSUMÉ}

La répartition des médecins entre les régions est inégale dans pratiquement tous les pays de l'OCDE, et cela pose la question de savoir comment continuer de garantir l'accès aux services de santé partout. L'accès aux services dans les régions rurales préoccupe tout particulièrement les responsables publics, même si, dans certains pays, les régions urbaines et suburbaines pauvres posent aussi un problème. En dépit d'importants efforts, les inégalités dans la répartition des effectifs médicaux persistent. Le présent document de travail examine, dans un premier temps, les critères déterminants, pour les médecins, dans le choix de leur lieu d'exercice et, dans un second temps, les réponses apportées par les pouvoirs publics dans un certain nombre de pays de l'OCDE.

Le choix du lieu d'exercice est complexe mais des études sur les médecins et les étudiants en médecine réalisées ces dernières années dans plusieurs pays de l'OCDE ont mis en lumière plusieurs facteurs clés. Premièrement, le relatif manque d'attractivité d'un lieu comme cadre de vie et de travail est la première cause d'inégale répartition des médecins entre les régions et les zones. Deuxièmement, le mode d'exercice et le mode de paiement des médecins sont déterminants dans leur choix d'installation. Troisièmement, si, dans certains pays, les revenus des généralistes sont plus élevés dans les zones rurales que dans les zones urbaines, cela peut ne pas suffire pour compenser des journées de travail plus longues et des conditions de travail plus difficiles. Par ailleurs, le prestige professionnel joue: les spécialités les plus prestigieuses tendent à se concentrer dans les zones urbaines et l'exercice de la médecine en zone rurale apparaît, de ce fait, moins attractif. Enfin, une origine rurale et l'expérience du milieu rural ont une influence car les médecins issus de régions rurales sont nettement plus susceptibles de s'y installer que ceux issus d'un milieu urbain.

Si une politique de développement régional véritablement globale peut aider à corriger la mauvaise répartition des effectifs médicaux entre régions, les décideurs du secteur de la santé peuvent envisager trois grandes stratégies pour rééquilibrer l'offre de médecins.

- La première stratégie consiste à cibler les futurs médecins pour maximiser les effectifs de médecins prêts à exercer dans les régions relativement mal pourvues. Cela implique d'augmenter le nombre de médecins qualifiés disposés à exercer dans ces régions et/ou de faire en sorte que ces médecins soient disposés à fournir un nombre plus important d'heures de travail. La formation des médecins est le point crucial de cette stratégie.

- La deuxième stratégie consiste à cibler les médecins en exercice pour maximiser la proportion de médecins installés dans les régions moins bien loties. Cela suppose un système d'incitations adapté, fondé sur la logique de la carotte et du bâton, qui associerait aux incitations financières des mesures réglementaires de nature à influencer les médecins dans leur choix du lieu d'exercice.

- La troisième stratégie consiste à composer avec moins, autrement dit accepter le fait que les effectifs seront moins importants dans certaines régions et se concentrer sur une refonte des services et de nouvelles configurations. Cela peut passer par un élargissement du rôle des nonmédecins dans la fourniture des soins de santé. L'innovation également peut être utile, qu'il s'agisse de mettre à profit l'innovation technologique (meilleure utilisation de la télémédecine, par exemple), de mieux gérer les ressources humaines et leur charge de travail, ou d'articuler ces deux dimensions. 
Dans la plupart des pays, les décideurs devront emprunter des éléments à chacune de ces trois stratégies et adapter le dosage en fonction des évolutions. Le meilleur dosage dépendra de plusieurs facteurs: besoins des patients, démographie générale et démographie médicale, caractéristiques du système de santé, situation budgétaire et contexte global de la réforme de la santé. Si l'on peut distinguer de grandes caractéristiques en matière d'interventions, il faudrait des évaluations plus fines pour améliorer la base de données probantes sur ces politiques et stratégies et, ainsi, permettre aux décideurs de prendre des décisions plus éclairées. 


\section{TABLE OF CONTENTS}

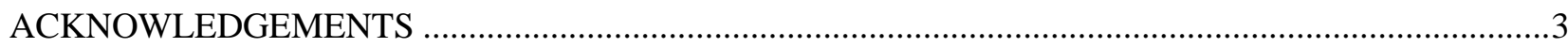

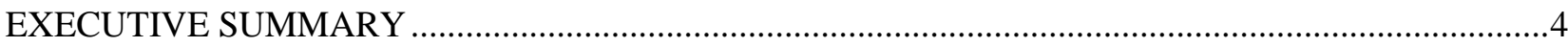

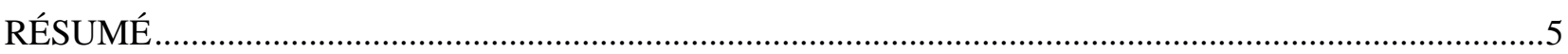

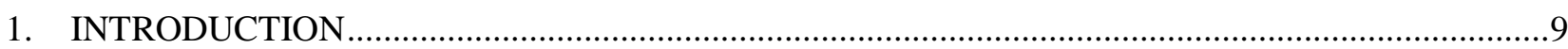

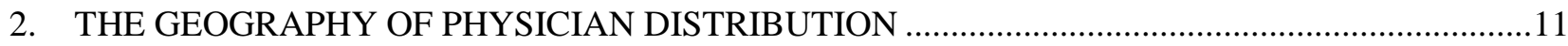

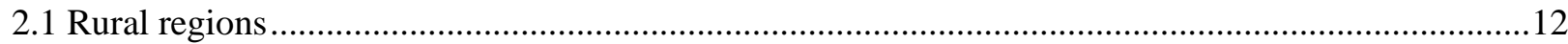

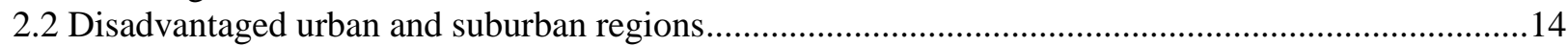

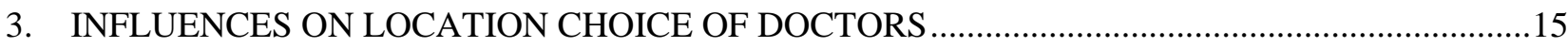

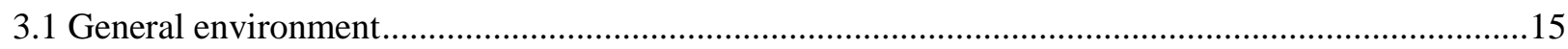

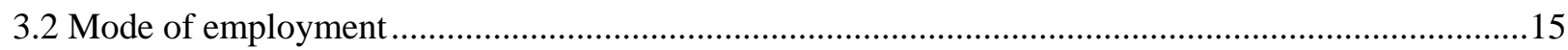

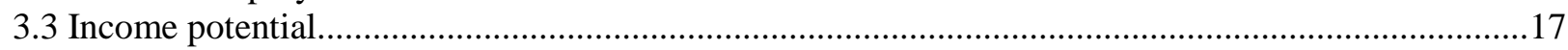

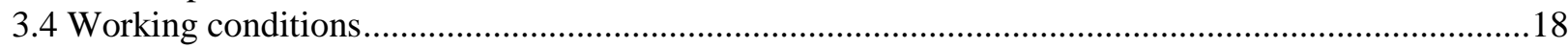

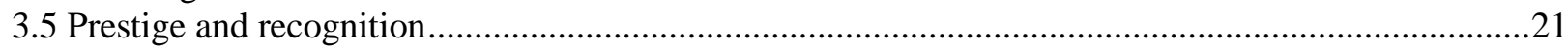

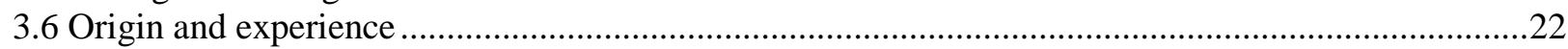

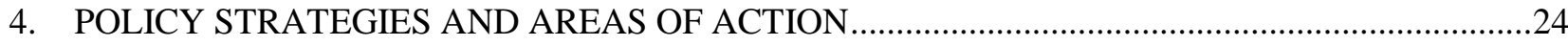

5. TARGETING FUTURE DOCTORS: MEDICAL EDUCATION POLICIES ....................................25

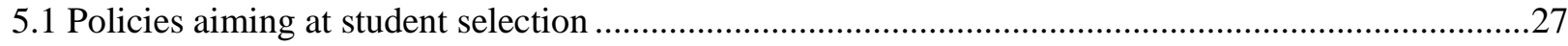

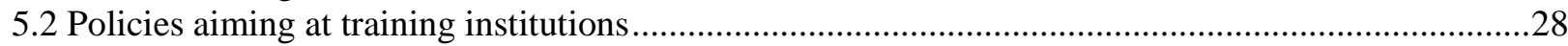

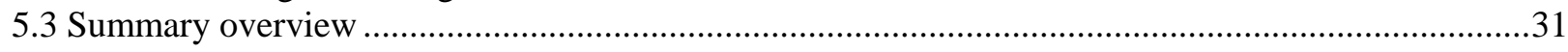

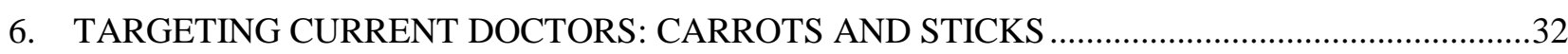

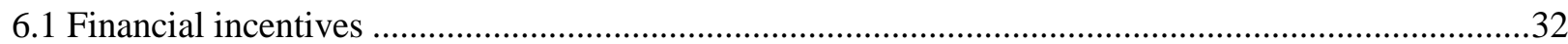

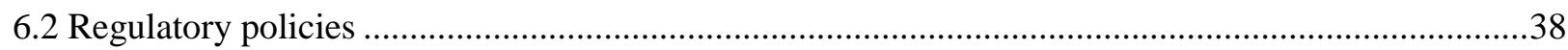

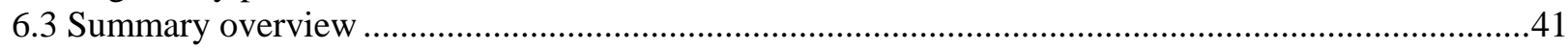

7. DOING WITH LESS: SERVICE DELIVERY REORIENTATION ................................................42

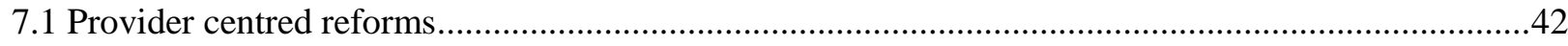

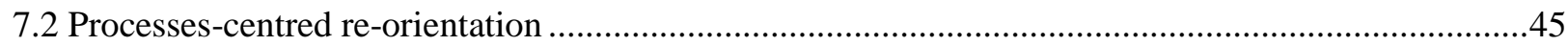

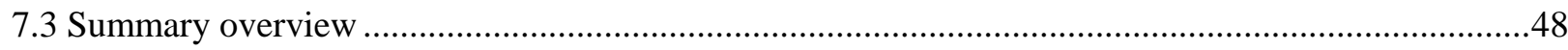

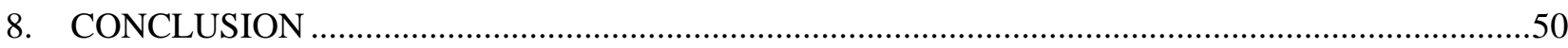

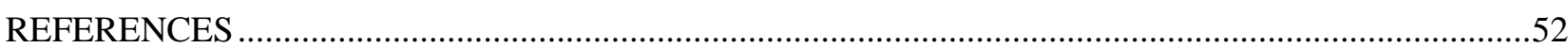

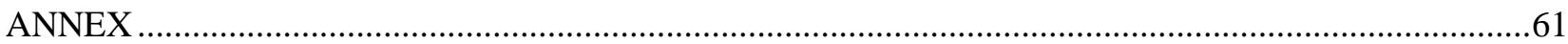




\section{Tables}

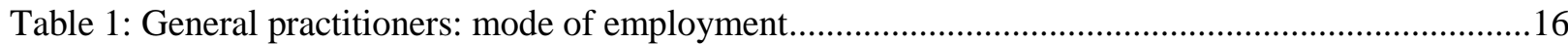

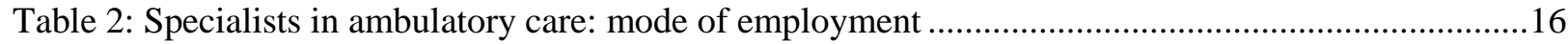

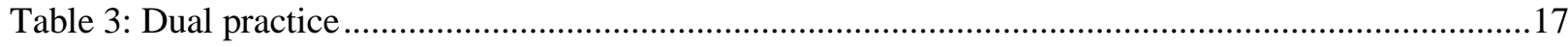

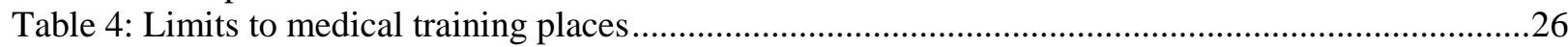

Table 5: Reported financial incentives to foster a better geographic distribution of physicians ................33

Table 6: Summary of payment mechanism across different institutional arrangements ............................36

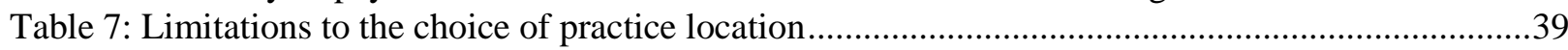

Table 8: Experience with or recent introduction/expansion of non-physician provider roles ...................44

Table 9: Strategies, areas of actions: impact lag and cost structure ........................................................51

\section{Figures}

Figure 1: Current issues in physician supply ......................................................................................

Figure 2: Traveling distance and means of transportation as reasons for unmet care needs, by age group (EU-SILC 2011)

Figure 3: Physician density in TL2 regional number of physicians per 1000 inhabitants, OECD countries, 2011 (or closest years).................................................................................................. Figure 4: Physicians in predominantly urban (PU) and predominantly rural (PR) regions by 1000

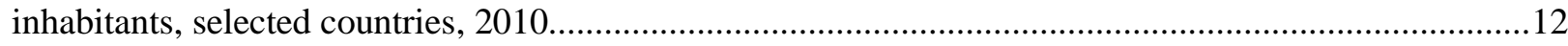

Figure 5: Population density in predominantly rural areas, inhabitants per $\mathrm{km}^{2}, 2012$ or latest...............13

Figure 6: Density of doctors in Paris and surrounding departments, 2009 .........................................14

Figure 7: Income or revenue of GPs/ Primary health care physicians, rural/urban ratios, selected

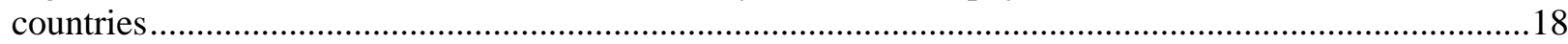

Figure 8: Total hours worked per week of GPs/Family Physicians, urban vs. rural regions, selected

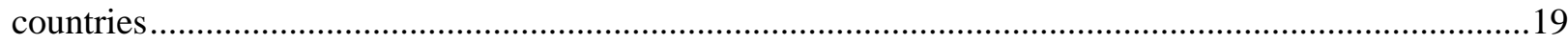

Figure 9: Hours worked and on call, by size of community, Australia, 2010 ......................................20

Figure 10: Ranking of prestige and lifestyle of physician specialty, Australian medical students ............22

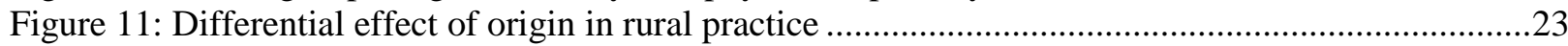

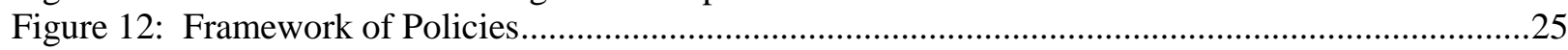

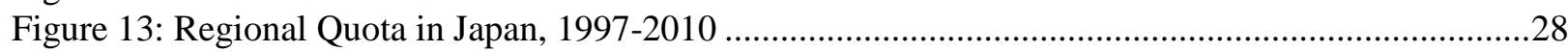

Figure 14: Relative percentage of practicing in rural area, in comparison to non-JMU graduates............29

Figure 15: One-time financial support for practice openings in EUR, German Länder y .........................34

\section{Boxes}

Box 1: Changing perspective on work and life balance among younger physicians? .............................21

Box 2: The French ECN, combining choice of region and choice of specialty ........................................31 


\section{INTRODUCTION}

1. Geographic maldistribution of physicians has been a recurring phenomenon and has been part of health policy discussion for many decades (Weiskotten, et al., 1960; Cooper et al., 1972). Nevertheless, the mismatch of physicians to population health in different geographic regions is the most commonly named current human resource policy concern in the health sector across OECD countries. According to the 201213 OECD Health System Characteristics Survey, out of 34 OECD countries only one, the Netherlands, does not consider the distribution of doctors to be an issue (four countries did not yet reply) (Figure 1).

Figure 1: Current issues in physician supply

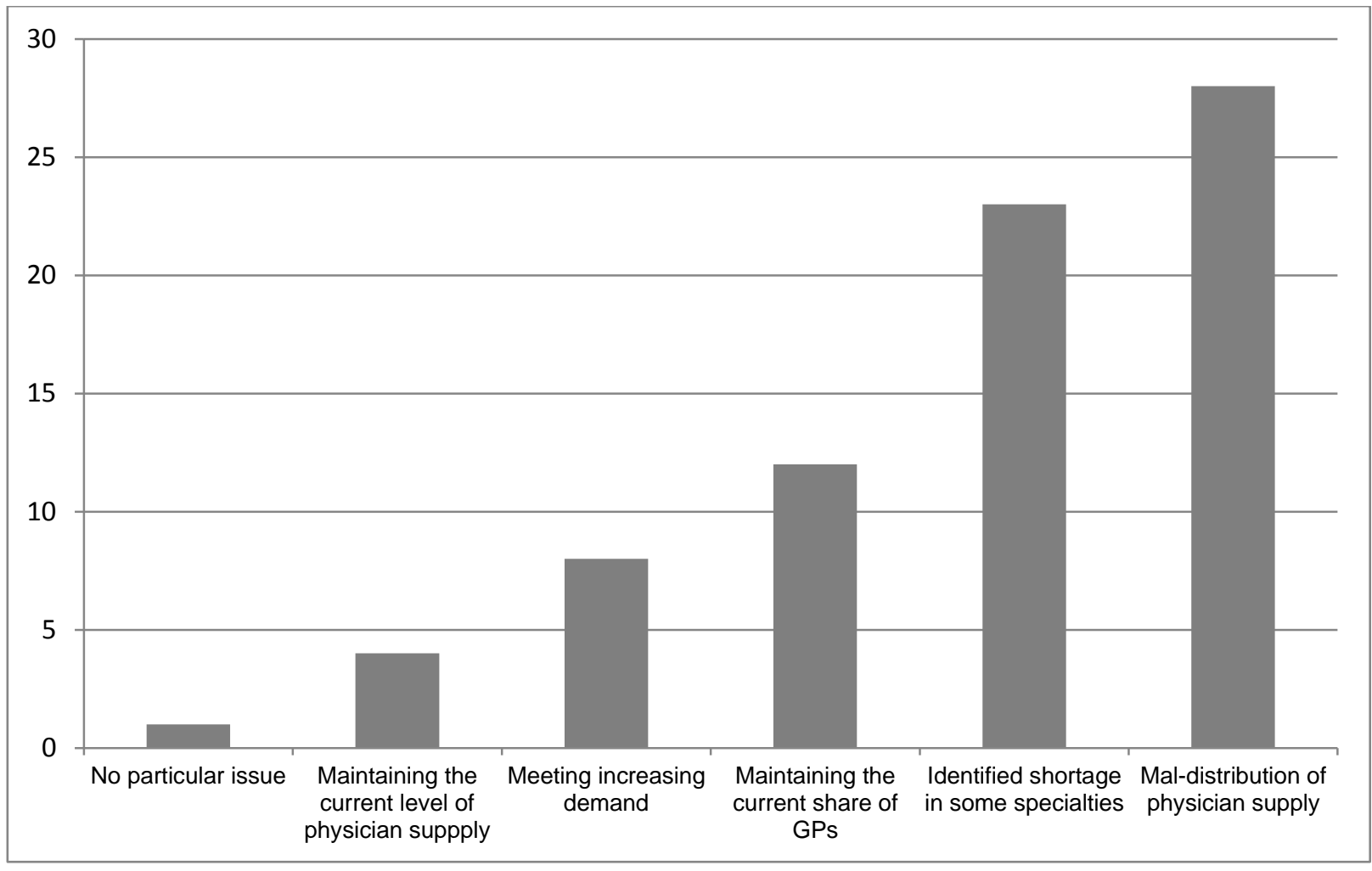

Note: "No particular issue": Netherlands.

Source: 2012-13 OECD Health System Characteristics Survey, as of February 2014.

2. The supply of physicians in different localities is most commonly measured in terms of the number of doctors per inhabitants (physician density, or physician to population ratio). While the overall physician density has increased substantially in most OECD countries over recent decades, disparities in the density of physicians between different regions still exist in all OECD countries. Typically, rural regions and socio-economically challenged urban regions have lower staffing than more affluent and/or urban ones, and a relatively high level of health worker availability is often observed in capital regions.

3. Many doctors are reluctant to practice in rural and socio-economically disadvantaged urban regions due to various concerns regarding their career, family and lifestyle. Many countries have tried a variety of incentives or regulations to influence or direct the choice of practice location of physicians. Such policies stretch across different areas of action, such as medical education, financial incentives, regulation 
or service delivery reorganisation. While there have been several recent reviews of these policy areas (Dolea et al., 2010; Bärninghausen and Bloom, 2009), the fact that these incentives are often implemented as bundled or sequenced policies, and general lack of follow-up assessment or evaluation of their implementation create challenging circumstances for a systematic evaluation.

4. The geographic location of physicians will likely continue to be at the forefront of health workforce policy concerns as populations age. For example, $6 \%$ of those over the age of 65 with unmet health needs report that the travel distance and transportation limitations are reasons for unmet care in the 27 EU countries and candidate countries (Figure 2) and this is especially pronounced in countries such as Poland, Estonia and Greece. This is expected to be a particular challenge in countries where elderly populations are more concentrated in underserved regions.

Figure 2: Traveling distance and means of transportation as reasons for unmet care needs, by age group (EUSILC 2011)

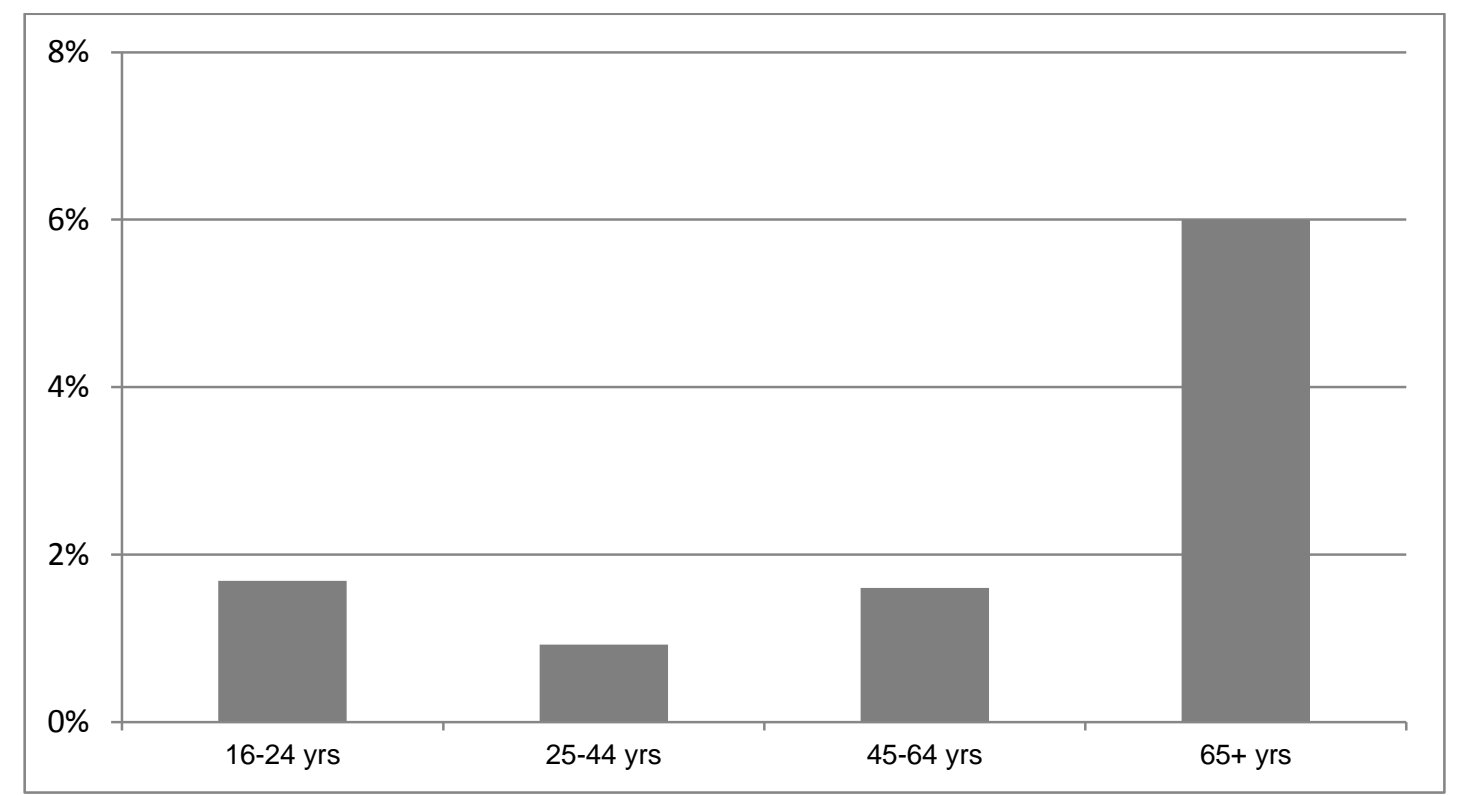

Source: OECD analysis, The European Union Statistics on Income and Living Conditions (EU-SILC 2011).

5. This paper examines and provides a synthesis of factors known to influence physicians' decisions on practice location, and presents a review of policies which have been implemented to address these factors and to improve access to health services in underserved areas in various OECD countries. It documents policies with specific attention to characteristics of locality, physicians and the health system.

6. The paper begins with a description of the geography of distribution of physician supply (Section two); examining the characteristics of localities we are concerned with. It then turns to investigating factors known to influence physicians' decisions on practice locations (Section three). Section four proposes a framework for analysis of policy responses. Following this, the paper details policy responses OECD countries have chosen to tackle maldistribution by focussing on future doctors (Section five), current physicians (Section six) and in doing with less (Section seven). Section eight concludes. 


\section{THE GEOGRAPHY OF PHYSICIAN DISTRIBUTION}

7. In many countries, rural regions and socio-economically challenged urban areas are less wellstaffed in general and by doctors in particular than other regions, and this may pose a significant barrier for access to medical services among its inhabitants. OECD countries display very different levels in the total number of practicing physicians in the country, ranging from two physicians per 1000 population or less in Chile, Turkey and Korea, four and more in Austria, Greece, Italy and Spain (OECD 2013). Whatever the overall density of physicians, in all OECD countries, it varies across regions (Figure 3).

Figure 3: Physician density in TL2 regional number of physicians per 1000 inhabitants, OECD countries, 2011 (or closest years)

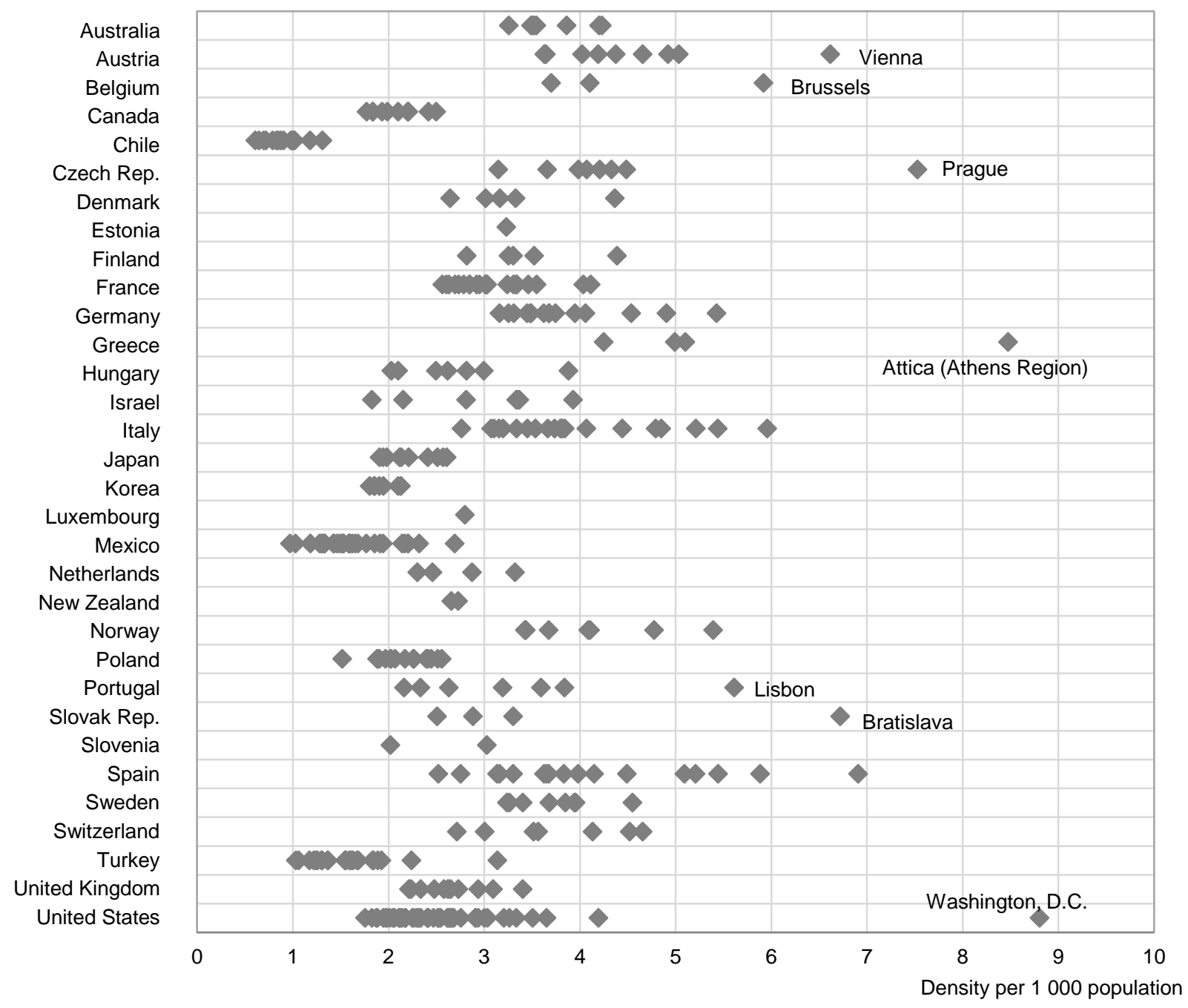

Note: Each observation (point) represents a TL2 region (for example, region in France, Länder in Germany or state in the USA) of the countries shown in the vertical axis.

Source: OECD (2013a), Health at a Glance. 


\subsection{Rural regions}

8. Across OECD countries, the number of physicians per capita (i.e. density of physicians) is consistently greater in urban regions, reflecting the concentration of specialist and tertiary services such as surgery and the preference of specialised practitioners and physicians to practice in urban settings. However, the extent of divergence of density between urban and rural areas varies between countries. Differences in the density of physicians between predominantly urban regions and rural regions were highest in the Slovak Republic, the Czech Republic and Greece, while they are more equal in Japan, Korea and Turkey (Figure 4).

Figure 4: Physicians in predominantly urban (PU) and predominantly rural (PR) regions by 1000 inhabitants, selected countries, 2010

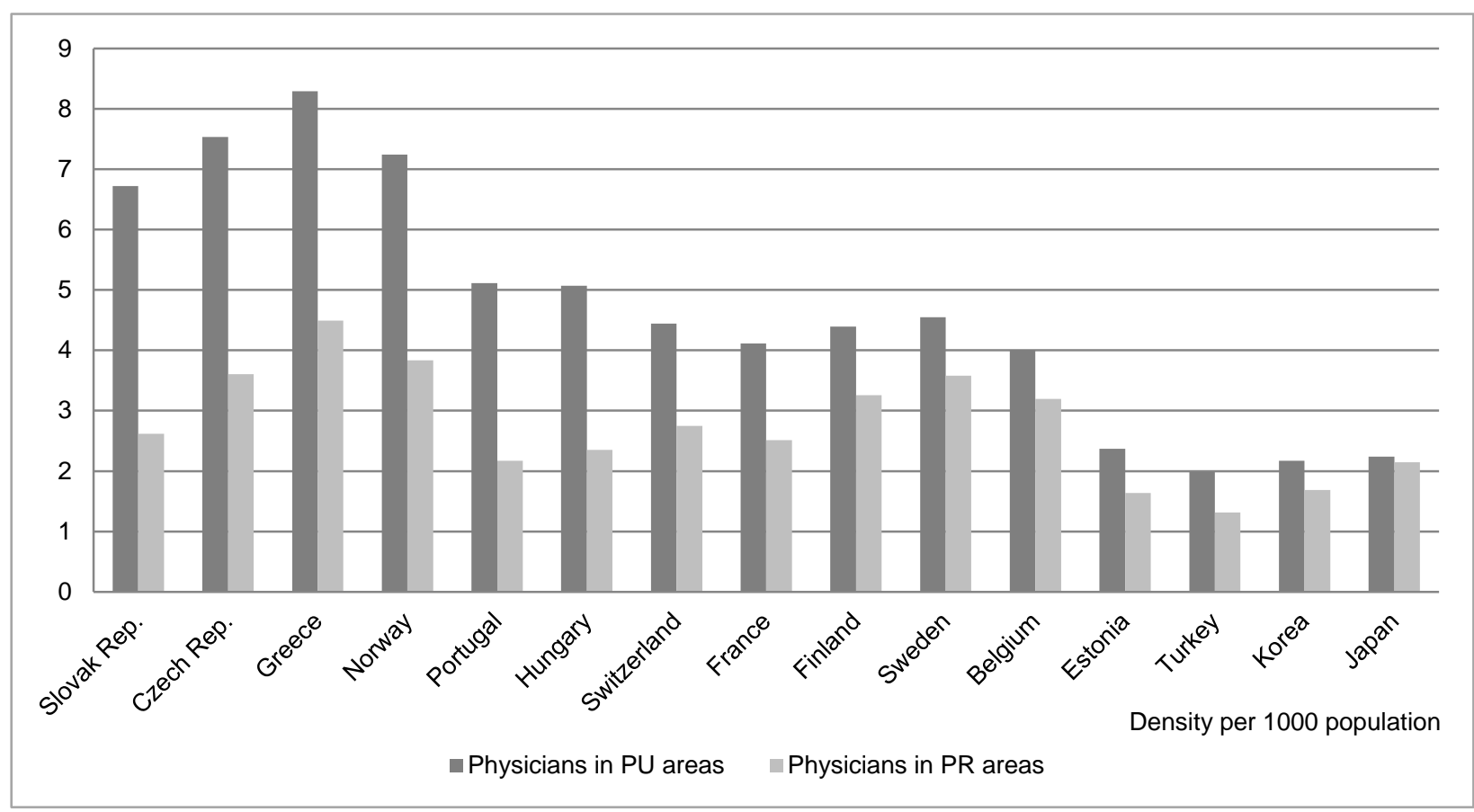

Source: OECD (2013a), Health at a Glance.

9. By definition, rural regions have relatively few inhabitants that are widely dispersed. Nevertheless, rural regions significantly differ across OECD countries in population density. The $O E C D$ Regional Database shows that in Iceland, Australia, Canada and Norway, population density of predominantly rural regions ${ }^{1}$ is less than 10 inhabitants per $\mathrm{km}^{2}$ while in predominantly rural regions of Germany, Japan and Korea have at least 100 inhabitants per $\mathrm{km}^{2}$ (Figure 5). Whilst lower population density is a universal characteristic of rural areas, it is important to note that the extent and characteristics of "rurality" can vary markedly in different countries, which may limit the transferability of policy options. Some of the key variations are identified in this section of the report.

$1 \quad$ Predominantly urban regions are defined as regions with a less than $15 \%$ of population share in local rural areas. Predominantly rural regions are defined as regions with more than $50 \%$ of the population living in local rural areas and no urban centre of at least 200000 inhabitants holding more than $25 \%$ of the region's population (OECD, 2011b). 
Figure 5: Population density in predominantly rural areas, inhabitants per km², 2012 or latest

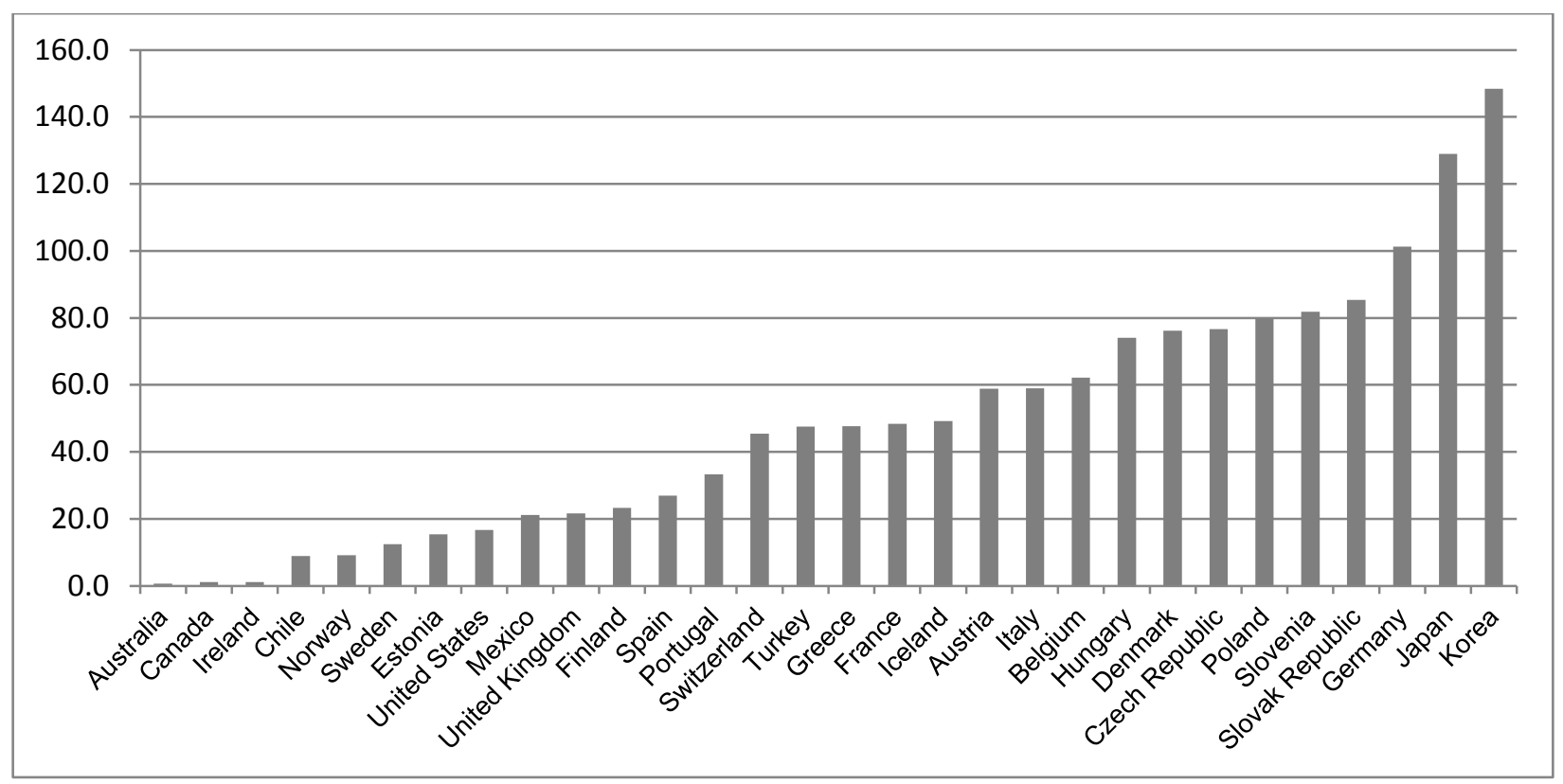

Source: Based on OECD (2013b), Regional Database.

10. Low population density makes rural regions a challenging environment for health service provision, as for any other service industries that require direct, "face to face" contact to link services with consumers and clients. There are several elements to this impact of rurality.

- First, because populations are widely dispersed, and transport infrastructures often limited, the distance and travel time and complications to the nearest point of service is usually much longer than in urban areas.

- Second, widespread low density rural populations lack the critical mass and concentration that assist in efficient location of specialist services.

- Third, if low population density also means low staffing numbers, this small "headcount" of staff also implies that staffing mix options are limited, and there may also be staffing constraints over $24 / 7$ service provision.

11. Some countries also make a distinction between "rural" and "remote" in terms of service provision and workforce availability. For example, in Australia "it needs to be emphasised that whilst the rural and remote sectors have some issues in common, there are also some stark differences. The biggest, for example, is the relative absence of medical practitioners in remote areas. Remote health is predominantly reliant on the core workforce of Aboriginal and Torres Strait Islander health workers, and practitioners and remote area nurses (RANs) with support from a range of multi-disciplinary health professionals across the fly in fly out (FIFO) and drive in drive out (DIDO) allied health and medical professions" (Health Workforce Australia, 2013:10). In Scotland, "rural and remote" covers low density population in the mainland highlands, where transport infrastructure is limited, but also includes population clusters on many small islands only accessible by boat or plane. In Japan, the designation of "isolated rural areas (hekichi)" also takes into account natural terrain and climate (islands and mountainous area with heavy snow) that create hindrance to accessing necessary services. 


\subsection{Disadvantaged urban and suburban regions}

12. While the distance to a physician's location of work is a dominant factor determining the access to health services in rural areas, the factors creating barriers to access in urban disadvantaged areas can be less obvious, and perhaps more complex. People who live in disadvantaged urban and suburban regions may have distinctly different educational, economic, cultural, and demographic backgrounds from their more affluent neighbours. Inhabitants of disadvantaged urban areas tend to have a worse health status and thus potentially higher demand for health services. Moreover, their life circumstances require health providers who understand their health needs and social conditions and can provide appropriate care.

13. As the first point of access to health care, it is ideal for a GP-based service or family health practice to be in their community and understand their needs and health condition (Huisman et al., 2013; Chandola, 2012). However, socio-economically disadvantaged urban areas have difficulties attracting physicians (BMG, 2011) as exhibited from the distribution of physicians. For example, in Paris, the density of GPs ranges from 3.18 per 1000 population in the (wealthy) $8^{\text {th }}$ arrondissement (city district) to 0.76 GPs per 1000 population in the (poor) $20^{\text {th }}$ arrondissement. Differences in densities are even more pronounced if compared to the surrounding departments (districts). In socio-economically disadvantaged areas in Seine-Saint-Denis, the general density is much lower and decreases to 0.42 GPs per 1000 population in Bobigny and 0.35 GPs per 1000 population in Neuilly-Plaisance (Figure 6, URPS Médecins IDF).

\section{Figure 6: Density of GPs in Paris and surrounding departments, 2009}

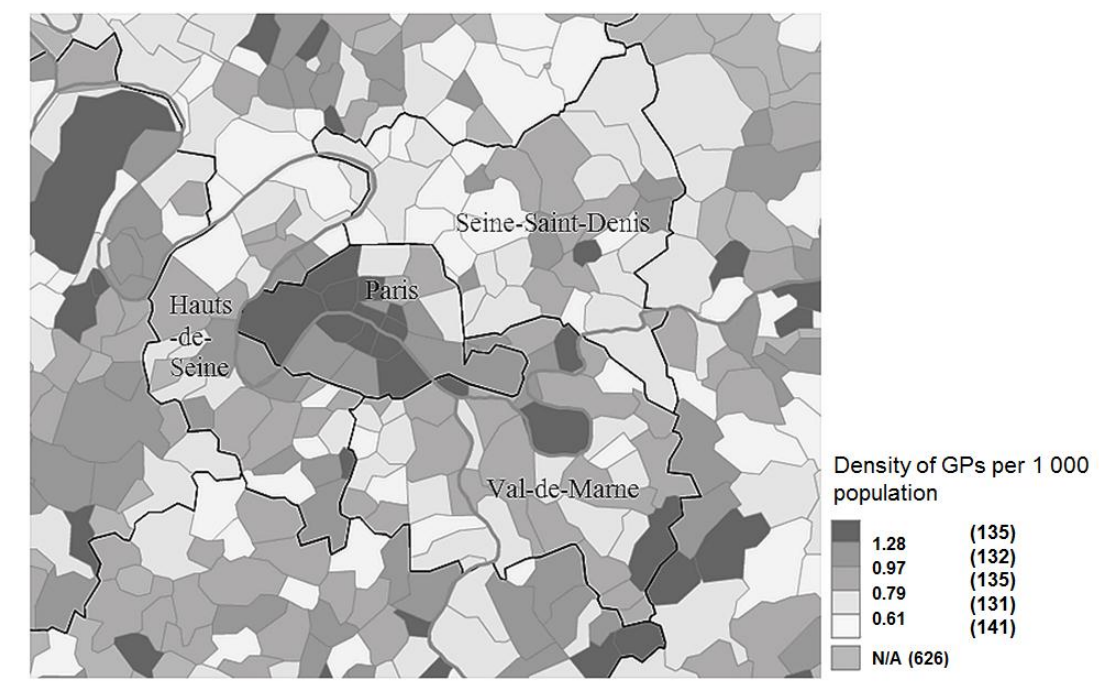

Source: URPS médecins lle-de-France (2013), Soigner en lle de France, Offre de Soins.

14. These findings in Paris and surrounding area are consistent with examples from other countries. For example, in the United States, there are shortages of GPs in socio-economically disadvantaged urban areas (Heisler, 2013). In German cities, the share of long-term unemployed inhabitants correlates with a lower density of doctors. Districts with a percentage share of inhabitants on unemployment benefits below $8.7 \%$ had a density of 0.91 GPs per 1000 population inhabitants whereas the density was only 0.60 GPs per 1000 population for districts with a share above 15.5\% (Greß and Stegemüller, 2011). 
DELSA/HEA/WD/HWP(2014)2

\section{INFLUENCES ON LOCATION CHOICE OF DOCTORS}

15. This section turns to factors that are likely to play a role in the decision of a physician to practise in a certain region. Motivations are complex and many different factors can influence the choice of practice location of physicians and other health professionals. Among the many issues that can play a role, several factors have been identified to be of particular relevance: First, the general attractiveness of the locational environment, including educational options for children, career opportunities for spouses as well as personal safety concerns, housing and access to cultural activities. Second, the mode of employment, determining the options physicians have who enter the labour market or wish to take up a new position. Third, the income potential, which is likely to be influenced by payment schemes as well as health financing arrangements. Fourth, the working conditions a physician faces, including working hours, access to appropriate medical equipment and support services, challenging patient populations, and career and professional development opportunities. Fifth, issues of prestige and recognition play a role, as many medical students and physicians appear to value general medicine and in particular rural medicine less than other fields. Finally, the expectations medical students have towards work and life in underserved regions and their capacity for adjustment to working in a rural or socio-economically challenged region.

\subsection{General environment}

16. Socio-economically disadvantaged urban areas and rural regions are often considered to be less attractive environments to live in. In rural areas a number of characteristics, such as inferior infrastructure, limited educational opportunities for children, or limited career opportunities for spouses are increasingly considered to be important drivers of practice location choice (Veitch and Crossland, 2005; Hartmannbund, 2012). Socio-economically disadvantaged urban regions are difficult environments as well, with factors such as security and poor schools potentially influencing the desirability of different locations (Mead, Dodson and Ellway, 2006).

17. In qualitative surveys of family medicine graduates in Canada, lifestyle issues and family obligations were listed as one of reasons for not practicing in rural area, along with other work concerns (Lu, Hakes and Bai, 2008). Similarly, a study in Germany cites that few leisure facilities are one of negative aspects of rural practice (Natanzon et al., 2010). However, this is also a matter of personal preferences of individual physicians and which type of "leisure facility" matters may vary significantly. For some physicians, the rurality of a location may be an attraction in itself. For example, a survey from Colorado, USA, reports that $70 \%$ of rural physicians respond that recreational or leisure activity was one of the very important factors in keeping them in rural settings (Colorado Health Institute, 2012).

\subsection{Mode of employment}

18. The mode of employment of a doctor will have a bearing on the policy options countries have to influence physicians to practice in underserved regions. For example, where doctors are salaried employees, such as in Finland, their choice of practice location is determined to a large extent by the availability of vacancies in any given region. Financial incentives are also delineated in part by the mode of employment. Where physicians are predominantly publicly employed, the government may have the scope to directly pay bonuses or vary salaries according to location. Where physicians are predominantly self-employed and capitation agreements or fee-for-service schedules are the basis of remuneration, these mechanisms need to be regionally diversified or weighted, or additional incentives may need to be paid outside of payment systems in order to provide sufficient financial incentives to recruit and retain staff in rural/ underserved areas (see section 6) 
19. The 2012-13 OECD Health System Characteristics Survey provides an overview of the predominant mode of employment, as indicated by the participating countries. In 19 of the countries included in this overview, general practitioners are self-employed or privately employed. However, in Finland, Israel, Portugal, Slovenia, Spain and Sweden, general practitioners are publicly employed. For specialists who work in ambulatory care the picture is similar although there are more countries where they are publicly employed (see Tables 1 and 2 below).

Table 1: General practitioners: mode of employment

\begin{tabular}{lll}
\hline Self-employed & Privately employed & Publicly employed \\
\hline Austria & Australia & Finland \\
Belgium & Poland & Israel \\
Canada & United States & Portugal \\
Czech Republic & & Slovenia \\
Denmark & & Spain \\
France & & Sweden \\
Germany & & \\
Greece & & \\
Ireland & & \\
Italy & & \\
Korea & & \\
Netherlands & & \\
New Zealand & & \\
Norway & & \\
Switzerland & & \\
United Kingdom & & \\
\hline Source: 2012-13 OECD Health System Characteristics Survey, as of February 2014. & \\
\hline
\end{tabular}

Table 2: Specialists in ambulatory care: mode of employment

\begin{tabular}{lll}
\hline Self-employed & Privately employed & Publicly employed \\
\hline Austria & Australia & Denmark \\
Belgium & & Finland \\
Canada & & Ireland \\
Czech Republic & Israel \\
France & Italy \\
Germany & New Zealand \\
Greece & Norway \\
Iceland & Portugal \\
Korea & Slovenia \\
Netherlands & Spain \\
Poland & Sweden \\
Switzerland & United Kingdom \\
United States & \\
\hline Source: $2012-13$ OECD Health System Characteristics Survey, as of February 2014. & \\
\hline
\end{tabular}

20. One aspect of different employment models that is of relevance to geographic distribution issues in some countries is the so called "dual practice", where the doctor holds two jobs; in many cases this will be both public and private-related work. Significant private sector earning opportunities are more likely to be available in higher-density urban areas, and this may influence choice of location of individual practitioners. As such, perceptions of limited dual practice opportunities may be another factor in deterring 
doctors to locate to areas of low population density or with relatively poor populations. The impact of dual practice varies from country to country, based on its extent and the presence or absence of regulatory policies (Table 3). A recent systematic review of dual practice found that there are three main categories of dual practice regulation mechanisms that have been used by national policy makers: 1) total banning of dual practice; 2) allow dual practice with restrictions; 3) allow dual practice without restrictions. The authors of the review concluded that the "most effective mechanisms" to regulate dual practice are likely to be multi-dimensional (Kiwanuka et al., 2011).

Table 3: Dual practice

\begin{tabular}{lll}
\hline Always allowed & Allowed in certain cases & Not allowed \\
\hline Austria & Canada & Germany \\
Belgium & Greece & Hungary \\
Chile & Iceland & Ireland \\
Czech Republic & Italy & Korea \\
Denmark & Japan & Luxembourg \\
Finland & Poland & Norway \\
France & Portugal & Sweden \\
Israel & Slovenia & \\
Mexico & Spain & \\
Netherlands & United States & \\
New Zealand & & \\
Switzerland & & \\
United Kingdom & & \\
\hline Source: 2012-13 OECD Health System Characteristics Survey, as of February 2014. &
\end{tabular}

\subsection{Income potential}

21. In fee-for-service systems or capitation systems, the number of services a doctor provides or the number of patients a physician has on his/her patient list directly impacts on income. Without financial adjustments in the payment scheme, physicians in rural and disadvantaged areas may earn less than colleagues who practice elsewhere because they have a lower number of patients or provide a lower volume of services.

22. A study in the US demonstrated that the unadjusted annual income of rural primary care physicians was slightly higher than their urban counterparts; however, they tended to work longer hours and have more patient visits to achieve that level of income (Weeks and Wallace, 2008). Similar effects of the population characteristics of rural or disadvantaged areas on income for physicians are observed elsewhere, although the precise nature of the financial disadvantage differs from one country to another. For example, in Germany, physicians claim that socio-economically disadvantaged urban regions are financially not sufficiently lucrative due to a smaller share of patients with private insurances which pay higher fees (Walendzik et al., 2008).

23. Differences in income potential between different geographic regions may well affect the relative success of different policies. Insofar as the problem is one of income, financial incentives may mitigate the negative financial aspect of rural practice. Available data from five countries show that unadjusted (for workload or working hours) physician's income or revenue is at least similar or higher in rural areas compared to income in urban environments. In Australia, France and Germany, work-related incomes of rural physicians are about $15 \%$ higher than those in urban regions, in the USA the figure is about $6 \%$. In some countries, incomes of physicians in rural areas may be lower, such as Norway, where incomes are slightly (1\%) lower in rural regions (Figure 7). 
24. Financial considerations are important for physicians' location choices. It is understandable that if rural areas or other underserved areas are undesirable for other reasons of work and personal life, relatively low financial benefits can be an additional factor in deterring doctors from working in these areas. While the data is limited (and not comparable between countries), it seems that such financial concerns have been addressed in some countries, with physicians in rural areas having higher reported income/revenue than in urban regions. Nevertheless, the maldistribution of physician supply remains a problem in those countries.

Figure 7: Income or revenue of GPs/ Primary health care physicians, rural/urban ratios, selected countries

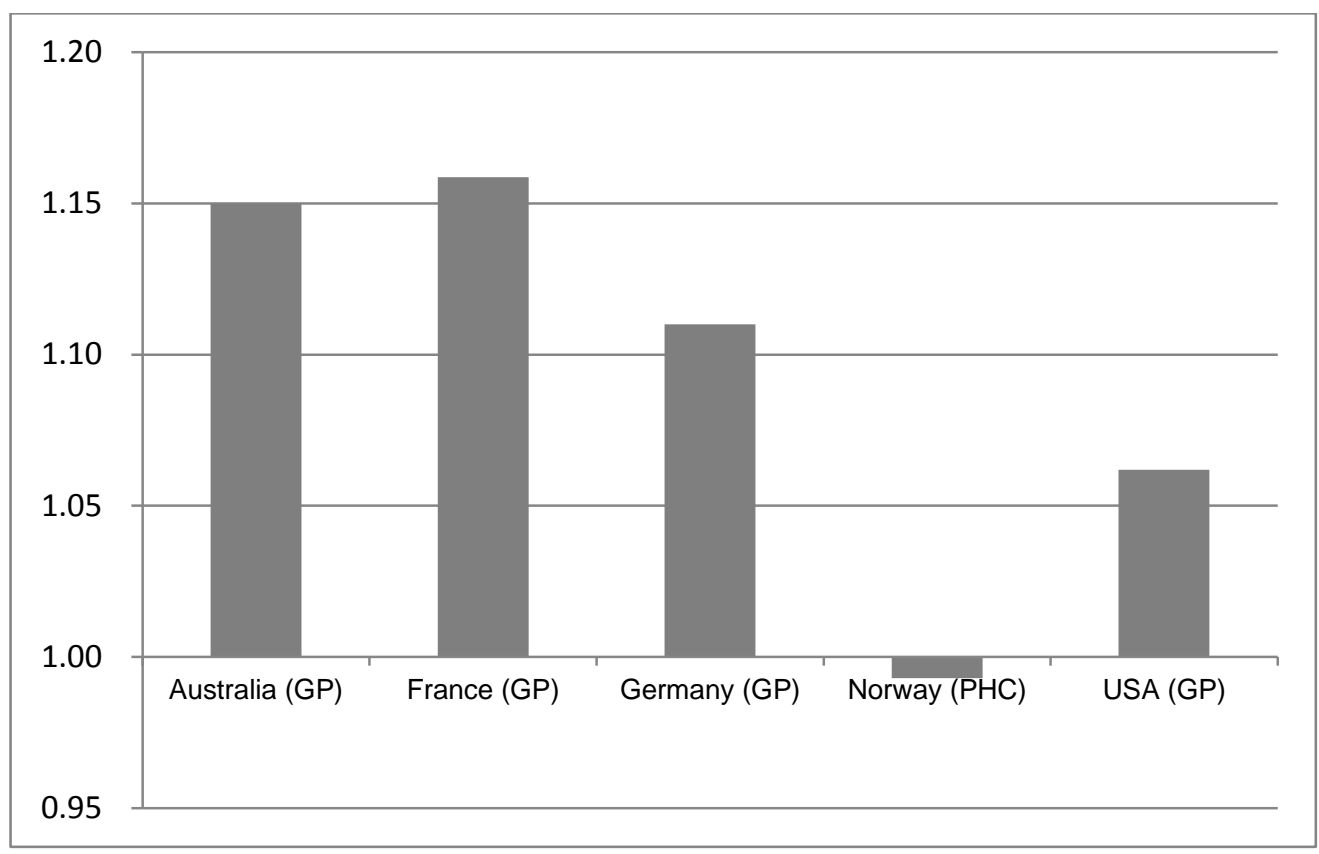

Sources:

Australia: Cheng et al. (2010), income, major cities vs. outer regional, rural and remote.

France: DREES (2013), income, predominantly urban area vs. predominantly rural using OECD definition, data provided to the OECD.

Germany: von Stillfried (2012), revenue major cities vs. rural areas. Norway: Deloitte (2011), income, cities with more than 50 000 inhabitants vs. the rest of the country.

USA: Weeks and Wallace (2008), income, metropolitan areas vs. non-metropolitan areas.

\subsection{Working conditions}

25. Working conditions are a crucial factor in the choice of practice location of physicians. Several studies have indicated that many medical students and recent graduates place a high value on the combination of work and family life, or more broadly, they see a good work-life balance as a very important factor in determining where they want to work (Gibis et al., 2012; Aasland, Røvik and WiersJenssen, 2008; Buddeberg-Fischer et al., 2008; Soethut et al., 2007).

26. The traditional view of the rural practice, "one physician, alone, always at work, always on call" (Elliott, 2012), summarizes the working condition concerns of pursuing a career in rural areas. Whilst this may not be an accurate or complete picture in all cases, the first concern is often long working hours in rural practice. In fact, in Australia, Canada, France and Germany, GPs or family physicians practicing in rural regions worked significantly more hours per week than their colleagues in cities (Figure 8). 
Figure 8: Total hours worked per week of GPs/Family Physicians, urban vs. rural regions, selected countries

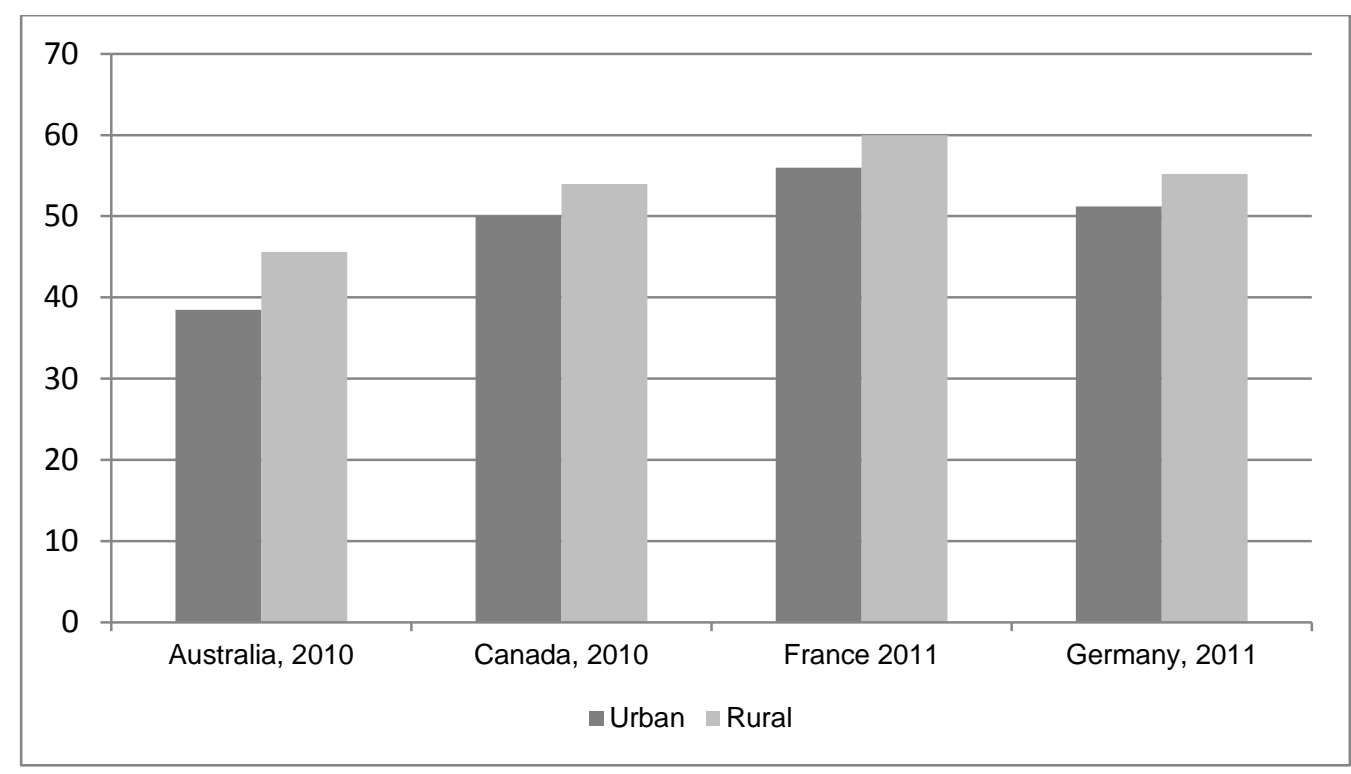

Sources:

Australia: McGrail et al. (2012), major cities vs. outer regional, rural, and remote.

Canada: Buske (2012), urban area vs. rural area which include small town, rural and geographically isolated/remote area. France: Jakoubovitch et al. (2012), urban vs. rural areas based on INSEE definition.

Germany: Steinhäuser et al. (2011), urban vs. rural area based on the level of rurality rated by physicians.

27. In addition to longer working hours, an additional concern for many physicians in underserved areas is extensive on-call duties. In underserved regions, especially in rural regions, doctors in solo practices may find themselves with no other health professional in near proximity, facing significant periods of time responding to on-call duties (Elliott, 2012; Natanzon et al., 2010). In particular for solo practice physicians or those working in relatively small geographically isolated teams, the inability to have assured periods of uninterrupted time away from work if they remain in the location may pose a significant source of stress (Sim, 2011). In Australia, for example, McGrail et al. (2012) find that combined working and on-call time for doctors in medium sized, small and very small rural communities is on average between a third and double of that of doctors in metropolitan areas (Figure 9). 
Figure 9: Hours worked and on call, by size of community, Australia, 2010

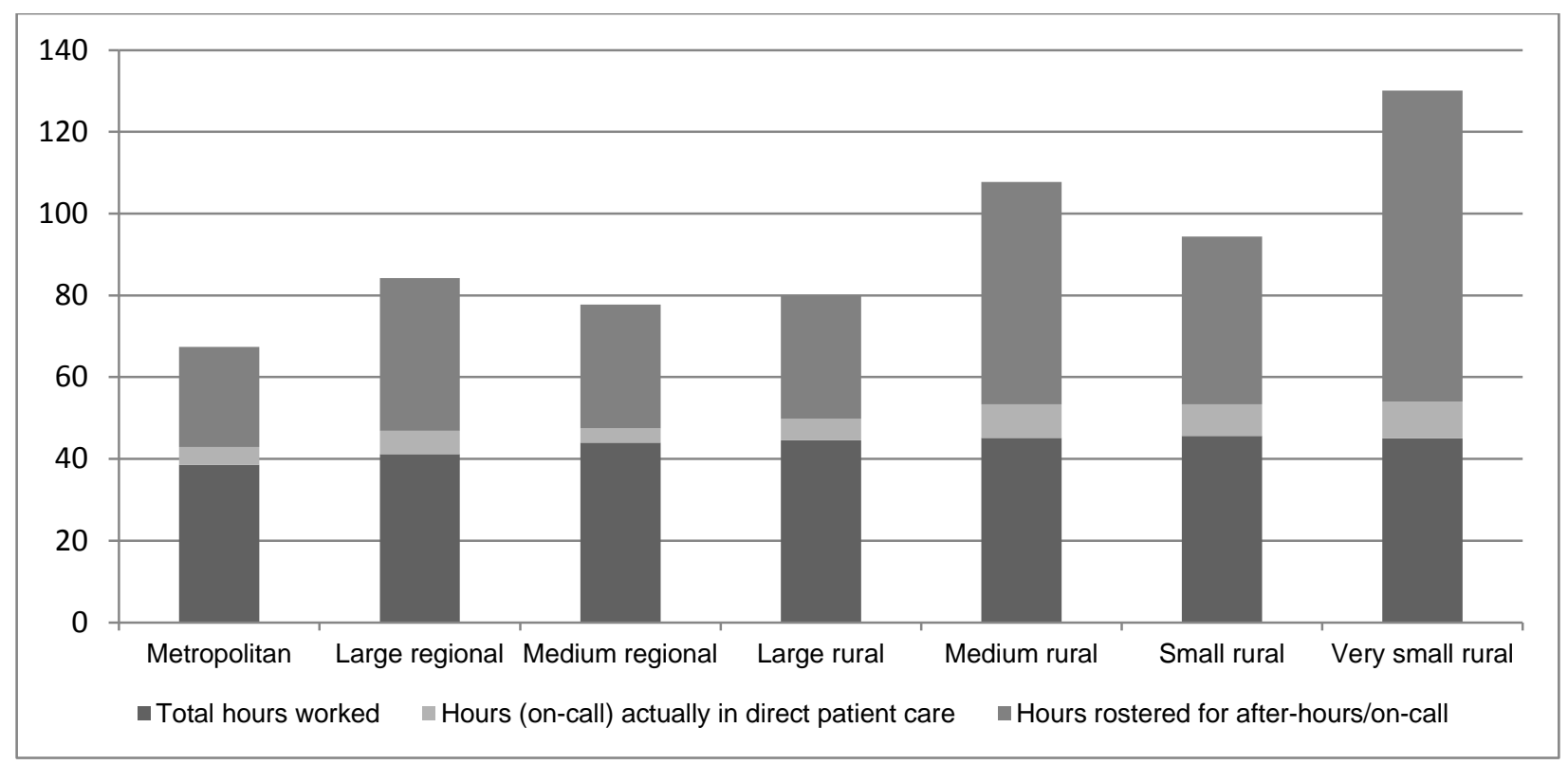

Source: McGrail et al. (2012).

28. Within urban areas, working conditions may play a role in the choice of practice location as well. In Germany, the lower overall density of GPs in socio-economically disadvantaged urban and sub-urban areas, a challenging demographic structure, and the higher morbidity of socio-economically disadvantaged populations have all been identified as drivers of potentially higher workload (Senatsverwaltung Berlin, 2013). In France, physicians in such areas report more difficult working conditions, such as language problems, difficulties with different cultural backgrounds and security concerns. The Parisian suburbs, for example, rank among the regions in which most physical attacks against physicians in France take place (ONM, 2012). 


\section{Box 1: Changing perspective on work and life balance among younger physicians?}

With high shares of labour participation of women and notably an increasing share of female physicians, perspectives on work-life balance are shifting, especially among younger physicians. Furthermore, career opportunities for spouses and partners of doctors are an increasingly important factor to consider for policy makers when designing incentives for practice in underserved regions.

\section{Female physicians prefer group practices in urban settings...}

A study from the USA cites the factors that influence practice choices for female physicians are: issues related to spouse or personal partner, flexible scheduling, family leave, and availability of childcare (Ellsbury et al., 2002). Urban areas can offer workplaces that fulfil the desire of female physicians much more than rural areas: First, urban areas offer more varied career options for spouses (because of the size of the labour market) and a better infrastructure/more options for education and leisure for children. Second, physicians who work in urban areas tend to work less than those in rural regions (Buske, 2012; Weeks and Wallace, 2008; Steinhäuser et al., 2011; see section 3.4 above for further details). Third, urban settings are more adept to group practices than rural regions for economic reasons, and such practices tend to offer more team work opportunities and flexible working hours, along with less financial risk for physicians. Female physicians tend to place a high value on the compatibility between work and family (KBV, 2011c; van den Hombergh et al., 2005). For example, in 2004 , only $1 \%$ of female medical graduates in Netherlands preferred a solo practice to a group practice (against 4\% in 1980) (Maiorova et al., 2007).

\section{But so do male "generation Y"-physicians.}

While female physicians have given a higher priority to a good work-life balance, the preferences of male generation-Y physicians (born between 1981 and 1990) are aligning with them (Buddeberg-Fischer et al, 2008) and they also increasingly prefer group practices. In the Netherlands, the preference for group practice of among male medical graduates has increased by 29 percentage points (from 51\% to 80\%) from 1980 to 2004, whereas the preference for solo practices has declined by 11 percentage points (from 17\% to 6\%) (Maiorova et al., 2007). Given this trend, preferences are expected to converge further in the future and the gender effect will be overridden by a cohort effect (Maiorova et al., 2007).

\subsection{Prestige and recognition}

29. The relative prestige and status of different medical jobs, specialties and work locations can be an important factor influencing physicians' choice of practice location. In particular rural practice has been regarded as having relatively low prestige in some countries. A recent study in Australia by Creed, Searle and Rogers (2010) finds that while many specialties rank either high in lifestyle or in prestige (e.g. high prestige but bad lifestyle for surgery; low prestige and good lifestyle for public health medicine), rural medicine as a specialty is ranked low both for prestige and lifestyle among Australian medical students (Figure 10). Other studies also indicated that physicians and students in Australia who placed less value on prestige and status were more likely to have worked in rural areas or intending to do so (Conomos, Griffin and Baunin, 2013). 
Figure 10: Ranking of prestige and lifestyle of physician specialty, Australian medical students

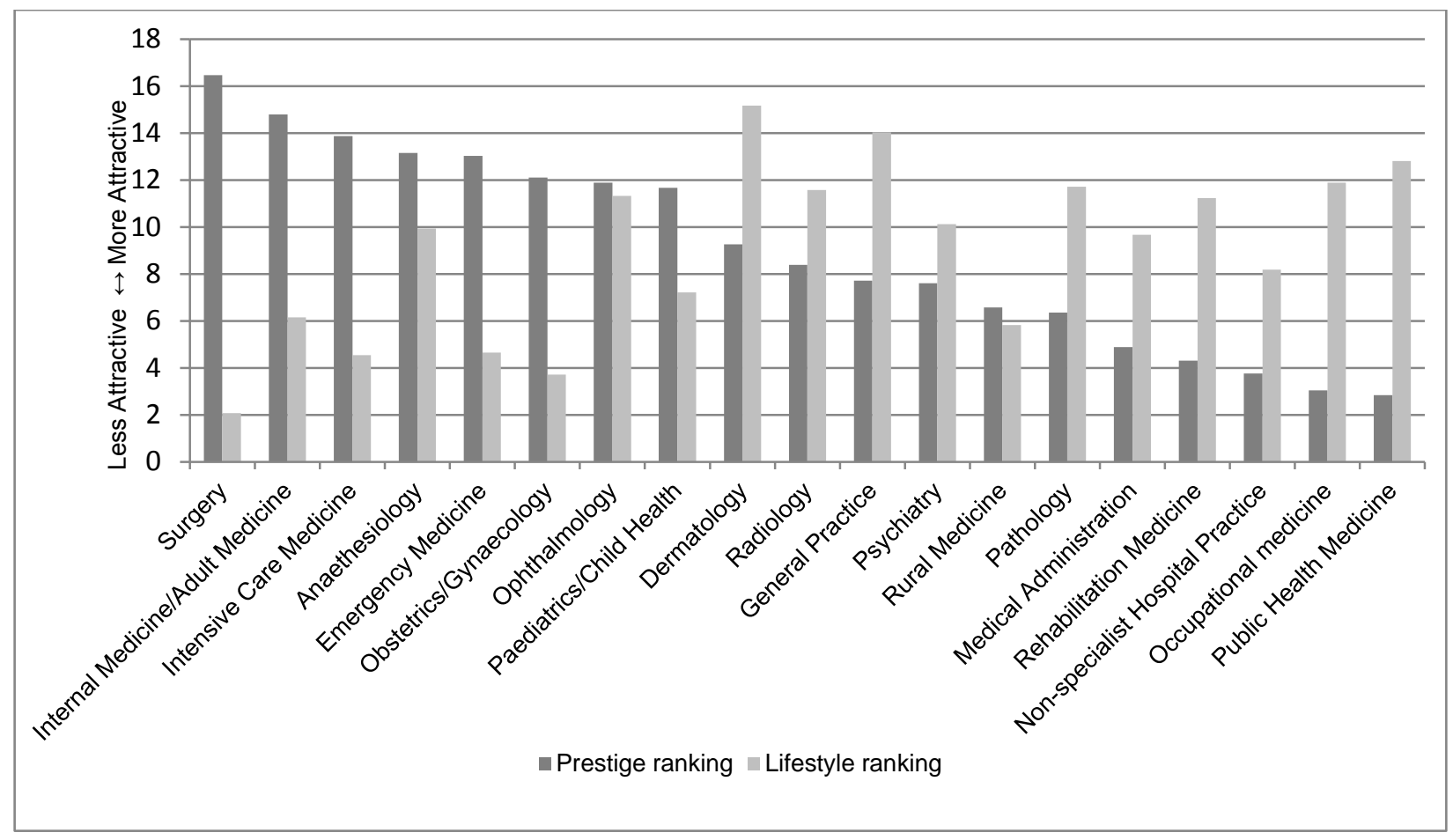

Source: Figures created by the authors, based on data presented in Creed, Searle and Rogers (2010).

30. Another factor that influences physicians' career choices is the recognition of their work contribution from peers and the community they serve. In a survey of osteopathic students and residents in the United States, $70 \%$ of students and $78 \%$ of residents considered rural practice to have greater community impact (Colegrove and Whitacre 2009). Similarly a survey of psychologists in Australia reported that they consider rural practice to have more opportunities for service and autonomy. Among them, those who have an intention to practice in rural areas tend to choose so because of community needs, and the recognition and appreciation by the community members, local government as well as other health professionals and peers are considered to be an important factor (Conomos, Griffin and Baunin, 2013).

31. There are several documented cases of management problems or solutions related to recognition of doctors by the community in which they work. In Japan, the mass resignation by physicians and subsequent closure of critical health services in some communities has been gaining attention, and the lack of appreciation by the community (i.e. local government and/or inhabitants themselves) and mismatched expectations of patient needs and doctors were considered to be contributing factors (Izaki, 2009).

\subsection{Origin and experience}

32. One factor that may influence choice of location is the extent to which expectations of practice in an underserved region match the reality. If the experience of practice in specific locations during training is positive or negative, this may change expectations of what later work would be like in similar types of location. A study from Germany indicates that medical students' expectations of work in a rural setting are actually much worse than the reality (Steinhäuser et al., 2011). Unsurprisingly, this coincides with a clear preference for practice in urban areas among medical graduates (Hartmannbund, 2012; Gibis et al., 2012; Jacob, Heinz and Décieux, 2010). 
33. Various studies have considered the link between a physician's origin and likelihood of choosing rural practice in various country settings (Weiskotten et al., 1960; Cooper, Heald and Samuels, 1972; Laven and Wilkinson, 2003; Wilson et al., 2009). Whilst a physician's rural origin is often reported as a determinant of choice of rural practice, it is not well-known exactly why rural background or rural childhood experience would lead to a higher likelihood of choice of rural practice location (Hancock et al., 2009). In the United States, Rabinowitz et al. (2011) examined why the Physicians Shortage Area Program (PSAP) of Jefferson Medical College in Pennsylvania (a program targeted to produce rural family practice physicians) has been effective and demonstrated that two key selection criteria for the program - rural upbringing and interest for family practice in the first year - are the reason of its success. Similarly, a study in Australia demonstrated that the number of years spent in rural area prior to entering to a medical school is a predictor for practicing in rural area for both GPs and specialists (McGrail et al., 2011; Figure 11). The strength of rural background as a factor in determining rural location of practice for physicians was also supported in studies in Canada, Japan and South Africa (Laven and Wilkinson, 2003; Wilson et al., 2009; Matsumoto et al., 2008; Feldman et al., 2008). Consequently, training physicians with a rural background has been advocated as a solution to filling vacancies in underserved (rural) regions (see section 5).

Figure 11: Differential effect of origin in rural practice

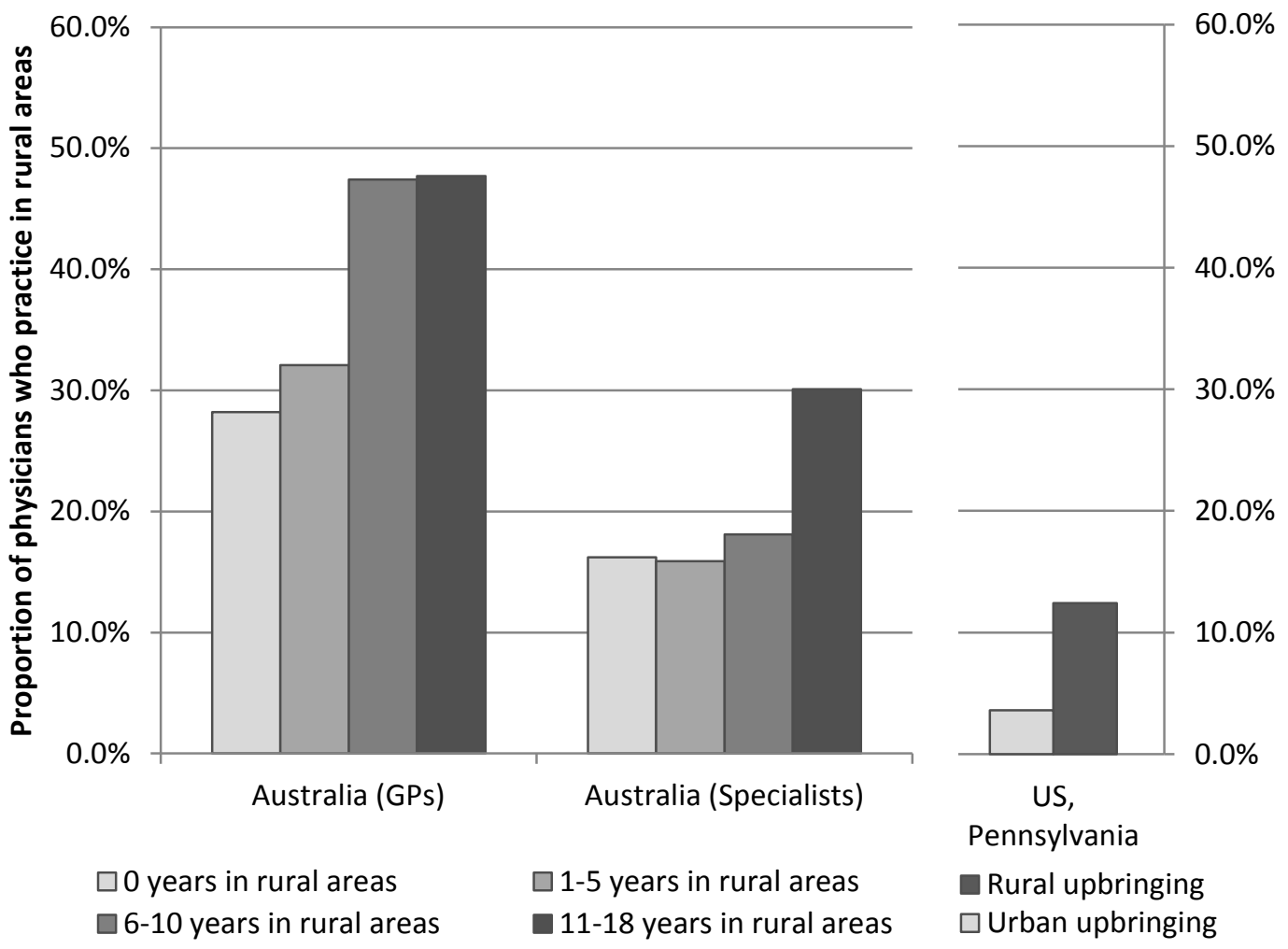

Sources: Australia: McGrail et al. (2011); USA: Rabinowitz et al. (2011). 
34. Following Bennett and Philips (2010), at any point across their training and career, physicians can be grouped into 1) those that are committed to practice in underserved regions; 2) those who may be interested, provided the right incentives are in place and 3) those who are never interested in practicing in underserved regions. The preferences of physicians may change throughout their career, and consequently, countries have multiple points of intervention across the professional lifespan of a doctor to influence their decision making on practice location. Policymakers should carefully consider policy objectives, mechanisms of influence and the target group of physicians, in order to maximize the policy impact.

35. There are three broad strategies policymakers can employ in response to geographic imbalances in physician supply. First, they can maximize the pool of physicians available for practice in relatively underserved regions, i.e. increase the number of qualified physicians who are interested in practice in underserved regions, and/or the number of working hours they are willing to provide. Second, they can maximise the share of potentially interested and qualified physicians who actually do go and practice in underserved regions. Third, they can develop service delivery models that allow for service provision with relatively fewer physicians.

36. In order to develop effective policies to influence physicians' choices, policies should target the concerns of future and current doctors, including those outlined in the previous section. Based on the classifications carried out in a number of international literature reviews (Jones, Humphreys and McGrail, 2012; Dolea, Stormont and Braichet, 2010; Wilson et al., 2009; Bourgueil, Mousquès and Tajahmadi 2006), policies can be grouped into four distinct areas of action:

37. First, through interventions at different points throughout medical education, policy may influence the later choice of practice location. The starting point of any physicians' career is entry to medical schools and the selection of candidates that comes with it. Similarly, entry to clinical training is another point at which policy may influence location choice, e.g. through placement and training curriculums.

38. Second, countries may regulate which type of physician is able to work where. Regulation can be anchored in entry to clinical training, e.g. in the form of return-of service agreements conditional on the choice of specialty. Location choice can also be legislated, through implicit or explicit regulation of the practice location at the timing when physicians set up their first practice.

39. Third, countries can offer financial incentives throughout professional lifecycle of physicians, from scholarship with return-of-service obligation at the entry to medical school and clinical training, oneoff payments at the time of setting up a first practice, recurrent payments to recruit and retain physicians in underserved areas during their practice, and/or when they near retirement age.

40. Fourth, service delivery reorientation may make the provision of service in otherwise unattractive areas less burdensome by improving working conditions and improve the life and job satisfaction of physicians practicing there. Policies may incentivize the taking-up of new processes of service delivery, or the use of new types of health service providers to provide an adequate level of access with fewer physicians in some areas, e.g. through the use of telemedicine or through shifting health service provision away from physicians and to other health service providers as much as possible. 

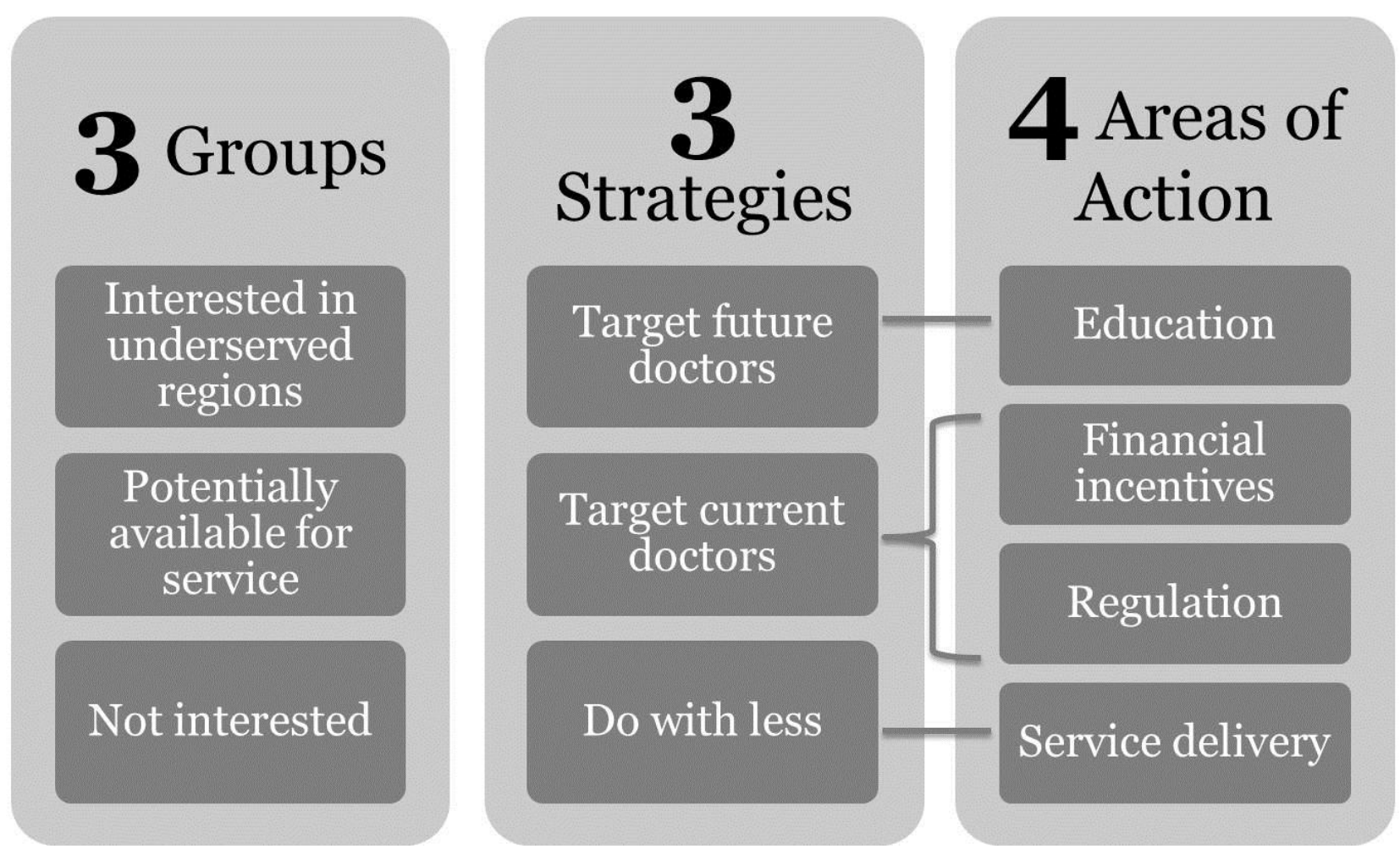

\section{TARGETING FUTURE DOCTORS: MEDICAL EDUCATION POLICIES}

41. A number of policies are in place in countries to motivate medical students to take up service in underserved regions. Such policies aim to encourage people interested in serving their communities to pursue medical careers and/or aim to reduce or remove barriers created by students' negative expectations of practice in rural or disadvantaged urban areas. Some policies emphasize the community engagement and support elements of the challenge associated with training and subsequent practice in underserved areas.

42. The extent to which countries control the access to medical education influences the policy space governments have to design incentives for medical students to take up a position in underserved areas. Among OECD countries, only the Czech Republic and the United States do not limit the number of training places in medical education (other than due to capacity constraints). Among the other OECD countries, there are two broad approaches: some countries restrict entry only into initial medical education, but place no limits on the choice of specialisation and other countries restrict both entry into initial medical education and also restrict entry into specialty training (Table 4). 
Table 4: Limits to medical training places

\begin{tabular}{lll}
\hline No limit to intake & $\begin{array}{l}\text { Initial medical education intake } \\
\text { limited }\end{array}$ & $\begin{array}{l}\text { Initial medical education and } \\
\text { specialist training intake limited }\end{array}$ \\
\hline Czech Republic & Australia & Belgium \\
United States & Austria & Canada \\
& Finland & Denmark \\
& Germany & France \\
& Greece & Korea \\
& Ireland & Netherlands \\
& Israel & Poland \\
& Japan & Portugal \\
& New Zealand & Slovenia \\
& Norway & Spain \\
& Sweden & \\
\hline Switzerland & \\
\hline United Kingdom & \\
\hline Source: $2012-13$ OECD Health System Characteristics Survey, as of February 2014. &
\end{tabular}

43. Another factor that affects the scope for countries to have influence over medical students is the way in which the costs of medical education are met, particularly the extent to which these costs are shared between public and private payers. For example, in countries, in which students bear a higher share of the costs, using scholarship or debt subsidy programmes as a way of influencing location may be a more attractive and potentially effective policy option than in countries where there are no private tuition fees.

44. Education policies may have an influence on the choice of practice location of newly trained physicians. Two levers have been explored in education policy that are reviewed in this section:

- Student selection: Selection to medical school can be used to leverage the future choices of practice location of medical graduates. Medical schools may give preference to students with a rural background or those who express interests serving in rural area, as they are more likely to pursue their careers in a rural area (see section 3.5). This approach has the advantage of being a relatively low-cost intervention; however due to the duration of medical training its effects come with a significant time lag and some potential for "talent erosion" if students prefer to stay in the urban area they are getting trained in (DoHA, 2008; Rouke, 2005; Jones, Humphreys and McGrail, 2012).

- Training institutions: Exposing students early on in their education to practices in underserved areas may have an effect on their location choice, as it can set right expectations of practice and working conditions (see sections 3.1 and 3.5). This focusses on the structure of training institutions, for example by establishing medical schools dedicated to training doctors for rural practice. Alternatively, medical education itself may be distributed into underserved areas, so exposing students to everyday interactions there. This may be done through internships, or rotations in underserved areas, or through locating training institutions (partly) in underserved regions. Setting up dedicated training institutions may be costly but it can be effective, although as with other education-focused policies, it takes time before the impact can be felt (Rouke, 2008; Rouke, 2010). 


\subsection{Policies aiming at student selection}

45. In Australia, the federal government offers three medical school placement schemes with or without financial support for students. Under the commonwealth-supported places (CSP) scheme, placements are funded through the Commonwealth Grants Scheme, with students paying a part of the medical degree and the reminder subsidized by the government. There are no conditions attached to taking a place offered under the CSP scheme. Two other placement schemes come with conditions attached: the Bonded Medical Places (BMP) Scheme and the Medical Rural Bonded Scholarship (MRBS) Scheme. Medical schools take the responsibility for the selection process for these bonded schemes after the shortlisting of student applications to study medicine (Australian Medical Association, 2013). Both bonding schemes require students to repay the cost of the medical education if they break the contract, and in the case of MRBS scheme recipient, physicians will not be able to practice privately and will not have access to the Medicare code for up to 12 years.

46. Under the BMP scheme, the Australian government offers an additional 600 placements per year for medical training, but in return, medical students taking these places have to sign a deed of agreement with the Australian government to work in a district of physician shortage for a period equal to the length of medical training. Students who are willing to accept the BMP scheme may have an increased chance of placement in medical schools, but do not receive financial support from that scheme. A recent review of government schemes (Mason, 2013) notes that more than 4500 participants have a deed of agreement with the Australian government, but only one participant has commenced his/her obligation and three have chosen to repay the cost of their medical education. In contrast, students who are offered the MRBS scheme receive substantial financial aid and sign a contract with the Australian government to work in a rural or remote area for six continuous years after completing the specialist training. This scheme has been operational since 2001, and there are 100 placements available each year. So far there is a total of over 1200 participants in the scheme and 50 recipients have commenced their return-of-service obligation period.

47. In Japan, an increasing number of medical schools have started to employ the regional quota system of student selection in order to increase the number of medical doctors within each prefecture. Under the policy of "one prefecture, one medical school" of 1973, Japan's 47 prefectures have each had at least one medical school since 1981 and these medical schools, in principle, are established to meet their prefectural needs. While the number of medical schools and total number of medical training spots are centrally controlled and have barely changed in the last three decades, each university is allowed to create its own student selection criteria and to give various incentives (including scholarships) to recruit medical students. The regional quota systems are slightly different in each medical school, but mainly involve offering a scholarship with a term-defined practice requirement (6-9 years), through 1) selection for medical school entry from within the same prefectures in which the medical schools are located, or 2) selection for medical school entry for students who are willing to serve in regional health services, regardless of their origin, or 3) the offer or a conditional scholarship for those who already are in medical school. In 1997, only two medical schools had regional quota system covering a total of eleven students, but by 2010, 67 out of 79 medical schools offered regional quota spots, in total for 1172 students (approximately 14\% of the total intake, see Figure 13). 
Figure 13: Regional Quota in Japan, 1997-2010

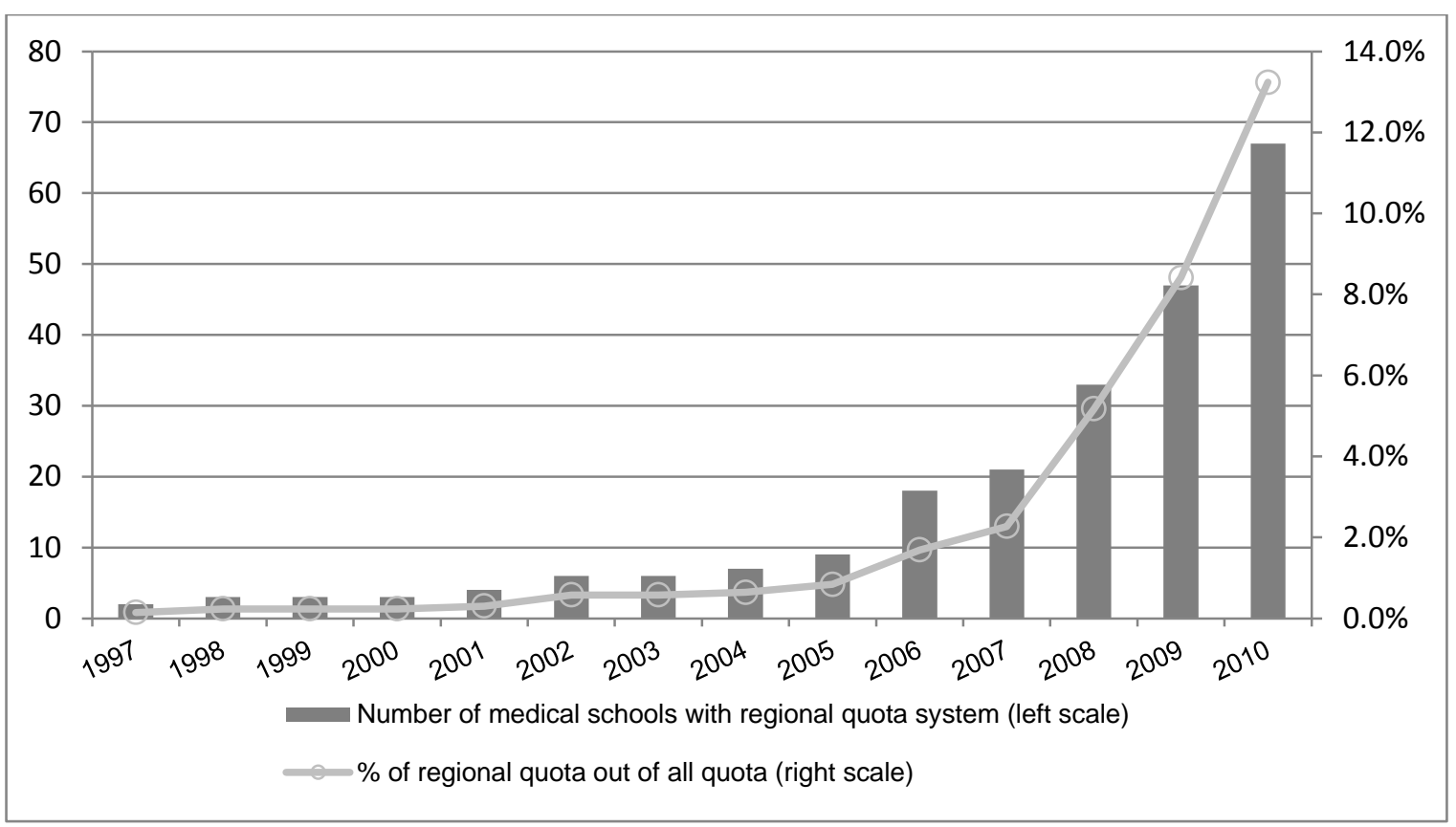

Source: Medical Education Division, Ministry of Education, Culture, Sports, Science and Technology (MEXT), (2011), Background note on the changes in medical education quota,

http://www.mext.go.jp/b_menu/shingi/chousa/koutou/043/siryo/_icsFiles/afieldfile/2011/01/18/1300372_1.pdf.

48. There is evidence that each medical school is increasing the proportion of students recruited from high school graduates within their own prefecture (30.1\% in 2003 and $36.7 \%$ in 2010). Evaluation has been so far been incomplete, as many of these quota systems are relatively new and not many students have graduated thus far. However, the Ministry of Education, Culture, Sport, Science and Technology (MEXT) conducted a study on six medical schools with regional-quota medical graduates, which shows that $89 \%$ of regional-quota graduates have remained within their prefecture, compared with 54\% of normal-entry graduates who do so. These statistics are relatively promising, though a follow-up study of long-term consequences is needed to consolidate this first impression (MEXT, 2011).

\subsection{Policies aiming at training institutions}

49. Countries have explored two different routes in using training institutions as a lever. First, there are dedicated institutions which train students specifically for service in underserved (rural) regions, and second, training itself may be distributed from universities and hospitals into ambulatory settings.

\subsubsection{Dedicated training institutions}

50. In Norway, the school of medicine of the University of Troms $\varnothing$ was established in 1972, for northern Norway, where a chronic shortage of physicians persisted. The medical school was established with a belief that location of medical training has a substantial impact on the choice of practice location after graduation. At the beginning of the programme, a quota of $25 \%$ was reserved for students from northern Norway, was increased to 50\% in 1979, and to 60\% in 1998 (Alexandersen et al., 2004). Whilst it is not known whether this quota was filled, it can be observed that the number of medical graduates with a north-Norwegian origin increased from $41.1 \%$ in the period from 1979 to 1988 to $57 \%$ in the period from 1996 to 2001. Previous research has shown that the majority of medical graduates from the University of Troms $\varnothing$ remained in northern Norway. Of the medical students who graduated between 1979 and 1988, 
56\% continued to work in northern Norway, though this share decreased to 51.3\% for graduates from 1996 to 2001. There is also evidence that the likelihood of graduates to remain in northern Norway is particularly high if they are of northern Norwegian origin. Among the University of Troms $\varnothing$ medical graduates from 1996 to 2001, 75.4\% of physicians with northern Norwegian origin chose to practice there, while only $19.3 \%$ of physicians with a southern Norwegian origin remained after graduation (Alexandersen et al., 2004).

51. Japan's Jichi Medical University was established in 1972 with the sole purpose of training physicians for areas with insufficient health workers. Jichi Medical University is technically a private university, but it has a unique management and funding scheme. It is managed by an educational foundation, co-funded by 47 prefectural governments and the national government. The recruitment/ selection is first conducted at each prefecture (each prefecture chooses two or three local high school graduates for admission), then a second screening is done by university. After the six years of medical training, all students are expected to return to their prefecture of origin for practice. Students receive loans while in medical school, which they are exempt from paying back if they work in public hospitals, designated by the prefectural governor, for a set period of time (9 years, which consists of 2-3 years clinical training as primary care generalists, followed by 6-7 years in rural services). By $2006,97 \%$ of Jichi medical school graduate physicians (a total of 2962) had completed or were completing their service obligation. The retention rate of graduates in their home prefectures beyond the time of their service obligation was 70\% (Matsumoto et al., 2010). Graduates of Jichi medical school that fulfil their service requirement are more likely to practice in a rural area than graduates from other medical schools. Inoue, Matsumoto and Sawada (2007) show that even after completion of their service obligation, the share of Jichi graduates practicing in rural areas is significantly higher (Figure 14). Furthermore, even among Jichi medical university graduates (who are intentionally chosen for rural service), those with rural upbringing and who chose primary care/general practice as their specialization are more likely to stay in a rural area beyond 9-year obligation (Matsumoto et al., 2008).

Figure 14: Relative percentage of practicing in rural area, in comparison to non-JMU graduates

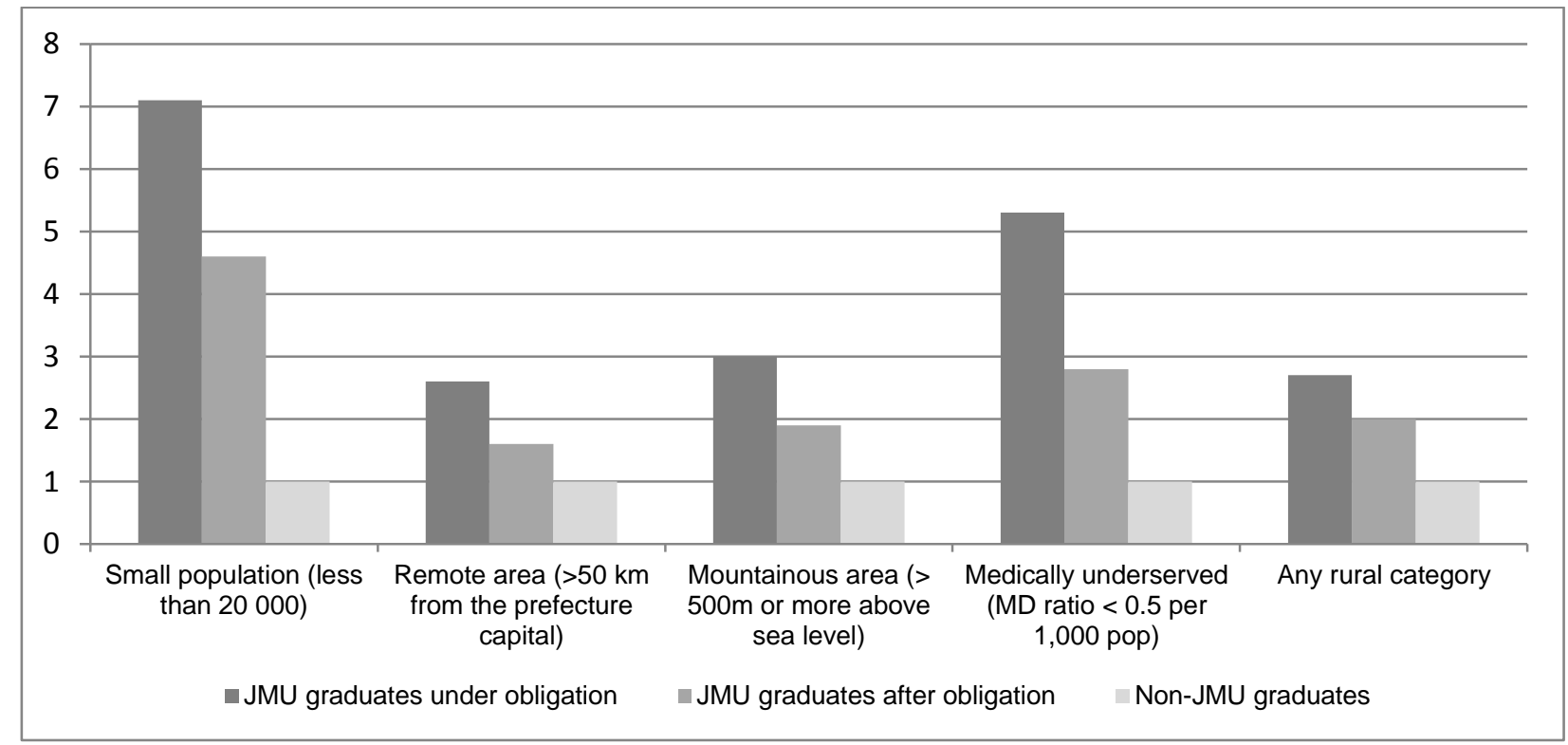

Source: Based on data in Table 2 of Inoue, Matsumoto and Sawada (2007). 


\subsubsection{Distributed education and training}

52. In Canada, an increasing number of medical schools are utilizing satellite campuses and multiple clinical training sites in order to provide their medical students with learning experiences in a variety of settings. The Northern Ontario School of Medicine (NOSM) is an example of such "distributed medical education", with its main campuses located in rural areas. Northern Ontario is a region of the about the size of Germany and France combined with a relatively small population of approximately 800000 (NOSM, 2012). NOSM is a joint initiative of two universities that are located about $1100 \mathrm{~km}$ apart and function as the two main campuses. It has a social accountability mandate to improve access and quality of health care in Northern Ontario and welcomed the first batch of medical students in 2005. It actively seeks to recruit students from Northern Ontario or from similar northern, rural, remote, aboriginal, or francophone backgrounds. Clinical education takes place in a wide range of community and health services settings and 70 teaching and research sites are distributed across Northern Ontario. Those students who completed their training and choose a rural area for their practice are eligible for additional funding from a "Rural Recruitment and Retention Initiative", a loan-repayment programme. As it is relatively new programme with the majority of NOSM graduates still in clinical training, it is too early to assess the long-term impact on physician supply in Northern Ontario. However, it is indicated that about 70\% of NOSM graduates are training in family medicine in predominantly rural regions.

53. Medical internships are also used as a way to increase exposure to rural practice and recruit young doctors in the underserved area. For example, in Norway, 18 months of mandatory practical training (including 6 months in primary care, after graduation but before granted full license as a physician) was combined with professional and social support services for interns to improve retention after the end of internship in Finnmark, the most northern and remote county of Norway. Straume and Shaw (2010) examined whether internship accompanied by group tutelage, enhanced recruitment and, if so, what were the main predictors for doctors taking their first voluntary job in the north of Norway. Out of the interns who started to work as a licensed physician immediately after their internship, $45.9 \%$ took their first job in Northern Norway. However, among those interns with a northern background $88.6 \%$ stayed.

54. Similarly in Australia, the New South Wales (NSW) department of health developed the NSW Rural Resident Medical Officer Cadetship Program in 1988 and it was managed by NSW Rural Doctors Network since 1993. The Cadetship Program offers bonded scholarships providing financial support for the final 2 years of medical school, and in return, they are contracted to complete 2 of 3 postgraduate years in the NSW rural hospital network. The evaluation was conducted to in 2004 to track the career choices and practice location of the physicians in the program. It showed that $43 \%$ of cadets (program participants) who entered the program before 1999 were working in rural location in 2004, while only $20.5 \%$ of medical practitioners nationally. Interestingly, having a rural background did not appear to influence practice location among the cadets: 14 out of $30(46.6 \%)$ cadets with metropolitan background choose to practice in rural area, while 11 out of 30 (36.7\%) cadets with rural background stayed in rural areas. The rural practice was especially more pronounced among cadets who have chosen general practice as their specialization.

55. In Scotland, a similar approach has been developed in the NHS, with a range of funded educational opportunities to recruit students from, and encourage training in, remote and rural areas. These include an initiative to support pupils from rural schools to undertake medical education at Aberdeen University, and additional interventions to support an annual undergraduate rural cohort of 20 students, rural track General Practice training, and funding for GP Rural Fellowships to provide opportunities to experience work in remote and rural practice (MacVicar and Nicoll, 2013). 


\section{Box 2: The French ECN, combining choice of region and choice of specialty}

In France medical studies are delineated by two points of selection. After the first year of medical studies a competitive examination determines who gets to progress with initial medical training - the numerus clausus. After the sixth year of studies, students complete their initial medical training. At this point another competitive examination, the Epreuves Classantes Nationales (ECN), determines a ranking of students. Students then get to choose a specialty training place in a region of their choice, according to their placement in the ranking, i.e. the best students choose first.

The ECN has been created in 2004, thus allowing for a first review of its impact on the first cohorts of students who took part. The number of places in the ECN has steadily increased from about 4000 in 2004 to about 7500 in 2012 and is set to increase further to about 8000 in 2016, reflecting a prior increase in numerus clausus. The growth in specialty training places has been used by the government to increase the number of training places for general practitioners, with specialty training places for general medicine making up $43 \%$ of the new training places created between 2005 and 2012, though the overall growth as well as the spread of new places across specialties has been uneven across regions.

As of 2012, only the first cohorts of students that passed the ECN in 2004 have entered the labour market, therefore it is difficult to evaluate the overall impact of the measure on the geographic distribution. However, across all practicing doctors in France, $63 \%$ are practicing in the region where they have been trained $(7 \%$ have been trained abroad).

\subsection{Summary overview}

56. In summary:

- At the point of selection and entry into medical education, countries can give preference to students committed to work in underserved areas or recruit students with a rural background. Examples reviewed above from Australia, Canada, Japan, and the United States show that in different health system contexts, the origin of medical students is a factor that influences their choice of practice location once they start working. A crucial benefit of an emphasis on student selection is that bears little cost, although cultural hurdles may be high in countries with a tradition of managing student selections only by competitive exams.

- As another policy lever in education, training structures may be adapted. Some countries, such as Japan and Norway have chosen to set up dedicated training institutions that prepare graduates for practice in underserved regions. In both cases, the institutions have proven to be effective in producing medical graduates who serve in such regions over decades. Setting up a new medical school requires infrastructure investment which may for some countries may be prohibitive in the short term.

- A number of countries are exploring ways to better connect graduate training with work experience, especially for students specialising in general medicine. This may work through compulsory internships, such as in France. Some regions of Canada have decided to distribute clinical training into underserved regions to expose students to service there. This moves training, at least partly, out of the traditional hospital context and into underserved areas, where experienced physicians serve as trainers. So far, the experience of the Northern Ontario School of Medicine is encouraging in that it brings medical workforce into underserved areas. The setting up of teaching facilities and the training of trainers does, however, require upfront investment. 


\section{TARGETING CURRENT DOCTORS: CARROTS AND STICKS}

57. The second strategy available is to target current doctors to maximise the share of physicians in the health system who practice in underserved regions. This requires a suitable incentive system, which may include both "carrots and sticks", i.e. financial incentives but also suitable regulatory measures to influence physician location choices.

\subsection{Financial incentives}

58. In order to rectify the income disadvantage many physicians perceive as a barrier to choosing to practice in a predominantly rural region or in socio-economically disadvantaged urban areas (see Section 3.2), many countries have introduced financial incentives, Table 2 below provides an overview. Such incentives may take many different forms, depending on the context in which they are implemented, and different types of incentives may be combined. This section reviews examples from two broad approaches that countries explore by using financial incentives:

- Non-wage related incentives: including subsidies for setting up practices, or one-off payments aimed at retaining and attracting doctors during their career or close to retirement

- Wage-related payments: such as income guarantees, or bonus payments at different points of the career of a physician practising in an underserved area

59. Financial incentives can be used to level the playing field between more rural and more urban practices, in compensating for longer working hours or an otherwise less advantageous "business environment" for doctors who practise in rural or underserved areas. However, the evaluation of the effect of financial incentives is difficult, as they are part of a package with various separate incentives, and/or physicians may receive multiple financial incentives from different sources at the same time. Some financial incentive programmes have been found effective in placing medical graduates but the overall results appear inconclusive. It should be noted that most programme evaluations are from the United States, where the share of private financing of medical education is significantly higher than in most other OECD countries. Furthermore, it is difficult (and unadvisable) to design financial incentives which target only those who is willing to move to underserved area because of financial incentive. It always incurs "wastage" by providing incentives to those who would have practiced underserved area regardless of government intervention. Financial incentives are costly, although the extent of the financial commitment depends on the design of policies (Bärninghausen and Bloom, 2009; Dolea, Stormont and Braichet, 2010). 
DELSA/HEA/WD/HWP(2014)2

Table 5: Reported financial incentives to foster a better geographic distribution of physicians

\begin{tabular}{|c|c|}
\hline Incentives in place & No incentives \\
\hline Australia & Austria \\
\hline Belgium & Czech Republic \\
\hline Canada & Iceland \\
\hline Chile & Ireland \\
\hline Denmark (Regions) & Italy \\
\hline Finland & Japan \\
\hline France & Luxembourg \\
\hline Germany & Netherlands \\
\hline Greece & Poland \\
\hline Hungary & Spain \\
\hline \multicolumn{2}{|l|}{ Israel } \\
\hline \multicolumn{2}{|l|}{ Korea } \\
\hline \multicolumn{2}{|l|}{ Mexico } \\
\hline \multicolumn{2}{|l|}{ New Zealand } \\
\hline \multicolumn{2}{|l|}{ Norway } \\
\hline \multicolumn{2}{|l|}{ Portugal } \\
\hline \multicolumn{2}{|l|}{ Slovenia } \\
\hline \multicolumn{2}{|l|}{ Sweden } \\
\hline \multicolumn{2}{|l|}{ Switzerland } \\
\hline \multicolumn{2}{|l|}{ United States } \\
\hline United Kingdom (England and Wales) & \\
\hline
\end{tabular}

\subsubsection{Non-wage-related payments (one-off payment)}

60. A range of non-wage-related payments are available or offered to physicians to encourage them to move to or stay in underserved areas. In some cases these are "up-front payments" intended to help facilitate a location choice, in others they are conditional on criteria being met, which may be based on practice size or volume of activity.

61. Several countries have non-wage-related incentives targeting various stages of the career of physicians, in order to improve recruitment and retention in underserved areas. Many policies target physicians who are opening their practice for the first time, to influence them to locate these in underserved areas. However, there are also examples of financial incentives during the career of physicians aim at retaining those physicians already practicing physicians in such regions. There are even some special programmes aimed at deferring the retirement of physicians in underserved regions. The amount of money at stake often depends on the severity of the shortage or the rurality.

62. In Germany, eleven out of 16 federal states (Länder) offer financial incentives for GPs who are opening their practice for the first time. GPs can receive a one-time payment for opening a practice in designated shortage areas. The financial subsidies range from EUR 15000 to EUR 60000 depending on the state, the degree of shortage, the size of the municipality where the practice is to be located and the type of services the physician provides (Figure 15). The sources of financing differ across Länder. Costs are either shared between the state government, the association of statutory health insurance physicians and insurance companies or borne entirely by one of these stakeholders. In some states, such as MecklenburgWestern Pomerania, North Rhine-Westphalia and Lower Saxony, the one-time payment of practice opening comes with a return-of-service obligation of five to ten years. 
Figure 15: One-time financial support for practice openings in EUR, German Länder y

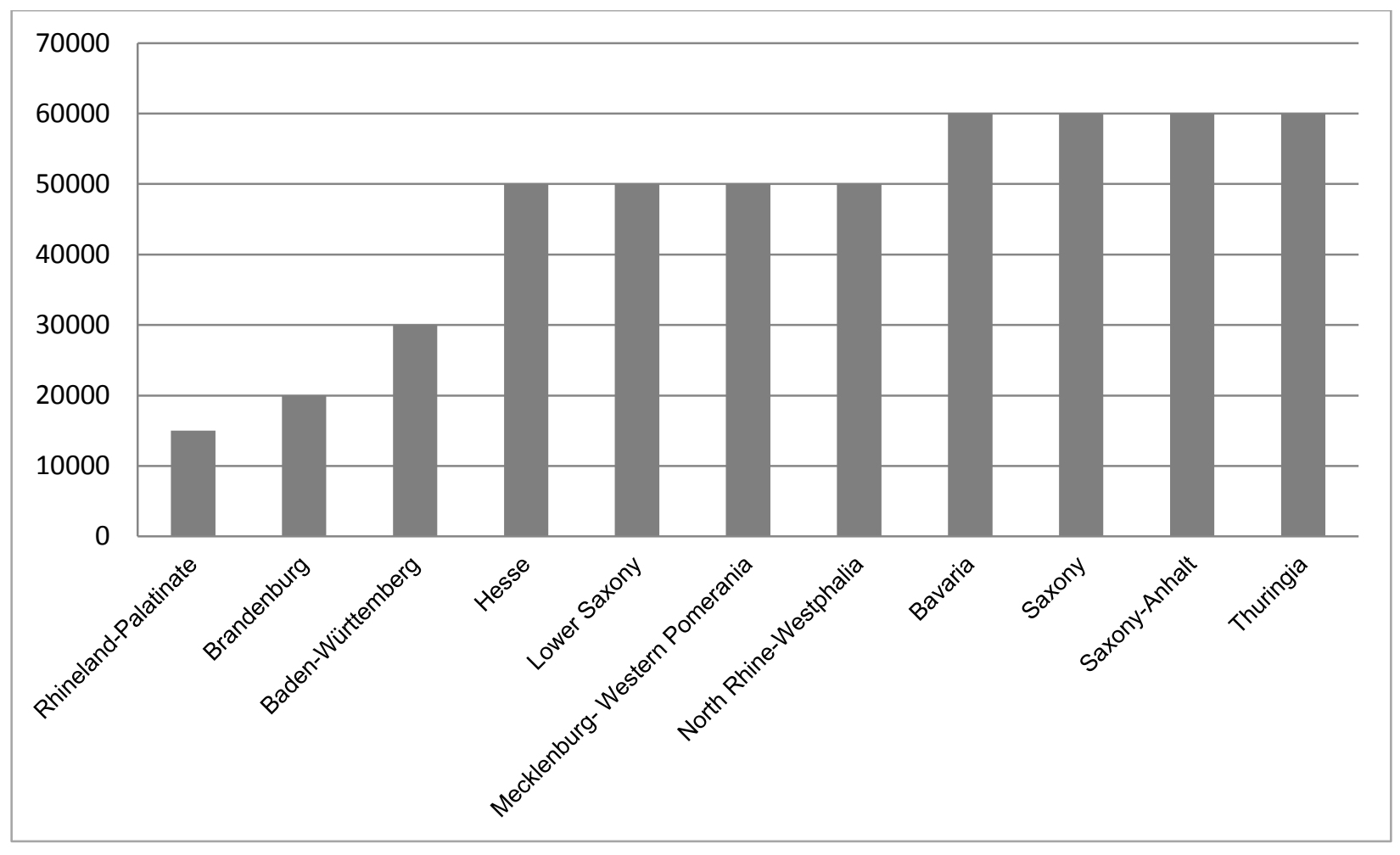

Source: compiled by the authors.

63. So far, there is no evaluation available as to whether and to which degree GPs have made use of this financial incentive and whether it has helped to recruit more physicians in rural areas and led to an improvement of the service coverage. Similar policies are in place in different Canadian provinces. In Ontario, for example, the Northern and Rural Recruitment and Retention Initiative offers grants of between CAD 80000 and CAD 117600 for a practice opening in a rural area (HPM, 2008).

64. Other financial support policies are available at any point during the career of physicians and aim at improving their working conditions. In Canada, various provinces offer financial supports to GPs to hire locum GPs for holidays or other reasons of absence (see also section 8.1 for policies on management of locum and on-call duties). Per diem rates range from CAD 510 in Nova Scotia to CAD 1200 in the North Western Territories and can include an additional contribution for travel costs. In Denmark, selected regions offer financial support to GPs for hiring additional staff. This support can be either limited to two years or not time-limited depending on the region. Northern Jutland, for example, grants DKK 110000 per quarter to GPs for employing a nurse in their practice (Praktiserende Lægers Organisation, 2013).

65. In some countries, incentives are in place for those who are considering retirement. In Denmark, for example, older GPs can receive a bonus for postponing their retirement age. In Southern Denmark, GPs aged from 63 can receive between DKK 320000 and DKK 1080 000, depending on the age of the GP, the size of the list of patients and the duration of the commitment. In Northern Jutland, GPs receive DKK 55000 per quarter between the age of 62 and 65 (Praktiserende Lægers Organisation, 2013). 


\subsubsection{Wage-related financial incentives (Recurrent payment)}

66. Physicians who work in underserved areas sometimes receive financial incentives linked to their incomes. Some incentives target particular stages in the lifecycle, where critical decisions for location and duration of practice are made. These payments aim to compensate for the smaller number of patients and/or longer working hours physicians face when working in underserved areas.

67. The way doctors are paid delineates how wage-related financial incentives can be brought to doctors. In Across OECD countries, a large variety of payment mechanisms exist across a range of institutional arrangements (Table 6). As pointed out in section 3.2, physicians work in different settings, such as solo or group practices or health centres, where they may be salaried or self-employed. Payments may be directed to both institutions (in the case of health centres of group practices, or directly to the individuals providing services (e.g. a doctor), or both.

68. Financial incentives can be arranged along with the existing payment structure to target specific physicians and their performance. Payments made to institutions comprise global budgets that define a maximum expenditure in a given time period (and often region), capitation agreements that pay health service providers in function of the number of patients enrolled in their practice, independent of service provision, fee-for-service arrangements that pay for each service provided, or pay-for-performance (P4P) arrangements that make at least part of a payment conditional on reaching certain objectives. Payments are made to individuals comprise salaries, capitation agreements, and fee-for-service schedules as well as other arrangements including P4P schemes.

69. While these different forms of payments are often combined in various ways, in countries, where physicians work predominantly in solo and group practices there is almost always an element of fee-forservice payments and some capitation-based payments whereas in countries where physicians work in health centres, salaries play a much more important role. 
Table 6: Summary of payment mechanism across different institutional arrangements

\begin{tabular}{|c|c|c|c|c|c|c|c|c|c|c|}
\hline \multirow[b]{2}{*}{$\begin{array}{l}\text { Type of } \\
\text { predominant } \\
\text { institution of } \\
\text { primary care }\end{array}$} & \multirow[b]{2}{*}{$\begin{array}{l}\text { List of } \\
\text { countries }\end{array}$} & \multicolumn{5}{|c|}{ Payment of institutions } & \multicolumn{4}{|c|}{ Payment of physicians } \\
\hline & & $\begin{array}{l}\overline{\mathbb{0}} \text { 헝 } \\
\text { 음 } \\
\text { 음 }\end{array}$ & 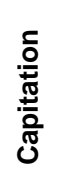 & 市: & 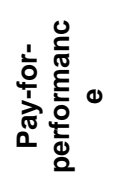 & 这 & $\frac{\frac{8}{d}}{\frac{\pi}{\pi}}$ & $\begin{array}{l}\frac{5}{0} \\
\frac{\pi}{\pi} \\
\frac{\pi}{0} \\
0 \\
0\end{array}$ & 市: & 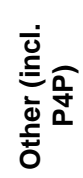 \\
\hline \multirow{8}{*}{$\begin{array}{l}\text { Doctors in solo } \\
\text { practice }\end{array}$} & Germany $^{*}$ & & & & & & \multicolumn{4}{|c|}{$\mathrm{X}$} \\
\hline & Austria* & & & & & & \multicolumn{4}{|c|}{$\mathrm{x}$} \\
\hline & Belgium* & & & & & & \multicolumn{4}{|c|}{$\mathrm{x}$} \\
\hline & Korea* & & & & & & \multicolumn{4}{|c|}{$x$} \\
\hline & France* & & & & & & \multicolumn{4}{|c|}{$\mathrm{X}$} \\
\hline & Greece* & & & & & & \multicolumn{4}{|c|}{$\mathrm{X}$} \\
\hline & Czech & & & & & & & $X$ & $X$ & $X$ \\
\hline & Switzerland ${ }^{*}$ & & & & & & & $x$ & $\mathrm{X}$ & \\
\hline \multirow{5}{*}{ Public centres } & Spain & & $\mathrm{X}$ & & $\mathrm{X}$ & & $\bar{X}$ & $\bar{x}$ & & $X$ \\
\hline & Finland & $x$ & & & & & $X$ & \multicolumn{3}{|c|}{$X$} \\
\hline & Iceland & $\mathrm{X}$ & & & & & \multicolumn{4}{|l|}{$X$} \\
\hline & Portugal & $x$ & $X$ & & $X$ & & \multicolumn{4}{|l|}{$X$} \\
\hline & Sweden & & $\mathrm{X}$ & $\mathrm{X}$ & $x$ & & \multicolumn{4}{|l|}{$X$} \\
\hline \multirow{8}{*}{$\begin{array}{l}\text { Group practice } \\
\text { with doctors } \\
\text { and other } \\
\text { health } \\
\text { professionals }\end{array}$} & Australia & & & $\bar{x}$ & $\mathrm{x}$ & & & & $\bar{x}$ & $\bar{x}$ \\
\hline & Denmark & & $X$ & $x$ & & & & $X$ & $\mathrm{X}$ & \\
\hline & Ireland & & $\mathrm{X}$ & & & & & $x$ & & \\
\hline & Netherlands* & $\mathrm{X}$ & $X$ & $X$ & $X$ & & & $X$ & $\mathrm{X}$ & $\mathrm{X}$ \\
\hline & New Zealand & & $X$ & $\mathrm{X}$ & $x$ & & $X$ & $\mathrm{X}$ & $\mathrm{X}$ & \\
\hline & Norway & & $X$ & $\mathrm{X}$ & & & & $X$ & $X$ & \\
\hline & $\begin{array}{l}\text { United } \\
\text { Kingdom }\end{array}$ & & $X$ & $X$ & $X$ & $X$ & & $x$ & $X$ & $X$ \\
\hline & Poland* & & $X$ & & & & & $X$ & & \\
\hline \multirow{2}{*}{$\begin{array}{c}\text { Group } \\
\text { practices with } \\
\text { only doctors }\end{array}$} & Canada & & $x$ & $x$ & & $x$ & $x$ & $x$ & \multicolumn{2}{|l|}{$X$} \\
\hline & Italy & & $X$ & & & & & & $x$ & $X$ \\
\hline
\end{tabular}

Source: 2012-13 OECD Health System Characteristics Survey, as of February 2014

70. Basic income guarantees may work as an incentive for physicians at the point in time when they set up a practice in an underserved region. France and Denmark, for example, provide revenue guarantees to GPs in the first two years after the establishment of their practice. In France, some recently qualified GPs benefit from a guaranteed annual income of EUR 55 000. This measure was introduced for 2013 and is available annually to 200 GPs and time-limited to the first two years of practice (Ministère des Affaires sociales et de la Santé, 2012b). In Denmark, similar revenue guarantees are in place in Northern Jutland and the Capital Region based on a fixed list size of 1600 patients per GP. If GPs have not yet enlisted 1600 patients, the government funds the revenue gap by paying DKK 1500 per 'missing' patient for two years until 1600 patients are reached. In the Capital region, this policy is linked with a return-of-service obligation of five years (Praktiserende Lægers Organisation, 2013).

71. In Denmark, financial incentives are bound to the list size of patients in order to compensate for the increased work load. This incentive is time-limited and aims at the transition periods between the closure of a practice and the opening of a new one. GPs are compensated for taking over patients who have lost their GP due to the closure. In the region of Northern Jutland, GPs receive a higher remuneration if they sign up more than 1760 patients. The revenue for any additional patient is multiplied by a factor of 2 . In the region of Zealand, a similar policy is used and the factor is scaled based on the list size. If GPs sign up 5\%-20\% more than the required 1600 patients, revenues for the additional patients are multiplied by a factor of 2. This factor increases to 2.5 if they sign up 20\%-30\% more and to 3 if they sign up more than 
$30 \%$. It is limited to two years, aiming mainly to smooth over transition phases, where a GP retires and is being replaced (Praktiserende Lægers Organisation, 2013).

72. Other financial incentives can be received during the entire career of physicians and aim at compensating for challenging working conditions in underserved areas. In the Canadian province of British Columbia, for example, the Rural Retention Programme (RRP) grants an annual premium fee (i.e. a bonus) to physicians based on the characteristics of their community. The premium fee ranges from CAD 6000 to CAD 30 000, and it is based on "isolation points" determined by the existence of other physicians and medical community in surrounding areas and geographic characteristics of the community. Physicians must have billed at least CAD 65000 in 9 months to be eligible for the RRP. In 2008, 144 communities were entitled to grant an allowance to physicians. In 2007/8, 1568 physicians benefitted from the RRP (Ministry of Health of British Columbia, 2012).

73. Financial incentives can also target doctors after several years of practice and/or at the end of their career to improve their retention and to encourage them to postpone their retirement. In Canada, several provinces and territories grant annual bonuses to GPs based on their years of practice. In rural areas of Alberta, for example, the annual bonuses range between CAD 4000 after five years of practice and CAD 10000 after 26 years of practice (HPM, 2008). In Germany, in the state of Thuringia, GPs aged 65 and above can apply to receive EUR 1500 per quarter in addition to their normal revenues for continuing to work in rural areas that are underserved or at risk of being underserved (AOK, 2011).

74. In the NHS in England and Wales, a new contract was introduced for (self-employed) GP's in 2004 , with the aim of achieving equitable pay for basic service provision, and to "recognise case mix and practice circumstances, and ensure money will flow according to patient need". The new contract was based on a payment mechanism formula which, amongst other indicators, included measures of population deprivation related workload, and a rurality index, to assign overall weightings to patients. The rurality index was a function of the distance the patient lives from the surgery and the population density. Each practice received three key income streams. The majority of practice funding came from protected capitation fees -- the minimum practice income guarantee (MPIG). Additional income was derived from the Quality and Outcomes Framework (QOF) as performance related pay, and supplementary (enhanced) services, which were mostly paid on fee for service basis (Rhys, Beerstecher and Morgan, 2010). A review of the implementation of the new contract by the National Audit Office concluded that it had been much more costly than estimated, had contributed to improved recruitment and retention of GPs, but that in the first two years of the contract, productivity had fallen by an average of 2.5 per cent per year because GPs were working on average seven hours less per week, partly because of the removal of the responsibility for out of hours care. The review also reported that nurses were delivering more practice work leaving GPs to spend more time with more complex cases. The review concluded that "some of the most deprived areas remain under-doctored" (National Audit Office UK, 2008:12).

75. In summary, financial incentives may compensate for some of the disadvantages of service in less attractive regions, rendering it economically less burdensome. However, while financial incentives may be necessary to level the playing field between regions, they are no game-changer for location choice: despite the fact in some countries doctors working in underserved regions can receive higher payments than their peers elsewhere, staffing levels in these regions generally have continued to remain markedly lower across time. Furthermore, from the limited available evidence, it appears that financial incentives may be more effective in channelling money to physicians in underserved regions but less effective at attract new recruits to these areas. Additional investment in financial incentive should be considered carefully on its merit. 


\subsection{Regulatory policies}

76. Regulatory measures can be a policy lever for countries to foster a better distribution of physicians. Rather than providing positive incentives to influence doctors to set up a practice in particular types of location, these measures restrict or direct the choice of practice location. There are two main ways the countries may set up such regulations.

- Regulations of practice location: there may be de-facto limitations that use system features to limit the location choice of physicians, or countries can induce a better distribution through outright legislation, for example, by allowing for new practices to be opened only in areas where the physician density is below a certain threshold.

- Targeting international medical graduates: countries can make the immigration of trained doctors, and/or their entry into specialty training, conditional on later practice there.

77. World-wide, there are about 70 countries with current or past experience with some form of regulatory approach, mostly low and middle income countries (Frehywot et al., 2010). The majority of OECD countries does not constrain the choice of practice location for physicians who want to set up an ambulatory care practice.

78. In the 2012-13 OECD Health System Characteristics Survey, four countries indicated that some de-facto limitations of the choice of practice location are in place. In Austria, contracts that physicians have to make with social insurance for reimbursement are regionally limited. Similarly, in the Czech Republic doctors need to engage in a reimbursement agreement whose availability may be easier in some regions than in others. In Finland, healthcare delivery is organised at the municipal level, therefore, the availability of vacancies in a given municipality determines the choice a physician has when choosing the location of service, while in the United Kingdom, commissioning arrangements may influence the availability of posts in different regions. A further four countries indicated that they restrict the choice of location outright: Denmark, Germany, Norway and Slovenia, as do two provinces in Canada (Table 7). 
Table 7: Limitations to the choice of practice location

\begin{tabular}{lll}
\hline $\begin{array}{l}\text { No restriction of choice of practice } \\
\text { location }\end{array}$ & $\begin{array}{l}\text { De facto limitation of choice of } \\
\text { practice location }\end{array}$ & $\begin{array}{l}\text { Restricted choice of practice } \\
\text { location }\end{array}$ \\
\hline Belgium & Austria & Canada (New Brunswick, Quebec) \\
Canada (except two provinces) & Czech Republic & Denmark \\
France & Finland & Germany \\
Greece & United Kingdom & Norway \\
Ireland & & Slovenia \\
Israel & & \\
Japan & & \\
Korea & & \\
Netherlands & & \\
New Zealand & & \\
Poland & & \\
Portugal & & \\
Spain & & \\
Sweden & & \\
Switzerland & \\
United States & & \\
\hline Source: $2012-13$ OECD Health System Characteristics Survey, as of February 2014. & \\
\hline
\end{tabular}

79. One advantage of regulatory approaches is that the direct financial cost to the system is low, generally just limited to administrative costs. However, only a few regulatory approaches have been formally evaluated. Evidence is particularly lacking on the regulatory framework on the basis of some benchmark, such as a density threshold, to improve geographic distribution of physicians. Some evidence is available on the impact of return-of-service agreements, which in some countries target foreign-trained physicians in particular. The available evidence points to mixed success, as placements that occur as part of some return-of-service agreement are effective in the short-term. However, such policies do not necessarily provide long-term staffing stability to underserved regions (Dywili et al., 2012; Wilson et al., 2009; Han and Humphreys, 2006).

\subsubsection{Regulation of practice location}

80. In Germany, the number of practice permits for ambulatory care physicians in a specific region is limited, based on a national service delivery quota. Physicians need to obtain a practice permit to be reimbursed by the statutory health insurance. The number of these permits is controlled by the National Association of Statutory Health Insurance Physicians (NASHIP) through its 17 state associations. The NASHIP is the self-regulated organisation of about 120000 physicians practicing under the statutory health insurance. It is mandated by the government to guarantee medical service coverage of the population based on a quota agreed within the self-administration of the German healthcare system. The service coverage is measured based on the ratio between physicians and inhabitants in each of the 395 planning regions. For GPs, a 100\%-coverage is achieved when the ratio of GP to inhabitant reaches 1:1 617. If the service coverage of a planning region exceeds $110 \%$, no further practice permits are issued for this region (Federal Joint Committee, 2013).

81. The target ratio of inhabitants to GP was set in 1990. Since 2013, this ratio is multiplied by a "demographic factor", allowing consideration of the population share of inhabitants aged 65 and above. This will re-open regions that were closed under the old regulation scheme and are mainly located in Southern and Western Germany. As these regions are economically stronger and more densely populated than others, they are more attractive for medical graduates. Notably, this regulatory system only applies to 
physicians under a contract with the statutory health insurance funds (collectively organised in the NASHIP). In 2011, it was estimated that there were around 11000 physicians who practiced exclusively under private insurance, i.e. they did not receive any reimbursements from statutory health insurance and only billed patients directly, so were not restricted in location in the same way. While this system of allocating new practice permits across planning regions is an established instrument of workforce policy in Germany, to date, there is no evaluation available as to whether physicians who could not obtain a permit in their region of first choice have located themselves in regions with permits available or whether they have left the country or the health sector, continued working in a hospital, or opened a private practice.

82. In Denmark, the geographic distribution of physicians is regulated through the access to "provider numbers" in each region (Capital region, Central Jutland, Northern Jutland, Zealand and Southern Denmark). The provider number identifies physicians that are permitted to be reimbursed by the public tax based health-system. Only these GPs have patients assigned to their lists. The amount of provider numbers is set by the regions to guarantee medical service coverage and efficient use of resources. Decisions about provider numbers are based on the number of patients under the gate keeping scheme (which is the vast majority) in the local area, the individual GP's wish for staff, turnover and list size and the geographical distance of the patient to the practices. The agreed aim is for all patients throughout the country to have a free choice between at least two practices in a $15 \mathrm{~km}$-distance. A GP has the right to close the list if the list size has reached 1600 patients. The list is re-opened if the number of patients enlisted falls below 1475 and is closed automatically if it reaches 1700 patients. Any change in the medical service delivery structure, such as practice relocation, the merger with another practice or the opening of satellite practices, must be in accordance with the regional health plan. If there is a lack of patient capacity within the practices in a local area, more provider numbers are issued. In addition to issuing new provider numbers, the regions can enter into agreements with GPs to temporarily enlist more patients or to relocate or extend their practice into shortage regions. Since April 2011, regions have also been allowed to set up their own GP-clinics to take care of the patients otherwise left without a regular doctor, in areas where no qualified physicians are willing to accept a provider number under normal conditions

\subsubsection{Policies targeting international medical graduates}

83. Another way some countries use to steer physicians into underserved area is regulation of the practice location of international medical graduates (IMGs). These regulations can either attach conditions to immigration for foreign-trained physicians or be a part of requirements to obtain full practice rights in the country.

84. In Australia, a "10-year moratorium" policy on IMGs (usually referred to as "overseas-trained physicians") has been used as an instrument to tackle a persistent physician shortage in rural and remote locations. The Health Insurance Act Section 19AB restricts IMGs access to Medicare provider numbers, and requires IMGs to work in a district of workforce shortage (DWS) for a minimum period of ten years from the date of their first medical registration. Section $19 \mathrm{AB}$ is often referred to as the " 10 year moratorium', it aims to distribute medical services across Australia, including services in outermetropolitan, regional, rural and remote locations. The intention is to encourage IMGs to work in a DWS, which enables IMGs access to Medicare benefits by exempting them from the restrictions under Section $19 \mathrm{AB}$.

85. There are several ways to reduce the required ten year time period. Physicians can complete this requirement under the Five Year Overseas Trained Doctors Scheme and work in the designated locations where recruitment and retention of physicians have been particularly difficult (Australian House of Representatives' Standing Committee on Health and Ageing, 2012). Another option is for an IMG to establish a private practice in an eligible location and a reduction of the 10 year requirement can be 
obtained through a 'scaling mechanism' depending on the remoteness of the location. Since the implementation of the moratorium policy in 1997, the number of GPs has significantly grown in regional and remote areas. The growth of GP numbers (measured in FTE) was 59\% in major cities, $42 \%$ in regional and 39\% in remote areas before the moratorium (between 1984-1997). In the period after the moratorium (1997-2011), the growth rates have drastically changed with a $20 \%$ growth in major cities, $47 \%$ growth in regional and 52\% growth in remote areas (Cameron and Kosmina, 2013), indicating a relative increase in GP based rural service provision. In this period, the number of Australian-educated GPs remained broadly constant, while the number of IMGs increased in major cities by $240 \%$, by $156 \%$ in regional areas and $169 \%$ in remote locations.

86. In Canada, IMGs who have not had previous North American postgraduate medical training are required to go through a residency programme. A separate matching stream for IMGs (for all provinces except Quebec) was established and matching services for clinical training in Canada were managed by the Canadian Resident Matching Services (CaRMS, 2010). For IMGs, getting clinical training in most of the provinces comes with a return-of-service requirement in a designated underserved area. Specific conditions and duration of service requirement vary between provinces, but IMGs are usually required to provide services for the same duration of time they took to receive their clinical training. Those who do not fulfil return-of-service requirement are obliged to repay their funding in full with interest. So far no evaluation has been done on this specific scheme of return-of-service requirements for IMGs. However, while they appear effective in placing physicians in the short-term, a recent study shows that $70.1 \%$ physicians with a specially funded return-of-service agreement in the province of Newfoundland and Labrador default on their service requirement (i.e. they do not fulfil service time or repayment requirement) and identifies one reason for this high default rate to be the high proportion of IMGs $(74.1 \%)$ who participate in the programme (Mathews et al., 2013).

87. Policy makers should note that, depending on their specificities and application, policies targeted at directing IMG's to specific locations could conflict with the articles of the WHO Global Code of Practice on the International Recruitment of Health Personnel, which was adopted by the World Health Assembly in 2010. The voluntary code requires recruiters to give equal treatment and career opportunities to internationally recruited health workers as to those that are as domestically trained (WHO, 2010).

\subsection{Summary overview}

88. In summary, regulatory measures are another lever to improve the share of physicians who serve in unattractive regions. In Denmark, Norway and Germany, desired staffing levels are defined in relation to the (patient) population in different regions. Regulation can take the form of reimbursement agreements with health insurers depending on whether these staffing levels are reached. Some countries use return-ofservice agreements as a form of regulating the supply of doctors to underserved areas. For example, in Australia and Canada there are programmes targeting international medical students who wish to complete specialty training in those countries. Regulatory approaches can be very efficient in placing medical graduates in certain areas, at least for a certain period of time and they involve relatively little financial cost. However, legislating the place of work may clash with constitutional rights in some countries. Where access to reimbursement is the lever used to direct location choices through regulation, having a single payer for services is important for regulation to be effective. For example, the existence of a parallel private health insurance system in Germany means that for physicians who do not want to practice in a certain region, there is always the alternative to open a practice in a region of their choice and simply only cater to privately insured patients. 


\section{DOING WITH LESS: SERVICE DELIVERY REORIENTATION}

89. Service delivery reorientation can have two different focal points:

- Provider-centred reform: mode of employment is a determinant of physicians' location choices (see section 3.2) and it can be leveraged to improve service delivery with reduced number of physicians.

- Process-centred reform: reforms may introduce new ways of service provision to try to separate at least some parts of service provision from the location of the patient, e.g. through the use of telemedicine.

\subsection{Provider centred reforms}

90. Provider-centred service re-orientation may comprise fostering group practices of different physicians or of doctors and non-medical health workers, creating networks of providers servicing certain regions and/or introducing new provider roles. For example, co-locating services may improve the working conditions of physicians, by making exchange with colleagues possible and reducing on-call commitments, as well as by improving the business case for rural practice, as set-up, administration and support staff costs may be shared. A different strategy can be to share responsibilities to serve in certain areas across a network of salaried or self-employed doctors that rotate in and out of very remote regions.

\subsubsection{Group practices and service co-location}

91. Group practices aim at improving the working conditions of physicians. In various countries, physicians demonstrate a preference towards working in group practices. In Germany, $90 \%$ of current medical students want to work in group practices and community health centers (Hartmannbund, 2012). Results are similar in Canada (Saarma et al., 2012) and Switzerland (Buddeberg-Fischer et al., 2008). Group practices are believed to lead to a reduced workload, better resource-sharing and better cooperation with other physicians.

92. In France, Maisons de Santé Pluridisciplinaires (MSP) were introduced in 2007. They differ from other forms of group practices which have existed since the 1970s because they allow physicians and other health professionals jointly to operate group practices while remaining self-employed. MSPs are either entirely financed by the health professionals themselves, or they may receive subsidies from various sources, such as the European Union, central and regional governments and the French health insurance. By 2012, 235 MSPs were already in operation in France and another 450 were planned. 80\% of them were located in rural areas (Ministère des Affaires sociales et de la Santé, 2012c). MSPs lead to better work conditions and greater accessibility for patients. In a survey conducted in Franche-Comté and Bourgogne (Bourgueil et al., 2009), the surveyed 71 GPs in 9 MSPs reported a weekly workload of 46 hours compared to 52-60 hours in other group and solo practices. Opening hours in MSPs were better than in other group and solo practices with an average of 5.5 opening days/ week and 11.5 opening hours per day. Also the quality of follow-up care of diabetes mellitus type 2 patients was improved.

93. In Germany, community health centers (MVZ) were established in 2004 through changes to the remuneration scheme of the statutory health insurance system. The aim was to improve working conditions of physicians by reducing their workload, better interaction with other specialties and higher earnings through resource-sharing, both in urban and rural regions. MVZ are generally owned by a physician (or groups of physicians) or a hospital and comprise at least two medical specialties. Physicians working in 
MVZ can be either salaried or self-employed. In 2011, 1750 community health centers existed with total of 9571 physicians, and most of them were GPs and internists. In 2011, 6\% of all physicians who were remunerated by the statutory health insurance worked in MVZ compared to 37\% working in other forms of group practice and 57\% working in solo practice (KBV, 2011a).

94. Physicians in MVZs and in other forms of group practice report better working conditions and higher satisfaction than those working in solo-practices. According to a survey by the National Association of Statutory Health Insurance Physicians (NASHIP), 58\% out of $414 \mathrm{MVZ}$ reported that founding or joining a MVZ was a good decision and 78\% said that the cooperation among specialties has improved (KBV, 2011b). Patients report high degrees of satisfaction. In a survey among 1080 patients from 2007, 95\% said that they would recommend MVZ (Schulte and Schulz, 2007). While 14.6\% of MVZs were located in rural areas, the rest were placed in urban areas. Nevertheless, MVZ are considered to hold potential for further expansion in rural areas because the advantages of establishing or joining an MVZ in were more pronounced there than in urban areas. A comparison of the workload in solo and group practices from 2011 shows that in rural areas, the physicians in group practices work on average 4.5 hours less than their colleagues in solo-practices, while this difference is only 2 hours per week in urban areas (Steinhäuser et al., 2011). In addition to improving the work environment, work in MVZ in rural regions is also considered economically attractive, as $31.5 \%$ of physicians in rural MVZ reported a strong economic improvement due to resource-sharing compared to $20 \%$ in urban areas. Rural MVZ also tend to co-operate more with other medical service providers than urban ones and patients report high degrees of satisfaction (KBV, 2011b).

\subsubsection{Network of Employed Physicians and Shared Responsibility}

95. In countries where employment rather than self-employment is a more common model for physicians, employers can create a network of physicians who can support each other for their practices in underserved area. In contrast, an individualised fee-for-service payment system may exert a negative influence on collaboration, as found in one survey of Canadian physicians (Saarma et al., 2012).

96. In Japan, the majority of physicians who serve in isolated rural areas are employed by local government or other public entities and tend to belong in a network that provide resources and support for rural health services. The typical approach to fill vacancies in isolated rural area in Japan is a rotation of 23 years: if nobody wants to go there permanently, physicians in the region have to share the burden. Patients may not have physicians who know them for their entire life, but they are ensured to have a continued care through the organized rotation of doctors. Furthermore, each isolated rural area clinic has a corresponding medium-sized hospital that will provide support for specialist and emergency care. Those hospitals tend to be a hub of physicians who would take a turn for rotation, so patients may see their previous clinic physicians in a hospital when they seek specialized or emergency care. If it is well organized in a network, continuous care from primary to tertiary care can be provided. The exact organization of these networks is different in different prefectures.

97. In Scotland, the NHS promoted the development of a policy of "obligated networks" in 2009, with the aim of improving services through sustaining networks of health professionals which would exist laterally, across organisational boundaries in remote and rural areas. These networks would be "a formalised arrangement between two or more healthcare organisations that secures access to sustainable services for the whole population served by these organisations", and could exist at strategic or operational level. The primary focus would be on designated clinical services, ensuring clear pathways of care, visiting service support, and possibly joint appointments of staff. A 2010 report suggested some progress in developing such lateral networks in some clinical services such as mental health and learning disabilities (NHS Scotland, 2010) 
98. Similarly, in Ireland, a recently announced reform would create a group of hospitals and physicians in clinical training and in employment to have an opportunity to move around within the group and participate in different type of practice environment. This is a new development and its effect is unclear - however, formation of such networks may provide an opportunity to provide necessary security for physician's career development, while allowing some to take practice in underserved area (Department of Health, 2013).

\subsubsection{Introduction or expansion of new provider roles}

99. In certain cases, other health care service providers can play a role in taking on some tasks from physicians. This may be of interest with regard to areas that are underserved by doctors, as other service providers, such as nurse practitioners or pharmacists, are in some countries more evenly distributed. Role expansion, for example in the area of "mid-level" providers, such as nurse practitioners or physician assistants is one form of using different types of service providers in healthcare. While this is not a new phenomenon (Delamaire and Lafortune, 2010) such roles are increasingly explored as a response to current health human resource concerns. Independent of the motivation, eleven countries indicated that they introduced such roles or expanded existing roles to provide a larger scope of practice, while twenty OECD countries indicated they do not (yet) use mid-level providers.

Table 8: Experience with or recent introduction/expansion of non-physician provider roles

\begin{tabular}{ll}
\hline $\begin{array}{l}\text { Prior experience or recent introduction or } \\
\text { expansion of non-physician provider roles }\end{array}$ & No expansion or introduction of such roles \\
\hline Canada & Australia \\
Chile & Austria \\
Denmark & Belgium \\
Finland & Czech Republic \\
France & Germany \\
\hline Ireland & Greece \\
Netherlands & Hungary \\
New Zealand & Iceland \\
Norway & Israel \\
Slovenia & Italy \\
Spain & Japan \\
Sweden & Korea \\
Switzerland & Luxembourg \\
United Kingdom & Mexico \\
United States & Poland \\
& Portugal \\
\hline
\end{tabular}

Sources: 2012-13 OECD Health System Characteristics Survey, as of February 2014 ; Delamaire and Lafortune (2010), Ministère des Affaires sociales et de la Santé (2012b).

100. For example, in 2012, there were no designated shortage areas of pharmacies in France and the distribution of pharmacists was relatively homogeneous with an average density of about 2900 inhabitants per pharmacy (and of 1200 inhabitants per pharmacist) (ONP, 2012). The licensing of pharmacies is regulated by demographic criteria based on the number of pharmacies per inhabitants and the size of the locality. The quota is set at 2500 inhabitants for the first license per commune and at 4500 inhabitants for every following one, which was increased from 3500 in 2011. Some additional regional arrangements exist. The role of pharmacists has been expanded in 2009 as part of the health-care reform law ("Hôpital, Patients, Santé, Territoires"). While this reform does not explicitly target shortages in rural areas, it aims at a general workload relief of physicians and the delegation of tasks to other providers. Since the reforms, pharmacists can, for example, coordinate the care of chronic patients and renew and adjust dosages, if 
necessary (IGAS, 2011). Since 2012, the monitoring of patients taking vitamin K, the supervision of asthma patients and the distribution of generics to elder people have been devolved to pharmacists (Ministère des Affaires sociales et de la Santé, 2012a).

\subsection{Processes-centred re-orientation}

101. Fostering the take-up of new processes in health care delivery and involving non-physician care providers in the delivery of services are ways in which countries can ensure access in regions with low physician density.

\subsubsection{Support Systems/ on-call duty management}

102. Whilst fixed-term contracted employment over an extended period of time is one possible solution for providing support to existing providers (this is discussed below), there is also usually also a need to look at ways of providing short term cover for absent physicians in undeserved regions. This will be necessary to provide cover for permanent staff to have vacation and study leave, but also can be a method of enabling them to stay in their location, but not be under pressure of being "on call" at all hours. This short term temporary (locum) cover can be for planned absence (e.g. when the permanent physician is on vacation or study leave) or unplanned absence (e.g. when the permanent doctor becomes ill).

103. The service delivery impact if temporary cover is not provided for the "missing physician" can include: reduced access, and diminished continuity of care (and possibly quality); delays or postponements in service delivery; and reduced ability to provide supervision to trainees and leadership to other staff in teams.

104. The need to arrange cover for absent staff will impact on any health service, but the challenges become more pronounced in services where there may only be only one physician in post in a remote area, or where there are only a few doctors providing a broader range of services in a small remote hospital. In these situations there is no "on site" ability to co-ordinate cover or provide "on-call" support from other available staff, because none exist, so cover must be physically brought into the location. If the post requiring cover is remote and in a hard-to-fill location, the same factors that make it hard to fill with permanent staff also make the arrangement of temporary cover more challenging, and often more costly, because of the payment of additional incentives and additional travel and accommodation costs.

105. The extent of use of locums can be high where there are sustained difficulties in recruiting permanent staff. For example a survey of use of locum physicians in a small remote Scottish hospital with a permanent establishment of 17 medical consultant posts, reported that over an 8 year period, 188 different short term locum doctors had been used, to cover 535 locum periods (Sim, 2011).

106. Policy responses to more effectively manage the level of use of locum medical staff have been identified in studies in several countries, such as Australia (Skinner et al, 2006), Scotland (Audit Scotland, 2010) and Northern Ireland (Northern Ireland Audit Office, 2011) and include the following:

- An emphasis on minimizing the need to use external locum staff through time planning, work scheduling and co-ordination of study leave and vacation time, and by developing mechanisms to provide on-call or cross organizational "cross border" support from other permanent staff, where that is feasible- this is discussed above.

- Managing locum costs by using in-house co-ordination or by tight cost control on use of external locum agencies- for example by negotiating procurement contracts where agencies have fill rate 
targets, costs are capped and quality assurance includes skills verification and recruitment and travel co-ordination.

- Maximizing the "fit" between vacancies and locum skills by clear definitions of skill requirements and timely and effective recruitment of locum physicians.

- Developing standard policies relating to pre-employment checks, induction, supervision, and performance management of locum physicians and ensure these are implemented across the organization.

- Developing appropriate continuous professional development (CPD) requirements that can reflect the development needs and requirements of physicians who work long term in locum posts.

\subsubsection{Long term “temporary" staff cover}

107. Some countries make use of relatively long term temporary or locum contracts to recruit and retain physicians in specific "hard to fill" locations. These contracts will be for months or years, rather than the more usual short term locum cover of days or weeks. Longer term contracts of this type can allow employers to provide additional one-off or recurring incentives to the post holder to retain them in the poste.g. additional recurring payments, housing allowances, end of contract bonuses etc. This can enable targeted additional incentives to relatively small numbers of staff who are treated as "exceptional" because of the challenges of the location, but obviously also has additional cost implications. It can also raise additional personnel management challenges of managing staff on different terms of employments, and may undermine a team ethos if some staff is being treated "exceptionally" whilst others are not.

108. Other models of providing temporary staff cover or service provision are also used. In Australia, these include outreach, Fly in/Fly Out (FIFO and DIDO services, where mobile doctors and other service providers will cover large geographic regions on a scheduled or needs based approach, travelling to provide emergency services or basic essential packages of care (Health Workforce Australia, 2013a). In the outreach model, physicians who live and work in one location are contracted to provide services to outlying remote areas as an adjunct to their primary work (Battye and McTaggart, 2003). These 'remote relievers' each make scheduled visits to a number of remote communities for only a few days, periodically. One example of a FIFO model was described by Margolis (2012) where physicians spend a fixed number of work days at their work location, but geographically remote from their home and families, followed by a fixed number of days back in their home location not working, including designated time not being available for telephone consultation. A recent report suggested that the use of FIFO doctors have helped increase the number of rural general practitioners in regional Western Australia, for the first time since 2008 (ABC News, 2013). These types of mobile service provision will incur additional costs, and will require increased management and administrative support to co-ordinate schedules and ensure that local communities and services are prepared for visits by mobile physicians, and that the necessary follow-on and follow- up clinical procedures (e.g. post-operation care) are also planned and delivered.

\subsubsection{Technology/ Telemedicine}

109. The use of technology has been advocated as one way of reducing the imbalance between rural and urban areas, in terms of service delivery and access- such as the use of information technology to support distance learning and telemedicine. However rural areas are often characterized by "sub-optimal technological capacity" - many new technologies are characterised by high fixed costs and a relatively low variable cost. Whilst telemedicine solutions may provide cost efficient delivery alternatives in some cases, service provision in rural areas is generally more costly per user than elsewhere. This is often compounded 
by weaker communication networks (including transport, infrastructure and ICT networks) even in those rural areas where there is access to services, there is inevitably less choice between different providers (OECD, 2010). There are two main factors to consider:

- Firstly, the scope to improve service access, support physicians and other service providers may be more apparent than real if rural areas lag behind in access to new technology, if costs are higher, and the available IT is not effective.

- Secondly, there are often higher costs, and less scope to have savings in the use of new technology. Rural areas often do not provide an environment to realize the same cost savings expected from technological change in urban settings, as limited numbers of users mean smaller scale effects. While new technologies may therefore help improve access, they are unlikely to do so at the same cost levels as in urban areas.

110. Telemedicine can connect patients and physicians at distance while reducing administrative and travel costs. Technological developments and improved infrastructure enable telemedicine to enter the daily life of physicians' practice. Across OECD countries, there are numerous initiatives under way to use telemedicine to improve health services. While it is beyond the scope of this paper to investigate the current and potential use of telemedicine in detail, the evaluation of a tele-health network in the Canadian province of British Columbia illustrates how telemedicine can be a cost-saving mechanism for health services in rural communities while ensuring access. A tele-health network in British Columbia became operational in 2001, using videoconferences to link patients, health-care providers and health-care administrators in 12 communities to resources in Vancouver. It has expanded to approximately 200 telehealth facilities with 470 videoconferencing end points, providing 18000 consultation in the fiscal year 2007-2008 (Ministry of Health of British Columbia). Schaafsma et al. (2007) evaluated a tele-health network with 5 different sites which are connected with Vancouver. It provides clinical support for maternal/child care, medical, nursing, and health education, and administrative meetings. All sites are equipped with a videoconferencing unit and some also have diagnostic equipment. Annualized tele-health utilization rates in 5 sites amounted to 67 clinical consultations, 45 education sessions and 88 administrative sessions. Total travel costs were reduced by CAD 724457 per year, which is greater than the annual fixed and variable costs of the telemedicine sessions (CAD 553 740).

\subsubsection{New delivery structures}

111. In areas with extremely low population density and/ or which are particularly geographically remote, it may be necessary to examine the potential to develop shared services between different government, public sector and voluntary organisations. For example, in Australia it has been noted that "A particular priority is the development of a workforce that has the capacity to work across the whole continuum of care from acute to community-based and population-based interventions. Another priority is the recognition that in many remote and very remote communities it is the same people who are required to provide all of these different aspects of health care. Similarly, workers in health, law enforcement, emergency services, child protection and education, need to work collaboratively more frequently in remote communities" (Health Workforce Australia, 2013). Furthermore, there may be a need to look "beyond the workforce", to broader service delivery solutions to the challenges of providing access to care in areas where it is difficult to retain physicians (Humpreys et al., 2008).

112. Such new processes may also entail the reorganisation of existing practices. In response to growing service need and tough financial constraints, Slovenia, introduced "model practices" with the aim of strengthening primary healthcare (Slovenian Ministry of Health, 2013). Model practices are general medicine practices which are staffed by a family doctor (general practitioner), in addition to a junior nurse, reinforced by a graduate trained nurse (registered nurse) with supplementary knowledge, which ensures the 
transfer of some of the competences from the physician to the graduate nurse, who treats and manages mostly chronic patients. This team is supported by a dedicated administrative assistant. The graduate nurse also copes with certain other tasks to be carried out in general practice, in particular in the area of preventive care and healthcare in general practices of the registered population. The aim is to transform the majority of general practices into model practices in a period of 5 to 7 years. Since the programme started, 313 model practices have been set up, representing approximately a third of all general outpatient clinics. The aim is that all geographic regions are equally represented, considering the size of the region.

\subsubsection{New roles and delivery systems}

113. In Germany, physicians can delegate home visits of older patients with reduced mobility in rural and remote regions to non-physician practice assistants. These are physician assistants and nurses with an additional qualification designed by the German Medical Association. The services performed are mostly checking diagnosis-related parameters (such as measuring blood pressure and glucose levels) and basic medical services (such as bandaging and injections). This scheme was implemented nationwide in 2009 by the integration of the remuneration of these services into statutory health insurance. Only services to patients in rural and remote areas aged 65 and above with at least one chronic disease and immobile patients are remunerated. This scheme is based on the pilot project named "AGnES" (GP-supporting, community-based, e-health-assisted systemic intervention) (Bundesrat, 2007). It was initiated by the University of Greifswald and tested in Mecklenburg-Western Pomerania, Brandenburg, Saxony and Saxony-Anhalt. At the time of the project evaluation on 8 July 2008, 38 non-physician practice assistants and 53 GPs had participated in the project and 8386 home visits to 1486 patients had been undertaken. Out of 42 surveyed GPs, 38 rated the project as "supporting" and "disburdening". Out of 667 patents, 94.3\% found that non-physician practice assistants could take over general home visits and $98.7 \%$ responded that they are competent service providers.

\subsection{Summary overview}

114. In summary, as with other policies and programmes, there is some evidence from some countries that service delivery innovations may be effective in either placing more doctors in underserved areas or managing with fewer physicians there. They vary significantly across countries, and where they involve investment in new infrastructure, e.g. the setting up of new group practices or telemedicine systems, they may be costly (Bourgueil et al., 2006; Schaafsma et al., 2007).

- Group practices can assist in providing physicians with better working conditions. Several examples from the reviewed countries show that implementation is achievable in the medium term and depending on the design of subsidies can contribute to staffing underserved areas. However, as the example from France shows, these new structures are likely to be costly to set up and run. Another crucial point to take into consideration is that an increase in group practices may go together with greater concentration of services, reduced solo practices and therefore larger distances between some patients and these services.

- Improving the management of on-call duties may be effective in the short term in relieving doctors from a big source of stress. Examples from Denmark and Scotland show that this can be effective in alleviating shortage pressures as well. However better on-call duty management comes at a price, with locums often costing more than permanent staff.

- New provider roles may have a significant impact on resources deployment. This may comprise the creation of new "mid-level provider" roles, such as Nurse Practitioners or the expansion of the scope of practice of existing roles. In some countries, notably Germany, recent pilot initiatives have demonstrated the scope for services delivered by mid-level providers in 
collaboration with doctors and are now being scaled up. Evaluations of advanced nursing roles have also shown little cost impact, similar levels of quality of care and increased patient satisfaction. Nevertheless, the introduction of such roles may be easier in health systems whose workforce consists of salaried professionals, because in fee-for-service system, the introduction of new providers taking on tasks previously undertake by physicians could mean smaller revenues for physicians. Furthermore, the need to design scope of practice regulations, provide adequate training and continuous professional development, as well as salary and/or reimbursement structures implies that such roles are a medium-term strategy and no quick fix.

- Though only reviewed briefly in this paper, telemedicine is another field where examples of costeffective interventions exist. Both in connecting providers and patients and in networking different providers, telemedicine can contribute to bridging access gaps. Where budgets allow for investment, and the necessary upfront cost can be funded, training of providers is still a requirement that may pose a hurdle to smooth implementation, as may cultural hurdles for patients and providers. 


\section{CONCLUSION}

115. Maldistribution of doctors exists in virtually all OECD countries, in two main areas. Firstly, rural regions with low population densities, and reduced access related to relatively long distances to points of care, secondly, socio-economically disadvantaged regions. This maldistribution is increasingly considered problematic, with the vast majority of OECD countries indicating that achieving a more effective geographic distribution of physicians is a concern in health workforce policy.

116. A multitude of policies are in place, or have been tried, to foster a better distribution of physicians, but the unequal geographic distribution of doctors remains a concern. There is a lack of methodologically sound evaluations of the implementation of policies and programmes to improve distribution, both within countries and internationally. One reason is difficulty of isolating the effect of individual policies, but even so, given the level of funds involved, there have been surprisingly little attempt to assess impact and cost-benefit ratios of different policies. This means that policies are largely conceived and implemented in the absence of evidence.

117. Policy responses need to take into account the reasons physicians choose to locate in certain regions. Crucial influences on the choice of practice location are also found in the organisation of service delivery, the income potential and working conditions of physicians, the prestige and recognition they derive from working a certain region and specialty and finally the origin of doctors. The underlying issue contributing to an unequal distribution of physicians across regions is the relative unattractiveness of some regions as places to live and work. A truly comprehensive regional development policy is therefore a supportive framework for any type of policy or programme that aims to distribute physicians more evenly across regions.

118. Specifically within the health sector, three broad strategies are available to policymakers to respond to imbalances in physician distribution.

- The first strategy is to target future physicians to maximize the pool of physicians available for practice in relatively underserved regions. This means increasing the number of qualified physicians who are interested in practice in underserved regions, and/or the number of working hours they are willing to provide. The crucial focal point of action for this strategy is the education of medical students.

- The second strategy is to target current physicians to maximise the share of physicians in the health system who practice in underserved regions. This requires a suitable incentive system, which may include both "carrots and sticks", i.e. not only financial incentives but also suitable regulatory measures to influence physician location choices.

- The third strategy is to do with less, i.e. accept that staffing levels will be lower in some regions and focus on service re-design or configuration solutions. This can be done through expansion of involvement in health service delivery by non-physician providers. Service delivery innovations can also make a difference, by the use of technology (e.g. through better use of telemedicine), better management of human resources and their workload, or a combination thereof. 
119. Rather than aiming for the illusion that one strategy will "fix all" issues related to distribution of physicians, the reality for policy makers in most countries is that they will have to blend strategies, and review this mix over time. The best mix of such strategies will depend in part on the specific patient needs, demography of the population and of the physician workforce, health care system characteristics, the budgetary situation, and the overall health reform context.

120. The different strategies play at different time horizons: investment into and changes of medical education will take considerable time to have an impact because of the duration of training; in contrast financial incentives and regulation of location choice may be introduced relatively more quickly, while service delivery reform may play at the medium or long-run, depending on which policy is put forward. Strategies also differ in their cost structure. However, there are currently insufficient evaluations to enable a detailed cost assessment, and some interventions are more easily costed than others. Nevertheless a basic overview of possible areas of policy action, likely impact and cost (upfront/recurring and fixed/variable) is provided below (Table 9).

Table 9: Strategies, areas of actions: impact lag and cost structure

\begin{tabular}{|c|c|c|c|}
\hline Strategy & Area of action & Impact lag & Cost structure \\
\hline Targeting future doctors & Medical education & Long-term & $\begin{array}{l}\text { Moderate fixed } \\
\text { cost, moderate variable } \\
\text { cost }\end{array}$ \\
\hline \multirow[t]{2}{*}{ Targeting current doctors } & Financial incentives & Short to medium term & Significant variable cost \\
\hline & Regulatory policies & Short term & $\begin{array}{l}\text { Moderate variable } \\
\text { (administrative) cost }\end{array}$ \\
\hline Doing with less & Service delivery reform & Medium to long-term & $\begin{array}{l}\text { Significant fixed (upfront) } \\
\text { cost, moderate variable } \\
\text { cost }\end{array}$ \\
\hline
\end{tabular}

121. It is also important to keep in mind the contributions that non-state actors can make. Underserved communities themselves may find innovative ways of attracting physicians, or organising access to services where state-sponsored solutions are not sustainable. Examples of community scholarships, local citizen initiatives and other forms of civic engagement exist. It is important that governments support these and allow for local innovation. Similarly, professional associations have an important role to play. In some countries, medical associations already develop solutions e.g. involving practising doctors in mentoring and recruitment schemes, supporting informal or formal locum and staff cover, or supporting new task sharing arrangements on the basis of reviewed scopes of practice of non-physician health workers. Peer networks can also play an important role in enabling continuous professional education for health professionals in underserved areas.

122. Finally, in times of austerity, countries may face limitations in what is financially feasible in the short-term. This may, by default, orientate policy makers away from options that have upfront cost implications, such as some types of comprehensive service delivery reforms or the extension of financial incentives, and towards policy options that are less costly, but which may have a longer lead-in time to any impact, such as some education interventions, or may be politically controversial, such as some regulatory changes. It is important that policy makers look beyond the short term when assessing the options. Independent of their strategic choices, policymakers need to be able to make better informed decisions. While broad characteristics of interventions can be identified, more robust evaluations are required to improve the evidence basis of policies to tackle imbalances in physician supply. 


\section{REFERENCES}

Aasland, O.G.; Røvik, J.O. and J. Wiers-Jenssen (2008), "Motives for choice of specialty during and after medical school", Tidsskr Nor Legeforen; 128: 1833-7.

ABC News (2013), FIFO doctors push up regional GP numbers, Australian Broadcasting Corporation,http://www.abc.net.au/news/2013-06-17/fifo-doctors-push-up-regional-gpnumbers/4757752 (accessed 16 September 2013).

Alexandersen, $\varnothing$ et al. (2004), "Medisinerutdanningen i Troms $\varnothing$-sikrer den legerekrutteringen til NordNorge?" [Medical education in Troms $\varnothing$ - does it ensure the recruitment of physicians in Northern Norway?], Tidsskr Nor Lageforen, Nr. 16; 124: 2107-9.

AOK Saxony and Thuringia (2011), Gemeinsame Presseerklärung: Ärzte erhalten finanzielle Förderungen bei Niederlassung in Thüringen [Joint press declaration: Physicians receive financial support for practice opening in Thuringia], https://www.aokplus-

online.de/zielgruppe/presse/pressearchiv/einzelansicht/artikel/gem-presseerklaerung-aerzte-erhaltenfinanzielle-foerderung-bei-niederlassung-in-thueringen.html (accessed 31 Mary, 2013).

Audit Scotland (2010), Using locum doctors in hospitals, Edinburgh, http://www.auditscotland.gov.uk/docs/health/2010/nr_100617_medical_locums.pdf (accessed 1 August 2013).

Australian House of Representatives' Standing Committee on Health and Ageing (2012), Lost in the Labryinth: Report on the inquiry into registration processes and support for overseas trained doctors, Canberra.

Australian Medical Association, Becoming a doctor and bonded medical school places - a guide for prospective medical students, https://ama.com.au/becoming-doctor-and-bonded-medical-schoolplaces-guide-prospective-medical-students (accessed 27 May 2013).

Barlet, M. et al. (2012), "L'accessibilité potentielle localisée (APL) : une nouvelle mesure de l'accessibilité aux médecins généralistes libéraux", DRESS Etudes et Résultats $N^{\circ} 795$ (3), DREES, Paris, http://www.drees.sante.gouv.fr/IMG/pdf/er795.pdf (accessed 30 May 2013).

Bärnighausen, T. and D. Bloom (2009), "Financial incentives for return of service in underserved areas: a systematic review", BMC Health Services Research, 29(9): 86.

Battye, K.M. and K. McTaggart (2003), "Development of a model for sustainable delivery of outreach allied health services to remote north-west Queensland, Australia", Rural and Remote Health 3(3): 194.

Bennett, K.L. and J.P. Phillips (2010), "Finding, recruiting, and sustaining the future primary care physician workforce: a new theoretical model of specialty choice prosess", Acad Med 2010 Oct;85(10 Suppl):S81-8. 
BMG (2011), Bundestagsdrucksache: Entwurf eines Gesetzes zur Verbesserung der Versorgungsstrukturen in der gesetzlichen Krankenversicherung (GKV-Versorgungsstrukturgesetz-GKV-VStG), [Legal draft to improve the service structures of care delivery in public insurance (Public insurance fondscare delivery structure law)], 5 September, http://dipbt.bundestag.de/dip21/btd/17/069/1706906.pdf (accessed 30 May 2013).

Bourgeuil, Y; Mousquès, J. and A. Tajahmadi (2006), “Comment améliorer la répartition géographique des professionnels de santé ? Les enseignements de la littérature internationale et des mesures adoptées en France", Rapport no 534, Paris.

Bourgueil, Y. et al. (2009), "An exploratory evaluation of multidisciplinary primary care group practices in Franche-Comté and Bourgogne", Issues in health Economics no 147, IRDES, Paris.

Buddeberg-Fischer, B. et al. (2008), "The new generation of family physicians - career motivation, life goals and work-life balance", Swiss Med Weekly 2008; 138(21-22):305-312.

Bundesrat (2007), Empfehlungen der Ausschüsse, Entwurf eines Gesetzes zur strukturellen Weiterentwicklung der Pflegeversicherung (Pflege-Weiterentwicklungsgesetz) [Recommendation of the committees, draft law for the structural development of the long-term care insurane (long-term care insurance development law)], Drucksache 718/1/07, Berlin.

Buske, L. (2012), A Profile of Rural Family Physician Practice, Canadian Collaborative Centre for Physician Resources, Canadian Medical Association, Ottawa, August.

Cameron, M. and S. Kosmina (2013), "GP distribution in rural Australia - has the OTD moratorium worked?", presented at Conference, 12th National Rural Health Conference: Strong Commitment. Bright Future, Adelaide, http://nrha.org.au/12nrhc/wp-content/uploads/2013/03/CameronMelissa_abs.pdf (accessed 10 June 2013).

Canadian Residency Matching Services (2010), Canadian Students Studying Medicine Abroad, http://www.carms.ca/pdfs/2010_CSA_Report/CaRMS_2010_CSA_Report.pdf (accessed 21 May 2013).

Chandola, T. (2012), "Spatial and social determinants of urban health in low-, middle- and high-income countries", Public Health Volume 126, Issue 3, March 2012, Pages 259-26, http://dx.doi.org/10.1016/j.puhe.2011.12.008.

Cheng, T.C. et al. (2010), "What factors influence the earning of GPs and Medical Specialists in Australia? Evidence from the MABEL Survey", Meobourne Institute Working Paper Series No.12/10. Melbourne Institute of Applied Economic and Social Research.

Colegrove, D.J. and B.E. Whitacre (2009), "Interest in rural medicine among osteopathic residents and medical students", Rural and Remote Health 9: 1192.

Colorado Health Institute (2012), A profile of Colorado's rural physicians, Colorado Rural Physician Survey: A Chart Pack, June 5, http://www.coloradohealthinstitute.org/uploads/downloads/Rural_Physician_Chartpack_Revised_5J une2012.pdf (accessed 10 November 2013).

Conomos, A.M.; Griffin, B. and N. Baunin (2013), "Attracting psychologists to practice in rural Australia: The role of work values and perceptions of the rural work environment", Australian Journal of Rural Health, 21: 105-111. doi: 10.1111/ajr.12021. 
Cooper, J.K.; Heald, K. and M. Samuels (1972), “The Decision for Rural Practice”, Journal of Medical Education 47: 939-944.

Creed, P.A.; Searle, J. and M.E. Rogers (2010), "Medical specialty prestige and lifestyle preferences for medical students”, Soc Sci Med 2010 Sep;71(6) :1084-8.

Delamaire, M. and G. Lafortune (2010), "Nurses in Advanced Roles: A Description and Evaluation of Experiences in 12 Developed Countries", OECD Health Working Papers No. 54, OECD Publishing. http://dx.doi.org/10.1787/5kmbrcfms5g7-.

Deloitte (2011), Inntekts- og kostnadsundersokelse for driftsåret 2009 - landets fastleger og avtalespesialister, Oslo.

Department of Health and Ageing (DoHA), Australian Government (2008), Report on the audit of health workforce in rural and regional Australia 2008, Commonwealth of Australia, Canberra.

Department of Health and Ageing, Australian Government (2012), Medical Rural Bonded Scholarship Scheme, Information Booklet for 2013, http://www.health.gov.au/internet/main/publishing.nsf/Content/7940D1B8CB28BE76CA257AD400 00D6E9/\$File/Medical\%20Rural\%20Bonded\%20Scholarship\%20Scheme\%202013.pdf (accessed 30 May 2013).

Department of Health and Ageing, Australian Government (2012). Bonded Medical Places Scheme, Information Booklet for 2013, http://www.health.gov.au/internet/main/publishing.nsf/Content/69044568EE7B08FCCA257AA9001 5A263/\$File/BMP\%20Scheme\%202013\%20Information\%20Booklet.pdf (accessed 15 June 2013).

Department of Health, Health Service Executive Ireland (2013), Securing the Future of smaller hospitals: a framework for development, Dublin: February 2013 http://www.dohc.ie/publications/pdf/SecuringSmallerHospitals.pdf?direct=1 (accessed 1 September 2013).

Dolea, C.; L. Stormont and J.-M. Braichet (2010), "Evaluated strategies to increase attraction and retention of health workers in remote and rural areas", Bull World Health Organ [online], vol.88, n.5, pp. 379-385.

Dywili, S. et al. (2012), "Experiences of overseas trained health professionals in rural and remote areas of destination countries- a literature review", Australian Journal of Rural Health, 20: 175-184.

Elliott, V.S. (2012), "Who still wants to be a country doctor?", Amed news, http://www.amednews.com/article/20121022/business/310229965/4/ (accessed 10 November 2013).

Ellsbury, K.E. et al. (2002), "Gender-related factors to the recruitment of physicians to the rural northwest”, J Am Board Fam Pract ; 15 :391-400.

EU-SILC (2011), Statistics on income, social inclusion and living conditions, available at: http://epp.eurostat.ec.europa.eu/portal/page/portal/income_social_inclusion_living_conditions/introd uction.

Federal Joint Committee (2012), Bedarfsplanungs-Richtlinie [Planning guideline of the Federal Joint Committee], Federal Ministry of Justice, http://www.g-ba.de/downloads/62-492-666/BPL-RL_201212-20_BAnz.pdf. 
Feldman, M.A. et al. (2008), "The difference between medical students interested in rural family medicine versus urban family or specialty medicine", Can J Rural Med 2008;13(2):73-9

Frehywot. S. et al. (2010), "Compulsory service programmes for recruiting health workers in remote and rural areas: do they work?", Bull World Health Organ [online], vol.88, n.5, pp. 364-370.

Gibis, B. et al. (2012), "The career expectations of medical students, findings of a nationwide survey in Germany”, Deutsches Aerzteblatt International, 109(18): 327-32.

Greß, S. and K. Stegmüller (2011), Gesundheitliche Versorgung Stadt und Land, ein Zukunftskonzept [Health care in cities and the countryside, a future concept], Friedrich-Ebert-Stiftung [Friedrich Ebert Foundation], Landesbüro Hessen [Federal Office of Hesse], Wiesbaden.

Grobler, L. et al. (2009), "Interventions for increasing the proportion of health professionals practising in rural and other underserved areas", Cochrane Database of Systematic Reviews, Issue 1. Art. No.: CD005314. DOI: 10.1002/14651858.CD005314.pub2.

Han, G. and J. Humphreys (2006), "Integration and retention of international medical graduates in rural communities: A typlogical analysis", Journal of Sociology 42 (2) 189-207.

Hancock, C. et al. (2009), "Why doctors choose small towns: A developmental model of rural physician recruitment and retention”, Social Science \& Medicine 69(2009) 1368-1376.

Harbour Peaks Management Inc. (HPM) (2008), British Columbia rural physician programs review, March 31.

Hartmannbund (2012), Der Arztberuf von morgen - Erwartungen und Perspektiven einer Generation, Umfrage unter den Medizinstudierenden des Hartmannbundes, "Wie sehen Sie Ihre Zukunft als Arzt oder Ärztin?", [The medical profession of tomorrow- Expectations and perspectives of a generation, survey of the Hartmannbund among medical studens, "How do see your future as a physician?"], Hartmannbund, http://www.hartmannbund.de/enews/2115/142/ (accessed 29 May 2013).

Health Workforce Australia (2013) National Rural and Remote Workforce Innovation and Reform Strategy.HWA:Adelaide, http://www.hwa.gov.au/sites/uploads/HWA13WIR013_Rural-andRemote-Workforce-Innovation-and-Reform-Strategy_v4-1.pdf(accessed 16 September 2013).

Heisler, E. J. (2013), Physician Supply and the Affordable Care Act, Congressional Research Service, 15 January, http://op.bna.com/hl.nsf/id/myon-93zpre/\$File/crsdoctor.pdf (accessed 15 September 2013).

Henry, L.; Hooker, R.S. and K.L. Yates (2011), "Role of Physician Assistants in Rural Health Care", The Journal of Rural Health 27:220-229.

Huisman, M. et al. (2013), "Socioeconomic Inequalities in Mortality Rates in Old Age in the World Health Organization Europe Region”, Epidemiol Rev 35(1): 84-97.

Humphreys, J.S et al. (2008). "Beyond workforce": a systemic solution for health service provision in small rural and remote communities”, Medical Journal of Australia 188(8), 77.

IGAS (2011), Pharmacies d'officine: rénumeration, missions, réseau, rapport, Paris. 
Inoue, K; Matsumoto, M. and T. Sawada (2007), "Evaluation of a Medical School for Rural Doctors", The Journal of Rural Health, 23(2): 183-187.

Izaki (2009), Chiki-Iryo: Saisei-he no Shohosen [Community Health: Prescription for Reform], Tokyo, Gyosei.

Jacob, R.; Heinz, A. and J.P. Décieux (2010), Berufsmonitoring Medizinstudenten [Monitoring of profession: medical students], http://www.kbv.de/publikationen/37141.html (accessed 31 May 2013).

Jakoubovitch, S. et al. (2012), "Les emplois du temps des médecins généralistes", Études et Résultats, N. 797, DREES Paris, http://www.drees.sante.gouv.fr/IMG/pdf/er797-2.pdf.

Jones, M.; Humphreys, J.S. and M.R. McGrail (2012), "Why does a rural background make medical students more likely to intend to work in rural areas and how consistent is the effect? A study of the rural background effect", Aust. J. Rural Health (2012) 20, 29-34.

KBV (2011a), Grunddaten zur medizinischen Versorgung in Deutschland [Basis data on medical service in Germany], Berlin, http://www.kbv.de/publikationen/2394.html (accessed 29 May 2013).

KBV (2011b), MVZ-Survey, Medizinische Versorgungszentren in ländlichen Regionen [Survey among community health centers, community health centers in rural areas], Berlin. http://www.kbv.de/koop/8791.html, (accessed 29 May 2013).

KBV (2011c), Beruf und Familie verbinden: Wie sieht das in der Praxis aus? [Combining work and family: How does this look like in practice?], Berlin.

Kiwanuka S.N. et al. (2011), Dual practice regulatory mechanisms in the health sector: a systematic review of approaches and implementation, EPPI-Centre, Social Science Research Unit, Institute of Education, University of London.

Laven, G. and D. Wilkinson (2003), "Rural doctors and rural backgrounds : how strong is the evidence? A systematic review", Aust J Rural Health 2003 Dec,11(6):277-84.

Lu, D.J.; Hakes, J. and M. Bai (2008), "Rural intentions. Factors affecting the career choices of family medicine graduates", Canadian Family Physician 2008;54 :1016-7.e1-5.

MacVicar, R. and P. Nicol (2013), "NHS Education for Scotland: Supporting Remote and Rural Healthcare", NES Board Paper, Edinburgh, August.

Maiorova, T. et al. (2007), "Gender shift in realisation of preferred type of gp practice: longitudinal survey over the last 25 years", BMC Health Services Research, 7:111.

Margolis, S. (2012), "Is Fly in/Fly out (FIFO) a viable interim solution to address remote medical workforce shortages?", Rural and Remote Health 12: 2261

Mason, J. (2013), Review of Australian Government Health Workforce Programs, Department of Health and Ageing, Australian Government, http://www.health.gov.au/internet/main/publishing.nsf/Content/work-health-workforce-programreview (accessed 1 September 2013). 
Mathews, M. et al. (2013), "Evaluation of Physician Return-for-Service Agreements in Newfoundland and Labrador", Health Care Policy, 8(3):42-53.

Matsumoto, M. et al. (2008), “A contract-based training system for rural physicians: follow-up of Jichi Medical University graduates (1978-2006)”, Journal of Rural health, 24(4):360-8.

Matsumoto, M. et al. (2010), "Retention of physicians in rural Japan: concerted efforts of the governments, prefectures, municipalities and medical schools". Rural and Remote Health 10:1432.

McGrail, M.R. et al. (2011), "Nature of association between rural background and practice location: A comparison of general practitioners and specialists", BMC Health Services Research, 11:63.

McGrail, M.R. et al. (2012), "How do rural GPs' workloads and work activities differ with community size compared with metropolitan practice ”, Australian Journal of Primary Health, 19(3): 228-233.

Mead, E.; Dodson, J. and C. Ellway (2006), “Urban Environments \& Health: Identifying Key Relationships \& Policy Imperatives”, Urban Research Program Research Monograph 10, Brisbane.

Ministère des Affaires sociales et de la Santé (2012a), Conclusion des négociations sur la convention pharmaciens d'officine, 29 March, Paris, http://www.sante.gouv.fr/conclusion-des-negociations-surla-convention-pharmaciens-d-officine.html (accessed 3 June 2013).

Ministère des Affaires sociales et de la Santé (2012b), le pacte territoire-santé” pour lutter contre les déserts médicaux, 13 December, press dossier, Paris.

Ministère des Affaires sociales et de la Santé (2012c), les maisons de santé, http://www.sante.gouv.fr/lesmaisons-de-sante.html (accessed 29 May 2013).

Ministry of Health of British Columbia (2012), Rural Retention Program (RRP), Policy Framework for Health Authorities, June.

Ministry of Health of British Columbia, Telehealth, http://www.health.gov.bc.ca/ehealth/telehealth_project.html (accessed 30 May 2013).

Natanzon, J. et al. (2010), "Future potential country doctor: the perspectives of German GPs", Rural and Remote Health 10:1347.

National Audit Office (2008), NHS Pay Modernisation: New contracts for general practice services in England, London. http://www.nao.org.uk/report/nhs-pay-modernisation-new-contracts-for-generalpractice-services-in-england/ (accessed 16 September 2013).

New York health (2011), Health Care Reform in New York City - Access to Primary Health Care before Reform, Epi Research Report, New York City Department of Health and Mental Hygiene, New York, http://www.nyc.gov/html/doh/downloads/pdf/epi/epiresearch-healthcare-access.pdf (accessed 30 May 2013).

NHS Scotland (2010), Final Report of the Remote and Rural Implementation Group. Remote and Rural Implementation Group, Edinburgh.

Northern Ireland Audit Office (2011), The Use of Locum Doctors in Northern Ireland Hospitals, Belfast, http://www.niauditoffice.gov.uk/niao_locum_final.pdf (accessed 15 September 2013). 
Northern Ontario School of Medicine (NOSM) (2012), "Distributed Community-Engaged Learning", document prepared for the Rendez-Vous 2012 Conference, Thunder Bay, 9-13October, http://www.rendez-vous2012.ca/wp-content/uploads/2011/11/Rendez-Vous-Program-Part-Three.pdf (accessed 6 June 2013).

OECD (2010), OECD Rural Policy Reviews: Strategies to Improve Rural Service Delivery, OECD Publishing, Paris. doi: 10.1787/9789264083967-en.

OECD (2011a), Health at a Glance 2011: OECD Indicators, OECD Publishing, Paris. doi:10.1787/health_glance-2011-en.

OECD (2011b), “Annex A: territorial grids and regional typology”, in OECD Regions at a Glance 2011, OECD Publishing, Paris. http://dx.doi.org/10.1787/reg_glance-2011-38-en.

OECD (2012), "Gender equality in employment", in Closing the Gender Gap: Act Now, OECD Publishing, Paris.

OECD (2013a), Health at a Glance 2013: OECD Indicators, OECD Publishing, Paris.

OECD (2013b), Regional Database, available at: http://stats.oecd.org/OECDregionalstatistics/\# (accessed 15 September 2013).

Ordre national des médecins (ONM, 2012), Observatoire pour la sécurité des médecins, Recensement national des incidents2012, Paris, http://www.conseil-

national.medecin.fr/system/files/observatoire_securite_medecins_2012.pdf?download=1 (accessed 1 July 2013).

Ordre national des pharmaciens (ONP, 2012), Les pharmaciens - Panorama au 1er janvier 2012, Paris.

Paris, V. et al. (forthcoming), OECD Health System Characteristics, OECD Working Paper, OECD Publishing, Paris.

Praktiserende Lægers Organisation (2013), § 2 aftaler og andre aftaler [\$2-agreements and other agreements], http://www.laeger.dk/portal/page/portal/LAEGERDK/Laegerdk/P_L_O/Overenskomster/2AFTALE R_OG_ANDRE_AFTALER. (assessed 30 May 2013).

Rabinowitz H.K. et al. (2011), "Increasing the supply of rural family physicians: recent outcomes from Jefferson Medical College's Physician Shortage Area Program (PSAP)", Acad Med. Feb;86(2):2649. doi: 10.1097/ACM.0b013e31820469d6.

Regioneres Lønnings- og takstnævn, Praktiserende Lægers Organisation (2011), Overenkomst om almen praksis [Agreement on General Practice], 1 April.

Rhys, G.; H.J. Beerstecher and C.L. Morgan (2010), "Primary care capitation payments in the UK. An observational study", BMC Health Services Research 10:156.

Rouke J. (2005), "Strategies to increase the enrolment of students of rural origin in medical school: recommendations from the Society of Rural Physicians of Canada", Journal of Ayub Medical College 172 (1): 62-65. 
Rouke, J. (2010), "How can medical schools contribute to the education, recruitment and retention of rural physicians in their region?", Bull World Health Organ, 88:395-396.

Rourke, J. (2008), "Increasing the number of rural physicians" CMAJ;178:322-5.

Saarma, S. et al. (2012), "Canadian family physicians' decision to collaborate: Age, period and cohort effects”, Social Science \& Medicine 75, 1811-1819.

Schaafsma, J. et al. (2007), "An economic evaluation of a telehealth network in British Columbia", $J$ Telemed Telecare, 13(5):251-6.

Schulte, H. and C. Schulz (2007), "Medizinische Versorgungszentren : Für gut befunden" [MVZs: judged positively], Dtsch Arztebl 2007; 104(28-29): A-2075 / B-1831 / C-1767.

Senatsverwaltung für Gesundheit und Soziales (2013), Patientenorientierte Bedarfsplanung der Ärztlichen Versorgung [patient-oriented demand planning of the supply of physicians] presentation at a press talk, 15 February, Berlin, http://www.berlin.de/imperia/md/content/lb-

patienten/aktuelles/praesentation_aerztliche_versorgung.pdf?start\&ts=1360931552\&file=praesentati on_aerztliche_versorgung.pdf (accessed 1 May 2013).

Sim, A. (2011), "Locum tenens consultant doctors in a rural general hospital - an essential part of the medical workforce or an expensive stopgap?", Rural Remote Health 11(4):1594.

Skinner, C. et al. (2006), "The challenge of locum working arrangements in New South Wales public hospitals", Med J Aust 2006; 185 (5): 276-278.

Slovenian Ministry of Health (2013), document provided to the OECD on 20 August 2013.

Soethout, M.B.G.; van der Wal, G. and O.T.J. ten Cate (2007), "Carrierewensen en beroepskeuze van recent afgestudeerden artsen" [Career preferences and choice of a career among recently graduated doctors", Nederlands Tijdschrift voor Geneeskunde 38:2118-24.

Steinhäuser, J. et al. (2011), "A comparison of the workload of rural and urban primary care physicians in Germany: analysis of a questionnaire survey", BMC Family Practice 12:112.

Straume, K. and D.M.P.Shaw (2010), "Internship at the ends of the earth - a way to recruite physicians?", Rural and Remote Health 10: 1366.

URPS Médecins IDF, Professionnels de santé en Ile-de-France, basé sur les données de la Caisse autonome de retraite des médecins français de 2009,

http://www.soignereniledefrance.org/geoclip/carto.php?lang=fr\&nivgeos=com\&curCodeDomCH=D M\&curCodeThemeCH=demomed\&typind $\mathrm{CH}=\mathrm{C} \&$ curCodeIndCH=age\&curCodeDomSB=ETAB \&c urCodeThemeSB=typoetab\&typindSB=P\&curCodeIndSB=typetab\&couchesymb=etab $($ accessed 10 November 2013).

Van den Berg, N. et al. (2009), "AGnES: Hausarztunterstützung durch qualifizierte Praxismitarbeiter, Evaluation der Modellprojekte: Qualität und Akzeptanz” [AGnES: GP support by qualified practice assistants, evaluation of model projects: Quality and acceptance], Dtsch Arztebl Int; 106(1-2): 3-9.

Van den Hombergh, P. et al.. (2005), "Saying 'goodbye' to single-handed practices; what do patients and staff lose or gain?”, Family Practice 2005; 22: 20-27. 
Veitch, C. and J.L. Crossland (2005), "Medical family support needs and experiences in rural Queensland", Rural and Remote Health, 5:467.

Von Stillfried, D. (2012), "Wirtschafts- und Arbeitssituation der Vertragsärzte - Zielsetzung und Ergebnisse des ZiPP" [Economic situation and working conditions of SHI physicians - goals and results of the Central institute's practice pannel], presentation at conference in Berlin, 20 November 2012, http://www.zi.de/cms/index.php?id=233 (accessed 10 November 2013).

Walendzik, A. et al. (2008), Vergütungsuntersschiede im ärztlichen Bereich zwischen PKV und GKV auf Basis des standartisierten Leistungsniveaus der GKV und Modelle der Vergütungsangleichung [Payment differences between private and statutory insurance on the basis of standardised payments by the statutory insurance and models of payment equalization], background note, faculty of economics, University of Duisburg-Essen, Essen.

Weeks, W.B. and A.E. Wallace (2008) "Rural-Urban Differences in Primary Care Physicians' Practice Patterns, Characteristics, and Incomes”, Journal of Rural Health, 24 (2): 161-170.

Weiskotten, H.G. et al. (1960),. "Trends in medical practice. An analysis of the distribution and characteristics of medical college graduates, 1915-1950", J Med Educ. 1960 Dec;35:1071-1121.

Wilson, N.W. et al. (2009), "A critical review of interventions to redress the inequitable distribution of healthcare professionals to rural and remote areas", Rural and Remote Health 9: 1060.

World Health Organization (2010), WHO Global Code of Practice on the International Recruitment of Health Personnel Geneva, http://www.who.int/hrh/migration/code/practice/en/index.html (accessed 30 June 2013). 


\section{ANNEX}

\begin{tabular}{|c|c|c|c|c|}
\hline & $\begin{array}{l}\text { Type (and page } \\
\text { number) }\end{array}$ & Location & Programme & Start Year \\
\hline \multirow{10}{*}{ 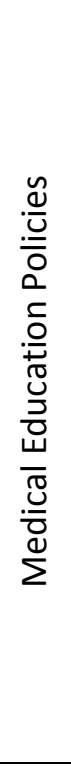 } & Student selection & Australia & Bonded Medical Places Scheme & 2004 \\
\hline & Student selection & Australia & Medical Rural Bonded Scholarship & 2001 \\
\hline & Student selection & Japan & Regional Quota & $2000 s$ \\
\hline & $\begin{array}{l}\text { Medical school for } \\
\text { rural area }\end{array}$ & Norway & Tromsoe Medical School & 1972 \\
\hline & $\begin{array}{l}\text { Medical school for } \\
\text { rural area }\end{array}$ & Japan & Jichi Medical School & 1972 \\
\hline & $\begin{array}{l}\text { Regionalized specialty } \\
\text { choice }\end{array}$ & France & Epreuves Classantes Nationales (ECN) & 2004 \\
\hline & $\begin{array}{l}\text { Distributed medical } \\
\text { school in rural area }\end{array}$ & Canada & Northen Ontario School of Medicine & 2005 \\
\hline & Internship & Norway & Finnmark internship programme & 1997 \\
\hline & Internship & $\begin{array}{l}\text { Australia } \\
\text { (NSW) }\end{array}$ & $\begin{array}{l}\text { Rural resident medical officer cadetship } \\
\text { programme }\end{array}$ & 1988 \\
\hline & Internships & $\begin{array}{l}\text { UK } \\
\text { (Scotland) }\end{array}$ & GP rural fellowships, several medical schools & varies \\
\hline \multirow{12}{*}{ 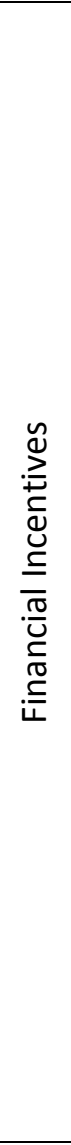 } & $\begin{array}{l}\text { New practice opening } \\
\text { incentive }\end{array}$ & Germany & Financial support for designated shortage & 2007 \\
\hline & $\begin{array}{l}\text { New practice opening } \\
\text { incentive }\end{array}$ & Canada & $\begin{array}{l}\text { Northern and Rural Recruitment and } \\
\text { Retention Initiative }\end{array}$ & 2010 \\
\hline & $\begin{array}{l}\text { Support for work-life } \\
\text { balance }\end{array}$ & Canada & Financial support to hire locum physicians & At least 2004 \\
\hline & $\begin{array}{l}\text { Support for work-life } \\
\text { balance }\end{array}$ & Denmark & Financial support to hire additional staff & $2008 /-9 /-10$ \\
\hline & $\begin{array}{l}\text { One installment - } \\
\text { retirement }\end{array}$ & Denmark & $\begin{array}{l}\text { Financial incentive for older GPs to postpone } \\
\text { retirement }\end{array}$ & $2009 / 2013$ \\
\hline & $\begin{array}{l}\text { Minimum income } \\
\text { gurantee }\end{array}$ & Denmark & $\begin{array}{l}\text { Guaranteed minimum income for two years } \\
\text { after practice opening }\end{array}$ & 2008 \\
\hline & $\begin{array}{l}\text { Minimum income } \\
\text { gurantee }\end{array}$ & France & $\begin{array}{l}\text { Guaranteed minimum income for two years } \\
\text { after practice opening }\end{array}$ & 2012 \\
\hline & $\begin{array}{l}\text { Bonus for rural } \\
\text { practice }\end{array}$ & Canada & $\begin{array}{l}\text { Annual bonus depending on conditions - } \\
\text { Rural Retention Programme }\end{array}$ & 2003 \\
\hline & $\begin{array}{l}\text { Bonus for rural } \\
\text { practice }\end{array}$ & Denmark & $\begin{array}{l}\text { Higher numeration for signing up more } \\
\text { patients on the list }\end{array}$ & $2006 / 7$ \\
\hline & $\begin{array}{l}\text { Bonus for rural } \\
\text { practices }\end{array}$ & $\begin{array}{l}\text { UK (England } \\
\text { and Wales) }\end{array}$ & $\begin{array}{l}\text { GP contract renegotiation including rurality } \\
\text { index }\end{array}$ & 2004 \\
\hline & $\begin{array}{l}\text { Bonus for retirement } \\
\text { delay }\end{array}$ & Canada & $\begin{array}{l}\text { Staged annual bonus based on years of } \\
\text { practice }\end{array}$ & 2003 \\
\hline & $\begin{array}{l}\text { Bonus for retirement } \\
\text { delay }\end{array}$ & Germany & $\begin{array}{l}\text { Quarterly support for GPs aged } 65 \text { and } \\
\text { above }\end{array}$ & 2009 \\
\hline
\end{tabular}




\begin{tabular}{|c|c|c|c|c|}
\hline & $\begin{array}{l}\text { Type (and page } \\
\text { number) }\end{array}$ & Location & Programme & Start Year \\
\hline \multirow{5}{*}{ 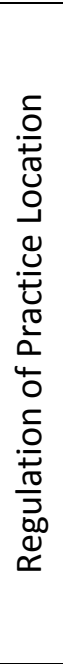 } & Practice restriction & Germany & $\begin{array}{l}\text { No practice permits are isssued for } \\
\text { overserved areas }\end{array}$ & 1993 \\
\hline & $\begin{array}{l}\text { Vacancy } \\
\text { determination and } \\
\text { practice restriction }\end{array}$ & Denmark & $\begin{array}{l}\text { Practice permits issued based on list size and } \\
\text { distance }\end{array}$ & 2011 \\
\hline & $\begin{array}{l}\text { Vacancy } \\
\text { determination and } \\
\text { practice restriction }\end{array}$ & Norway & $\begin{array}{l}\text { Practice permits issued based on list size and } \\
\text { general situation in municipality }\end{array}$ & 2001 \\
\hline & $\begin{array}{l}\text { Targeting } \\
\text { International Medical } \\
\text { Graduates }\end{array}$ & Australia & $\begin{array}{l}\text { 10-year moratorium for access to Medicare } \\
\text { payment }\end{array}$ & 1997 \\
\hline & $\begin{array}{l}\text { Targeting } \\
\text { International Medical } \\
\text { Graduates }\end{array}$ & Canada & $\begin{array}{l}\text { Return-of-Service obligation in several } \\
\text { provinces }\end{array}$ & varies \\
\hline \multirow{12}{*}{ 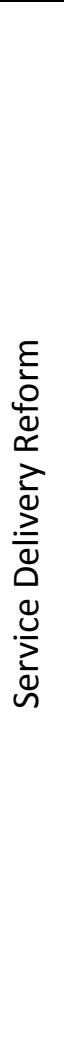 } & Group practice & France & Maison de Santé pluridisciplinaires & 2007 \\
\hline & Group practice & Germany & Medizinisches Versogungszentrum (MVZ) & 2004 \\
\hline & Group practice & Switzerland & Financially supported group practices & 2007 \\
\hline & Group practice & Japan & $\begin{array}{l}\text { Group practice with rotation of multiple } \\
\text { clinic }\end{array}$ & 2007 \\
\hline & $\begin{array}{l}\text { Group practice/task- } \\
\text { sharing }\end{array}$ & Slovenia & Model practices & 2011 \\
\hline & Rotation schemes & $\begin{array}{l}\text { UK } \\
\text { (Scotland) }\end{array}$ & Obligated Networks & 2009 \\
\hline & Rotation scheme & Ireland & Hospital groups & 2013 \\
\hline & Mobile doctors & Australia & FIFO/DIDO programmes & varies \\
\hline & $\begin{array}{l}\text { Management of on- } \\
\text { call duties }\end{array}$ & $\begin{array}{l}\text { AUS/UK(Scot } \\
\text { land, } \\
\text { Northern } \\
\text { Ireland) }\end{array}$ & $\begin{array}{l}\text { Effective management of locum medical } \\
\text { staff }\end{array}$ & varies \\
\hline & Telemedicine & Canada & $\begin{array}{l}\text { Telemedicine providing cinical support for } \\
\text { maternal/child care, education among } \\
\text { others }\end{array}$ & 2001 \\
\hline & $\begin{array}{l}\text { New roles/task- } \\
\text { sharing }\end{array}$ & Germany & $\begin{array}{l}\text { AGnES (non-physician practice assistants) } \\
\text { take over GP's home visits }\end{array}$ & 2009 \\
\hline & $\begin{array}{l}\text { New roles/task- } \\
\text { sharing }\end{array}$ & France & Pharmacist scope of practice extension & 2009 \\
\hline
\end{tabular}




\section{OECD HEALTH WORKING PAPERS}

A full list of the papers in this series can be found on the OECD website: http://www.oecd.org/health/workingpapers

No. 68 HEALTH SPENDING CONTINUES TO STAGNATE IN MANY OECD COUNTRIES (2014) David Morgan and Roberto Astolfi

No. 67 MEASURING AND COMPARING WAITING TIMES IN OECD COUNTRIES (2013) Luigi Siciliani, Valerie Moran and Michael Borowitz(Forthcoming)

No. 66 THE ROLE OF FISCAL POLICIES IN HEALTH PROMOTION (2013) Franco Sassi (Forthcoming)

No. 65 ALCOHOL CONSUMPTION AND HARMFUL DRINKING: TRENDS AND SOCIAL DISPARIETIES IN OECD COUNTRIES (2013) Franco Sassi (Forthcoming)

No. 64 MANAGING HOSPITAL VOLUMES: GERMANY AND EXPERIENCES FROM OECD COUNTRIES (2013) Michael Schoenstein and Ankit Kumar

No. 63 VALUE IN PHARMACEUTICAL PRICING (2013) Valérie Paris, Annalisa Belloni

No. 62 HEALTH WORKFORCE PLANNING IN OECD COUNTRIES: A REVIEW OF 26 PROJECTION MODELS FROM 18 COUNTRIES (2013) Tomoko Ono, Gaetan Lafortune and Michael Schoenstein

No. 61 INTERNATIONAL VARIATIONS IN A SELECTED NUMBER OF SURGICAL PROCEDURES (2013) Klim McPherson, Giorgia Gon, Maggie Scott

No. 60 HEALTH SPENDING GROWTH AT ZERO: WHICH COUNTRIES, WHICH SECTORS ARE MOST AFFECTED? (2013) David Morgan and Roberto Astolfi

No. 59 A COMPARATIVE ANALYSIS OF HEALTH FORECASTING METHODS (2012) Roberto Astolfi, Luca Lorenzoni, Jillian Oderkirk

No. 58 INCOME-RELATED INEQUALITIES IN HEALTH SERVICE UTILISATION IN 19 OECD COUNTRIES, 2008-09 (2012) Marion Devaux and Michael de Looper

No. 57 THE IMPACT OF PAY INCREASES ON NURSES' LABOUR MARKET: A REVIEW OF EVIDENCE FROM FOUR OECD COUNTRIES (2011) James Buchan and Steven Black

No. 56 DESCRIPTION OF ALTERNATIVE APPROACHES TO MEASURE AND PLACE A VALUE ON HOSPITAL PRODUCTS IN SEVEN OECD COUNTRIES (2011) Luca Lorenzoni and Mark Pearson

No. 55 MORTALITY AMENABLE TO HEALTH CARE IN 31 OECD COUNTRIES: ESTIMATES AND METHODOLOGICAL ISSUES (2011) Juan G. Gay, Valerie Paris, Marion Devaux, Michael de Looper

No. 54 NURSES IN ADVANCED ROLES: A DESCRIPTION AND EVALUATION OF EXPERIENCES IN 12 DEVELOPED COUNTRIES (2010) Marie-Laure Delamaire and Gaetan Lafortune 
No. 53 COMPARING PRICE LEVELS OF HOSPITAL SERVICE ACROSS COUNTRIES: RESULTS OF A PILOT STUDY (2010) Luca Lorenzoni

No. 52 GUIDELINES FOR IMPROVING THE COMPARABILITY AND AVAILABILITY OF PRIVATE HEALTH EXPENDITURES UNDER THE SYSTEM OF HEALTH ACCOUNTS FRAMEWORK (2010) Ravi P. Rannan-Eliya and Luca Lorenzoni

No. 51 EFFECTIVE WAYS TO REALISE POLICY REFORMS IN HEALTH SYSTEMS (2010) Jeremy Hurst

No. 50 HEALTH SYSTEMS INSTITUTIONAL CHARACTERISTICS A SURVEY OF 29 OECD COUNTRIES (2010) Valerie Paris, Marion Devaux and Lihan Wei

No. 49 THE CHALLENGE OF FINANCING HEALTH CARE IN THE CURRENT CRISIS (2010) Peter Scherer, Marion Devaux

No. 48 IMPROVING LIFESTYLES, TACKLING OBESITY: THE HEALTH AND ECONOMIC IMPACT OF PREVENTION STRATEGIES (2009) Franco Sassi, Michele Cecchini, Jeremy Lauer and Dan Chisholm

No. 47 HEALTH CARE QUALITY INDICATORS PROJECT: PATIENT SAFETY INDICATORS REPORT 2009 (2009) Saskia Drösler, Patrick Romano, Lihan Wei; and ANNEX Saskia Drösler

No. 46 EDUCATION AND OBESITY IN FOUR OECD COUNTRIES (2009) Franco Sassi, Marion Devaux, Jody Church, Michele Cecchini and Francesca Borgonovi

No. 45 THE OBESITY EPIDEMIC: ANALYSIS OF PAST AND PROJECTED FUTURE TRENDS IN SELECTED OECD COUNTRIES (2009) Franco Sassi, Marion Devaux, Michele Cecchini and Elena Rusticelli

No. 44 The long-term care workforce: overview and strategies to adapt supply to a growing demand (2009) Rie Fujisawa and Francesca Colombo

No. 43 MEASURING DISPARITIES IN HEALTH STATUS AND IN ACCESS AND USE OF HEALTH CARE IN OECD COUNTRIES (2009) Michael de Looper and Gaetan Lafortune

No. 42 Policies for Healthy Ageing: an Overview (2009) Howard Oxley

No. 41 THE REMUNERATION OF GENERAL PRACTITIONERS AND SPECIALISTS IN 14 OECD COUNTRIES: WHAT ARE THE FACTORS EXPLAINING VARIATIONS ACROSS COUNTRIES? (2008) Rie Fujisawa and Gaetan Lafortune

No. 40 INTERNATIONAL MOBILITY OF HEALTH PROFESSIONALS AND HEALTH WORKFORCE MANAGEMENT IN CANADA: MYTHS AND REALITIES (2008) Jean-Christophe Dumont, Pascal Zurn, Jody Church and Christine Le Thi

No. 39 PHARMACEUTICAL PRICING \& REIMBURSEMENT POLICIES IN GERMANY (2008) Valérie Paris and Elizabeth Docteur

No. 38 MIGRATION OF HEALTH WORKERS: THE UK PERSPECTIVE TO 2006 (2008) James Buchan, Susanna Baldwin and Miranda Munro 


\section{RECENT RELATED OECD PUBLICATIONS}

MENTAL HEALTH AND WORK: SWITZERLAND (2014)

MENTAL HEALTH AND WORK: UNITED KINGDOM (2014)

OECD REVIEWS OF HEALTH CARE QUALITY - SWEDEN (2013)

CANCER CARE - ASSURING QUALITY TO IMPROVE SURVIVAL (2013)

ICTS AND THE HEALTH SECTOR -TOWARDS SMARTER HEALTH AND WELLNESS MODELS (2013)

A GOOD LIFE IN OLD AGE? MONITORING AND IMPROVING QUALITY IN LONG-TERM CARE (2013)

STRENGTHENING HEALTH INFORMATION INFRASTRUCTURE FOR HEALTH CARE QUALITY GOVERNANCE (2013)

WAITING TIME POLICIES IN THE HEALTH SECTOR, WHAT WORKS? (2013)

OECD REVIEWS OF HEALTH CARE QUALITY - DENMARK (2013)

HEALTH AT A GLANCE (2013): OECD INDICATORS (2013)

See http://www.oecd.org/health/healthataglance for more information

OECD HEALTH DATA 2013

(Database available from http://www.oecd.org/els/health-systems/oecdhealthdata.htm)

HEALTH AT A GLANCE (2013): OECD INDICATORS (2013)

See http://www.oecd.org/health/healthataglance for more information

HEALTH AT A GLANCE: ASIA/PACIFIC (2012)

HEALTH AT A GLANCE: EUROPE (2012)

OECD REVIEWS OF HEALTH SYSTEMS - RUSSIAN FEDERATION (2012)

OECD REVIEWS OF HEALTH CARE QUALITY - KOREA (2012)

OECD REVIEWS OF HEALTH CARE QUALITY - ISRAEL (2012)

SICK ON THE JOB? MYTHS AND REALITIES ABOUT MENTAL HEALTH AND WORK (2011)

OECD REVIEWS OF HEALTH SYSTEMS - SWITZERLAND (2011)

A SYSTEM OF HEALTH ACCOUNTS (2011)

HELP WANTED? PROVIDING AND PAYING FOR LONG-TERM CARE (2011)

IMPROVING VALUE IN HEALTH CARE: MEASURING QUALITY (2010)

VALUE FOR MONEY IN HEALTH SPENDING (2010)

OBESITY AND THE ECONOMICS OF PREVENTION: FIT NOT FAT (2010)

For a full list, consult the OECD On-Line Bookstore at www.oecd.org,

or write for a free written catalogue to the following address:

OECD Publications Service

2, rue André-Pascal, 75775 PARIS CEDEX 16

or to the OECD Distributor in your country 